\title{
UMA AVALIAÇÃO DA INFLUÊNCIA DAS JANELAS DE TEMPO E DO PERÍODO DE MEDIÇÃO NA ANÁLISE DE DISTORÇÕES HARMÔNICAS E INTER-HARMÔNICASS EM INSTALAÇÕES EÓLICAS
}

JÉSSICA SANTORO GONÇALVES PENA

DISSERTAÇÃO DE MESTRADO

EM ENGENHARIA ELÉTRICA

\section{UNIVERSIDADE DE BRASILIA}

FACULDADE DE TECNOLOGIA

DEPARTAMENTO DE ENGENHARIA ELÉTRICA

BRASÍLIA, JANEIRO DE 2016 
UNIVERSIDADE DE BRASÍLIA

FACULDADE DE TECNOLOGIA

DEPARTAMENTO DE ENGENHARIA ELÉTRICA

\section{UMA AVALIAÇÃO DA INFLUÊNCIA DAS JANELAS DE TEMPO E DO PERÍODO DE MEDIÇÃO NA ANÁLISE DE DISTORÇÕES HARMÔNICAS E INTER-HARMÔNICAS EM INSTALAÇÕES EÓLICAS}

JÉSSICA SANTORO GONÇALVES PENA

ORIENTADOR: ANÉSIO DE LELES FERREIRA FILHO CO-ORIENTADOR: JORGE ANDRÉS CORMANE ANGARITA

DISSERTAÇÃO DE MESTRADO EM ENGENHARIA ELÉTRICA

PUBLICAÇÃO: PPGEE.DM - 614/2016

BRASÍLIA/DF: JANEIRO - 2016 


\section{UNIVERSIDADE DE BRASÍLIA \\ FACULDADE DE TECNOLOGIA \\ DEPARTAMENTO DE ENGENHARIA ELÉTRICA}

\section{UMA AVALIAÇÃO DA INFLUÊNCIA DAS JANELAS DE TEMPO E DO PERÍODO DE MEDIÇÃO NA ANÁLISE DE DISTORÇÕES HARMÔNICAS E INTER-HARMÔNICAS EM INSTALAÇÕES EÓLICAS}

\section{JÉSSICA SANTORO GONÇALVES PENA}

DISSERTAÇÃO DE MESTRADO SUBMETIDA AO DEPARTAMENTO DE ENGENHARIA ELÉTRICA DA FACULDADE DE TECNOLOGIA DA UNIVERSIDADE DE BRASÍLIA, COMO PARTE DOS REQUISITOS NECESSÁRIOS PARA A OBTENÇÃO DO GRAU DE MESTRE.

APROVADA POR:

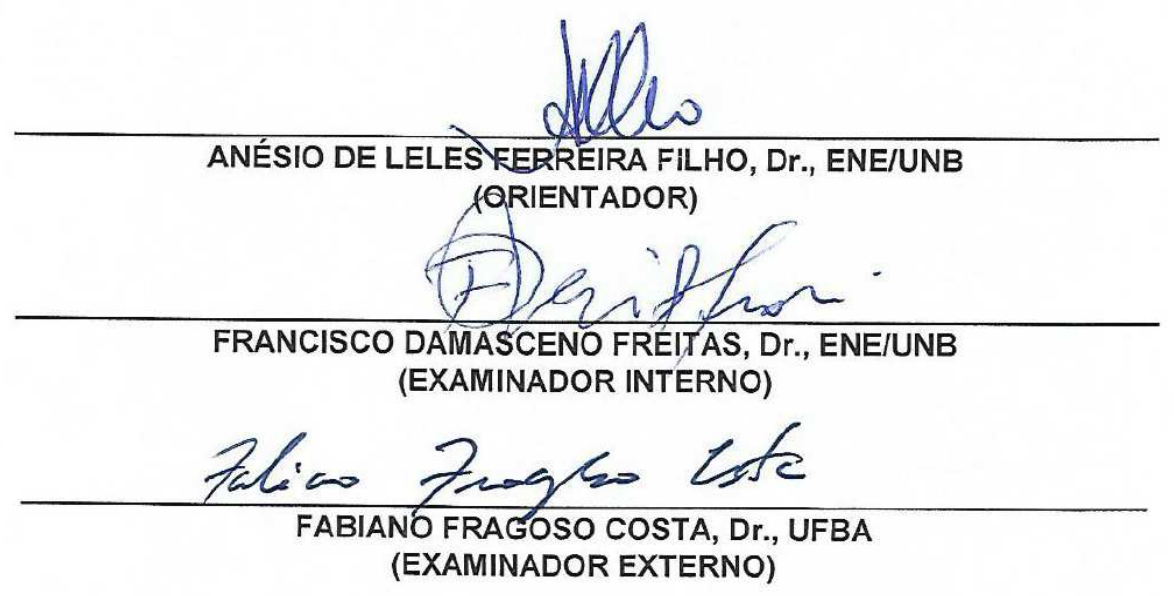

Brasília, 15 de janeiro de 2016. 
FICHA CATALOGRÁFICA

PENA, JÉSSICA SANTORO GONÇALVES

Uma avaliação da influência das janelas de tempo e do período de medição na análise de distorções harmônicas e inter-harmônicas em instalações eólicas [Distrito Federal] 2016. xiv, 85p., 210 x 297 mm (ENE/FT/UnB, Mestre, Engenharia Elétrica, 2016).

Dissertação de Mestrado - Universidade de Brasília. Faculdade de Tecnologia.

Departamento de Engenharia Elétrica.

1.Sistemas Eólicos

3.Processamento de Sinais

I. ENE/FT/UnB
2.Distorções Harmônica e Inter-harmônica

4.Qualidade da Energia Elétrico

II. Título (série)

\section{REFERÊNCIA BIBLIOGRÁFICA}

PENA, J. S. G. (2016). Uma avaliação da influência das janelas de tempo e do período de medição na análise de distorções harmônicas e inter-harmônicas em instalações eólicas, Publicação PPGEE.DM-614/2016, Departamento de Engenharia Elétrica, Universidade de Brasília, Brasília, DF, 85p.

\section{CESSÃO DE DIREITOS}

AUTOR: Jéssica Santoro Gonçalves Pena

TÍTULO: Uma avaliação da influência das janelas de tempo e do período de medição na análise de distorções harmônicas e inter-harmônicas em instalações eólicas.

GRAU: Mestre

ANO: 2016

É concedida à Universidade de Brasília permissão para reproduzir cópias desta dissertação de mestrado e para emprestar ou vender tais cópias somente para propósitos acadêmicos e científicos. $\mathrm{O}$ autor reserva outros direitos de publicação e nenhuma parte dessa dissertação de mestrado pode ser reproduzida sem autorização por escrito do autor.

Jéssica Santoro Gonçalves Pena

Brasília - DF - Brasil. 


\section{AGRADECIMENTOS}

Agradeço primeiramente a Deus por ter me dado o dom da vida e por seu infinito amor.

Ao meu marido, Douglas Pena, por todo amor, incentivo e compreensão. Esta caminhada não seria a mesma sem você.

A toda minha família, em especial aos meus pais, Orlando Gonçalves e Denise Gonçalves, e a minha irmã, Jamille Gonçalves por todo apoio e carinho.

Ao meu orientador, Prof. Anésio de Leles Ferreira Filho que, com muita paciência e dedicação, me orientou neste trabalho. Ao meu co-orientador, Prof. Jorge Andrés Cormane Angarita, pela contribuição durante todo o processo de execução da pesquisa.

Ao colega de mestrado Wesley Rodrigues de Oliveira e a toda equipe do Laboratório de Qualidade da Energia Elétrica e Smart Grids da UnB, que muito colaboraram com o meu trabalho.

A Brasventos S.A. pelo suporte durante a campanha de medições no parque eólico.

Aos professores do Programa de Pós-Graduação de Engenharia Elétrica da UnB pela oportunidade de crescimento profissional e aprendizado. 


\title{
RESUMO
}

\section{UMA AVALIAÇÃO DA INFLUÊNCIA DAS JANELAS DE TEMPO E DO PERÍODO DE MEDIÇÃO NA ANÁLISE DE DISTORÇÕES HARMÔNICAS E INTER-HARMÔNICAS EM INSTALAÇÕES EÓLICAS}

\author{
Autor: Jéssica Santoro Gonçalves Pena \\ Orientador: Anésio de Leles Ferreira Filho \\ Co-orientador: Jorge Andrés Cormane Angarita \\ Programa de Pós-Graduação em Engenharia Elétrica \\ Brasília, janeiro de 2016
}

Convencionalmente, a estimação do conteúdo harmônico e inter-harmônico dos sinais de tensão e corrente, é baseada no uso da Transformada Discreta de Fourier (ou DFT, do inglês Discrete Fourier Transform). Entretanto, o aumento da participação da geração eólica na matriz energética mundial justifica a execução de estudos que avaliem a adequação dos atuais procedimentos de medição das emissões dos mencionados fenômenos. As recomendações tradicionais são baseadas nos padrões IEC 61000-4-7 e IEC 61000-4-30, que, dentre outros aspectos, estabelece que o processamento dos sinais se dê por meio do emprego da DFT com uma janela de tempo retangular de 12 ciclos de $60 \mathrm{~Hz}$ e com um período de medição de pelo menos 7 dias. Porém, em sistemas eólicos, é esperada a ocorrência de harmônicas e de inter-harmônicas com variação temporal, o que pode tornar a estimação das componentes espectrais via DFT imprecisa e/ou o período de monitoração de 7 dias inapropriado. Posto isso, este trabalho visa apresentar uma metodologia de análise voltada para a identificação do tamanho da janela de tempo e do período de medição mínimo para o monitoramento das emissões harmônicas e interharmônicas no contexto da geração eólica. Para tal, realiza-se uma avaliação comparativa entre uma metodologia de medição oriunda da combinação do Método de Prony com o Filtro de Kalman e uma segunda fundamentada na DFT. Em seguida, utilizando-se ferramentas estatísticas, propõe-se um período mínimo de medição das distorções. A aplicação desta metodologia em sinais reais de tensão oriundos de uma usina eólica evidencia a necessidade de um intervalo de monitoramento mínimo de 3 dias e o uso de uma janela de tempo retangular de 15 ciclos de $60 \mathrm{~Hz}$.

Palavras-Chave: Sistemas Eólicos; Distorções Harmônica e Inter-Harmônica; Processamento de Sinais; Qualidade da Energia Elétrica. 


\title{
ABSTRACT
}

\section{AN EVALUATION OF THE INFLUENCE OF TIME WINDOWS AND MEASURING PERIOD IN THE ANALYSIS OF HARMONIC AND INTER- HARMONIC DISTORTIONS IN WIND POWER INSTALLATIONS}

\author{
Author: Jéssica Santoro Gonçalves Pena \\ Supervisor: Anésio de Leles Ferreira Filho \\ Co-supervisor: Jorge Andrés Cormane Angarita \\ Graduate Program in Electrical Engineering \\ Brasília, January 2016
}

Conventionally, the estimation of harmonic and inter-harmonic contents of voltage and current signals is based on the use of the Discrete Fourier Transform (DFT). However, the increase of the participation of wind power generation in the global energy matrix justifies the carrying out of studies which evaluate the adequacy of the current procedures for measuring emissions of the mentioned phenomena. The traditional recommendations are based on the IEC 61000-4-7 and IEC 61000-4-30 standards, which, among other aspects, establishes that the processing of the signals is given through the use of the DFT with a 60 $\mathrm{Hz}$ rectangular time window of 12 cycles and a measuring period of at least 7 days. However, in wind power systems, the occurrence of harmonic and inter-harmonic with time variation, which can render the estimation of the spectral components by the DFT inaccurate and/or the monitoring period of 7 days inappropriate is expected. With that said, this study aims to present a methodology focused on identifying the size of the time window and of the minimum measurement period for monitoring the harmonic and interharmonic emissions in the context of wind power generation. For such, a comparative evaluation between a measurement methodology derived from the combination of the Prony method with the Kalman filter and a second based on the DFT is carried out. Then, using statistical tools, a minimum period for measuring distortions is proposed. The application of this methodology in real voltage signals originating from a wind power plant shows the need for a minimum measurement interval of 3 days and the use of a $60 \mathrm{~Hz}$ rectangular time window of 15 cycles.

Keywords: Wind systems; Harmonic and Inter-Harmonic Distortions; Signal processing; Power Quality. 


\section{LISTA DE TABELAS}

Tabela 2.1 - Limites globais inferiores de tensão em porcentagem da tensão fundamental. Fonte: ONS, 2011

Tabela 2.2 - Limites individuais em porcentagem da tensão fundamental. Fonte: ONS, 2011 15

Tabela 2.3 - Janelas no domínio do tempo. Fonte: Ribeiro et al, 2014. 18

Tabela 4.1 - Estimação das amplitudes e das frequências para o sinal sintético. 47

Tabela 4.2 - Discrepância normalizada para o índice THD 54

Tabela 4.3 - Discrepância normalizada para o índice TID. 55

Tabela 4.4 - Descrição do conjunto global das séries de THD e TID obtidas em 30 dias. 58 


\section{LISTA DE FIGURAS}

Figura 2.1- Grupos e subgrupos do padrão IEC 61000-4-7.. ............................................... 9

Figura 2.2 - Esquema geral de um sistema eólico. Fonte: Pavinato, 2005............................. 12

Figura 2.3 - Ajustamento de funções de distribuição com o teste de Kolmogorov-Smirnov...31

Figura 3.1 - Diagrama de blocos para análise dos sinais coletados.........................................38

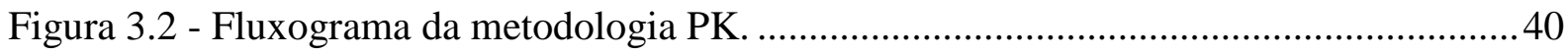

Figura 3.3 - Abordagem para estudo dos processos aleatórios $\operatorname{THD}(\mathrm{t})$ e $\operatorname{TID}(\mathrm{t})$....................42

Figura 4.1 - Formas de onda de tensão trifásica obtidas na instalação eólica. Fonte:

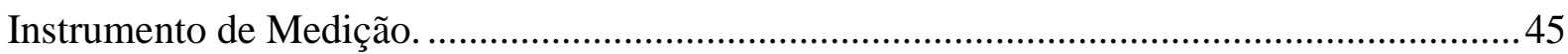

Figura 4.2 - Visualização da forma de onda do sinal sintético. Fonte: Oliveira, 2015............46

Figura 4.3 - Diagramas tempo-frequência obtidos com o processamento (a) via DFT com

janela de 12 ciclos e (b) por meio da metodologia PK.. Fonte: Oliveira, 2015.

Figura 4.4 - Evolução no tempo dos índices THD e TID para o sinal sintético. Fonte:

Oliveira, 2015.

Figura 4.5 - Valores de THD obtidos por meio da DFT para diferentes janelas de tempo ao longo de um dia de medição (em azul) comparados com a metodologia PK (em vermelho) .49 Figura 4.6 - Valores de TID obtidos por meio da DFT para diferentes janelas de tempo ao longo de um dia de medição (em azul) comparados com a metodologia PK (em vermelho) ..50 Figura 4.7 - Valores de (a) THD e (b) TID em 1 minuto de monitoramento do sinal .............51 Figura 4.8 - Valores de THD95 obtidos ao longo de uma semana de medição ........................52 Figura 4.9 - Valores de TID95 obtidos ao longo de uma semana de medição .........................52 Figura 4.10 - Exemplo do procedimento de cálculo das discrepâncias normalizadas. ............54 Figura 4.11 - Curvas expressando as discrepâncias como função do número de janelas ........55 Figura 4.12 - Comportamento do indicador THD ao longo das quatro semanas compreendidas no período de medição considerado.

Figura 4.13 - Comportamento do TID ao longo das quatro semanas compreendidas no período de medição considerado

Figura 4.14 - Parâmetros para o indicador THD (a) Média temporal ao longo dos 30 dias,

(b) média de probabilidade e (c) média temporal total por dia

Figura 4.15 - Diferença das médias temporais em cada dia com relação à média de probabilidade - THD.

Figura 4.16 - Parâmetros para o indicador TID (a) Média temporal ao longo dos 30 dias,

(b) média de probabilidade e (c) média temporal total por dia 60 
Figura 4.17 - Diferença das médias temporais em cada dia com relação à média de probabilidade - TID 61

Figura 4.18 - Testes de períodos de medição (a) para o THD e (b) para o TID. 62 


\title{
LISTA DE SÍMBOLOS, NOMENCLATURA E ABREVIAÇÕES
}

\author{
Nomenclatura e Abreviações \\ QEE Qualidade da Energia Elétrica \\ DFT Discrete Fourier Transform - Transformada Discreta de Fourier \\ IEC International Electrotechnical Comission \\ THD Total Harmonic Distortion - Distorção Harmônica Total \\ TID Total Interharmonic Distortion - Distorção Inter-harmônica \\ Total \\ PAC Ponto de Acoplamento Comum \\ PRODIST Procedimentos de Distribuição de Energia Elétrica \\ RMS Root Mean Square - Raiz do valor quadrático médio \\ PLL Phase Locked Loop \\ DFIG Doubly-Fed Induction Generator - Gerador de Indução de \\ Dupla Alimentação \\ VSI Voltage Sourced Imposed - Inversor Fonte de Tensão \\ DC Direct Current \\ CA Corrente Alternada \\ IGBT Insulated Gate Bipolar Transistor - Transistor Bipolar de Porta \\ Isolada \\ PWM Pulse Width Modulation - Modulação por largura de pulso \\ ONS Operador Nacional do Sistema Elétrico \\ DTHT Distorção de Tensão Harmônica Total \\ ABNT Associação Brasileira de Normas Técnicas \\ ANEEL Agência Nacional de Energia Elétrica \\ EPE Empresa de Pesquisa Energética \\ DTFT Discrete-Time Fourier Transform - Transformada de Fourier em \\ Tempo Discreto \\ PK Prony-Kalman \\ PM Prony Modificado \\ FK Filtro de Kalman \\ FIR Finite Impulse Response - Resposta ao impulso finita \\ CDF Cumulative Distribution Function - Função de distribuição \\ acumulada \\ SIN Sistema Interligado Nacional
}

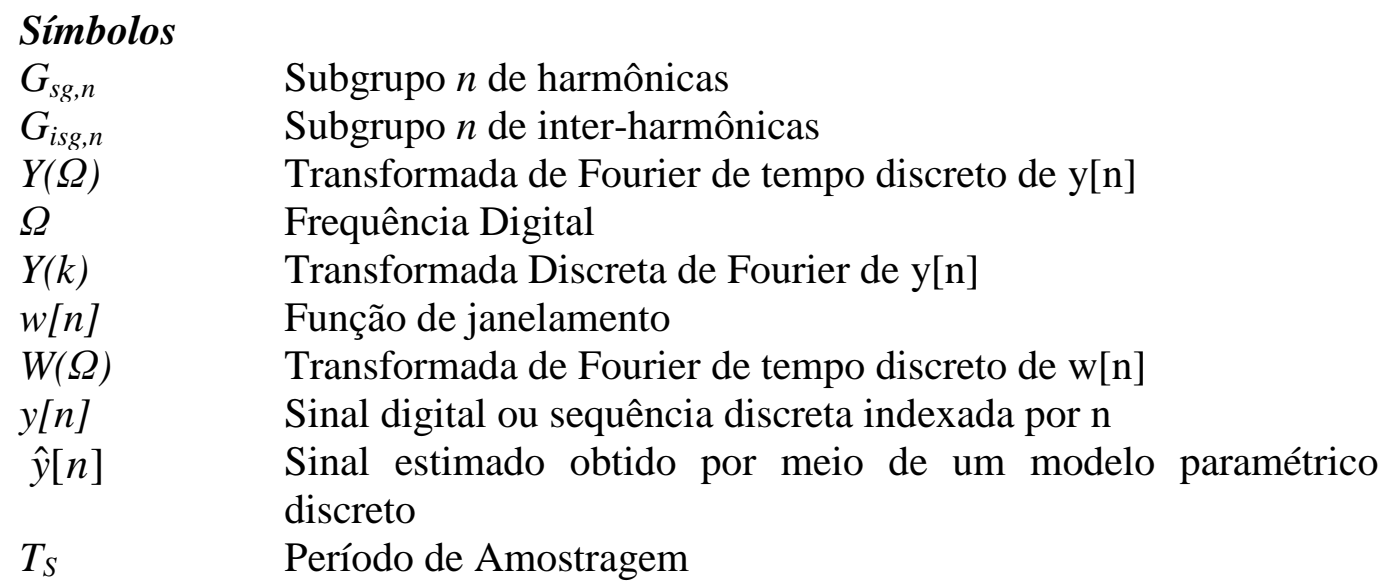


Frequência de Amostragem

$e[n] \quad$ Sequência discreta de erro de modelagem

$x_{n}$

$A_{n}$

$\zeta$

$X(t)$

Vetor x no instante/iteração $n$

Matriz A no instante/iteração $n$

Evento ou resultado de um experimento aleatório

Processo aleatório $\mathrm{X}(\zeta, \mathrm{t})$ ou função amostra do processo aleatório $\mathrm{X}(\zeta, \mathrm{t})$

$E[X] \quad$ Esperança matemática de uma variável aleatória $X\left(\right.$ média $\left.\mu_{X}\right)$

$\sigma_{X}$

Desvio-padrão de uma variável aleatória $X$

$S$

Desvio-padrão amostral de uma variável aleatória $X$

$\bar{X}$

Média amostral de uma variável aleatória $X$

$\langle X(t)\rangle$

Média de probabilidade de um processo aleatório X(t) $(\mathrm{E}[\mathrm{X}(\mathrm{t})])$

$\mathrm{DFT}_{1}$

$\mathrm{DFT}_{6}$

DFT com janela de 1 ciclo de $60 \mathrm{~Hz}$ (16 ms)

$\mathrm{DFT}_{10}$

DFT com janela de 6 ciclos de $60 \mathrm{~Hz}(100 \mathrm{~ms})$

$\mathrm{DFT}_{12}$

DFT com janela de 10 ciclos de $60 \mathrm{~Hz}$ (166 ms)

$\mathrm{DFT}_{15}$

DFT com janela de 12 ciclos de $60 \mathrm{~Hz}(200 \mathrm{~ms})$

$\mathrm{DFT}_{20}$

DFT com janela de 15 ciclos de $60 \mathrm{~Hz}(250 \mathrm{~ms})$

$\mathrm{DFT}_{30}$

DFT com janela de 20 ciclos de $60 \mathrm{~Hz}(333 \mathrm{~ms})$

$\mathrm{DFT}_{60}$

$\mathrm{Pu} \%$

DFT com janela de 15 ciclos de $60 \mathrm{~Hz}(500 \mathrm{~ms})$

$T_{H} D_{95}$

DFT com janela de 60 ciclos de $60 \mathrm{~Hz}(1 \mathrm{~s})$

$T I D_{95}$

Percentil de $u \%$

Jn

Valor P95\% do THD

Valor P95\% do TID

$d$

Janela de tempo retangular de $n$ ciclos de $60 \mathrm{~Hz}$

$\begin{array}{ll}T H D\left(t_{k}, d\right) & \text { d-ésima rea } \\ & \text { instante tk }\end{array}$

Dia ou realização dos processos aleatórios $\operatorname{THD}(\mathrm{t})$ ou $\operatorname{TID}(\mathrm{t})$

$T I D\left(t_{k}, d\right)$ d-ésima realização do processo aleatório $\operatorname{TID}(\mathrm{t})$ amostrada no instante tk

p.u.

Valor de medida por unidade 


\section{SUMÁRIO}

1 - INTRODUÇÃO.......................................................................................................................... 1

1.1 - CONSIDERAÇÕES INICIAIS.................................................................................1

1.2 - DEFINIÇÃO DO PROBLEMA...........................................................................................2

1.3 - ESTADO DA ARTE....................................................................................................... 3

1.4 - OBJETIVOS E METAS ................................................................................................ 6

1.5 - ESTRUTURA DO TRABALHO .................................................................................... 7

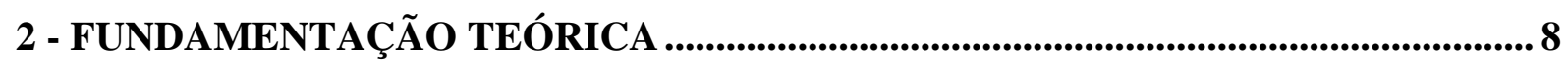

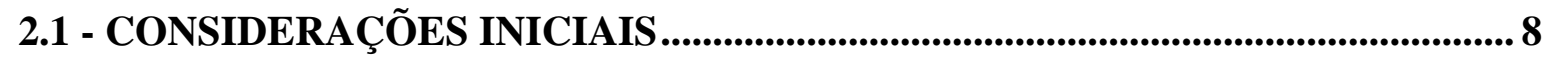

2.2 - DISTORÇÕES DE FORMA DE ONDA............................................................ 8

2.2.1 - Harmônicas e Inter-harmônicas ........................................................................... 8

2.2.2 - Normas IEC para Medição de Distorções............................................................9

2.3 - SISTEMAS EÓLICOS ............................................................................................ 11

2.3.1 - Funcionamento dos Aerogeradores .................................................................... 11

2.3.2 - Principais topologias para os sistemas eólicos .................................................... 12

2.3.3 -Sistemas eólicos e QEE ........................................................................................ 13

2.3.4 -Normas e Valores de Referência para Sistemas Eólicos................................... 14

2.4 - APLICAÇÃO DA DFT NA ANÁLISE DE SINAIS .................................................16

2.5 - MÉTODOS PARAMÉTRICOS PARA A MEDIÇÃO DE DISTORÇÕES......... 20

2.5.1 - Método de Prony Modificado..................................................................................21

2.5.2 - Filtro de Kalman .................................................................................................24

2.6 - PROCESSOS ALEATÓRIOS ............................................................................27

2.6.1 - Conceitos de Probabilidade e Estatística ........................................................27

2.6.2 - Processos estocásticos................................................................................................ 32

2.7 - CONSIDERAÇÕES FINAIS .......................................................................................34

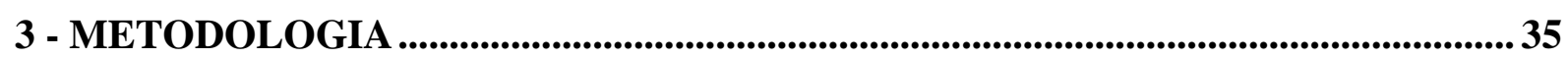

3.1 - CONSIDERAÇÕES INICIAIS...............................................................................35

3.2 - MEDIÇÕES E FORMAÇÃO DO BANCO DE SINAIS ...........................................35

3.2.1 - Procedimento de medição e armazenamento ......................................................35

3.3 - METODOLOGIA DE ANÁLISE .....................................................................36

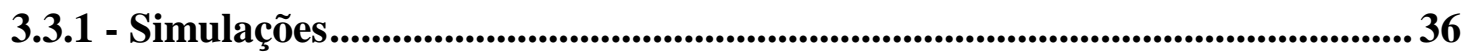


3.3.2 - Avaliação das Janelas de Tempo .........................................................................37

3.3.3 - Avaliação do período de medição ................................................................... 41

3.3.3.1 -Verificação da adequabilidade dos dados a uma função de distribuição de

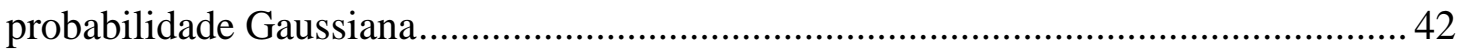

3.3.3.2 - Cálculo da média de probabilidade e da média e variância temporal ............ 43

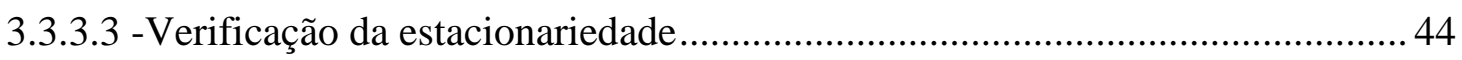

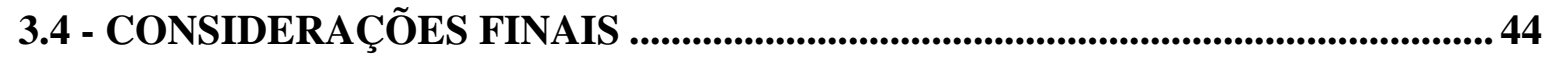

4 - RESULTADOS E DISCUSSÕES........................................................................... 45

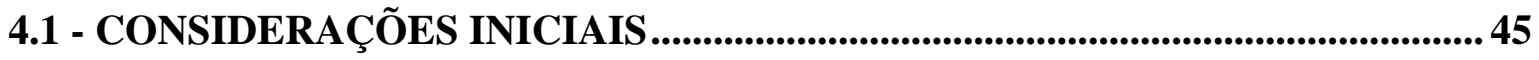

4.2 - MEDIÇÕES EM UMA INSTALAÇÃO EÓLICA..................................................... 45

4.3 - AVALIAÇÃO COMPARATIVA ENTRE OS MÉTODOS..................................... 46

4.4 - AVALIAÇÃO DAS JANELAS DE TEMPO................................................................ 48

4.4.1 - Análise das tendências ..........................................................................53

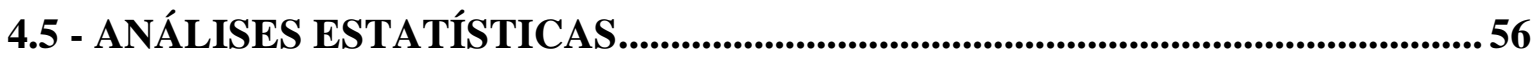

4.5.1 - Avaliação da estacionariedade ......................................................................58

4.5.2 - Avaliação dos períodos de medição ..................................................61

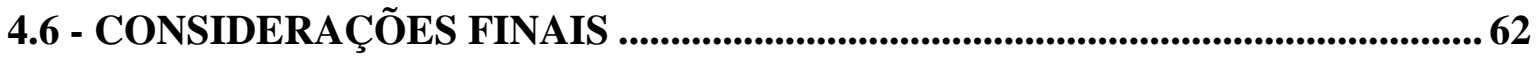

5 - CONCLUSÕES E TRABALHOS FUTUROS....................................................... 64

REFERÊNCIAS BIBLIOGRÁFICAS. ..........................................................................6 67 


\section{1 - INTRODUÇÃO}

\section{1 -CONSIDERAÇÕES INICIAIS}

A necessidade de recursos energéticos de baixo impacto ambiental tem impulsionado a inserção de fontes renováveis de energia nas matrizes energéticas de diversos países. Dentre essas fontes, a energia eólica tem sido uma alternativa para compatibilizar as exigências energéticas com as restrições ambientais.

Segundo o Conselho Mundial de Energia Eólica (GWEC, 2014), a capacidade instalada da mencionada fonte alcançou 318.137 MW em 2013, representando um crescimento de $12,5 \%$ em relação ao ano anterior. No cenário nacional, os crescentes investimentos no setor resultaram em uma potência acumulada de 3.898 MW no final de 2013, os quais representam cerca de 3,0\% da capacidade de geração de energia elétrica. A previsão para o ano de 2020 aponta que a energia eólica pode ocupar cerca de 9,0\% da matriz brasileira para a produção de eletricidade (EPE, 2013).

A expansão da fonte eólica no mercado de energia elétrica é resultado da combinação de fatores relacionados ao desenvolvimento tecnológico e da cadeia produtiva, além de aspectos regulatórios, tributários e financeiros (Ringer, 2014). Apesar dos reconhecidos avanços e domínios tecnológicos associados a essa fonte renovável, nota-se lacunas na literatura técnica sobre as instalações eólicas. Algumas preocupações residem no âmbito da Qualidade da Energia Elétrica (QEE) e estão, na maioria das vezes, atreladas à presença de distorções harmônicas e inter-harmônicas.

Convencionalmente, a estimação do conteúdo harmônico e inter-harmônico dos sinais de corrente e tensão, é baseada no uso da Transformada Discreta de Fourier (ou DFT, do inglês Discrete Fourier Transform). Um exemplo disso é o padrão IEC 61000-4-7, que traz recomendações técnicas para a instrumentação e medição de harmônicas e interharmônicas. Já a IEC 61000-4-30 é responsável por propor os protocolos de medição que devem ser empregados. Entretanto, faz-se necessário averiguar se essa abordagem é adequada no contexto da geração distribuída, pois nesse caso específico, tais fenômenos 
podem apresentar variação no tempo. Por essa razão, a aplicação de metodologias de medição baseadas na análise de Fourier pode fornecer resultados imprecisos.

\section{2 - DEFINIÇÃO DO PROBLEMA}

A IEC 61000-4-30 (IEC, 2008) e a IEC 61000-4-7 (IEC, 2002) são as principais referências internacionais para a medição de harmônicos em sistemas de potência. A primeira define métodos para mensurar e interpretar os resultados dos principais indicadores utilizados para aferir a QEE. A norma recomenda o período mínimo de medição de 7 dias para o cálculo das distorções. A IEC 61000-4-7 recomenda o uso da DFT com uma janela de tempo retangular de 12 ciclos para análise de sinais de sistemas elétricos de $60 \mathrm{~Hz}$, além de especificar o cálculo do indicador de distorção harmônica total (ou THD, do inglês Total Harmonic Distortion).

Não obstante, a aplicação da DFT se restringe a sinais em regime permanente. No caso da geração eólica, o vento apresenta comportamento intermitente em sua velocidade e direção, o que causa variações no potencial energético dessa fonte. Como consequência desse fenômeno natural, componentes espúrias surgem no espectro de frequência, afetando diretamente a quantificação dos indicadores de QEE. Em outras palavras, o sinal variante no tempo faz com que o resíduo da projeção ortogonal sob as funções de base da DFT (senos e cossenos) seja diferente de zero, favorecendo o surgimento de componentes de frequência inesperadas.

Embora a aplicação da DFT culmine em resultados imprecisos nesse caso, pode-se avaliar a variação do tamanho da janela de tempo com o intuito de atenuar as incertezas relativas ao processo de medição. Entretanto, é preciso averiguar quais implicações essa alteração pode causar, já que uma diminuição no tamanho da janela implicaria em uma menor resolução.

Outro aspecto importante, tendo em vista o perfil variável das distorções nas instalações eólicas, é a verificação do período mínimo de medição de 7 dias, recomendado pela IEC 61000-4-30. Pressupõe-se que tal período pode ser inadequado para a caracterização das distorções. Um período de medição superior ao recomendado pela IEC tornaria insuficiente o tempo proposto para a caracterização da distorção. 
Diante disto, a problemática desta dissertação consiste na escolha adequada do tamanho de uma janela de tempo que atenue as imprecisões advindas da aplicação da DFT e a análise do período mínimo de medição suficiente para caracterização do fenômeno em estudo.

\section{3 - ESTADO DA ARTE}

A crescente contribuição da energia eólica na matriz energética mundial revela a necessidade de se compreender os padrões de distorção atrelados aos estudos de QEE em usinas eólicas. Dentre as principais questões na área mencionada, cita-se a avaliação dos níveis de distorção de forma de onda de tensão e corrente gerada pelas usinas. Assim, pesquisas estão sendo desenvolvidas com o intuito de investigar a emissão e propagação das distorções, e de evidenciar os níveis de distorção associados às instalações eólicas, sugerindo diagnósticos e métodos de quantificação das distorções.

Yang (2015) denota um estudo sobre distorções harmônicas baseado em medições de campo no Ponto de Acoplamento (PAC) de um parque eólico com a rede e em três turbinas eólicas diferentes. As medidas foram obtidas utilizando-se um medidor de qualidade da energia em conformidade com as normas IEC 61000-4-7 e IEC 61000-4-30. Tal equipamento foi empregado em instalações eólicas reais respeitando todos os aspectos demandados. Dois tipos de dados foram obtidos: subgrupos de harmônicas e interharmônicas de tensão e corrente em intervalos de 10 minutos, com um período mínimo de medição de 7 dias. A estimação dos espectros foi realizada via DFT, com janela retangular de 200 ms. Os resultados mostram que harmônicas e inter-harmônicas estão presentes em níveis significativos, variando fortemente com o tempo. O espectro harmônico é diferente entre as três turbinas, contudo similaridades podem ser percebidas: o espectro médio é uma combinação das componentes dos espectros de banda larga e curta. Os níveis de distorção do PAC são comparados aos das turbinas individuais e verifica-se que, devido ao cancelamento de harmônicas e inter-harmônicas do parque eólico, as distorções individuais das turbinas são maiores. Constata-se que as inter-harmônicas apresentam grande dependência com a produção de energia ativa da turbina. A origem das distorções é relacionada ao uso dos conversores de energia e à diferença entre a frequência do gerador e do sistema. Na avaliação das emissões, o autor sugere um índice chamado distorção interharmônica total (ou TID, do inglês Total Interhamonic Distortion) que consiste da generalização do THD para os subgrupos de inter-harmônicas da IEC. Tal consideração 
fez-se necessária devido à ausência nas normas de um indicador explícito para interharmônicas. Segundo o autor, os resultados encontrados não podem ser generalizados para outros sistemas, no entanto, para espectros similares resultados semelhantes são esperados.

O trabalho de Parreiras e Silva (2012) apresenta um estudo do impacto da instalação de um sistema com conversores para geração eólica no tocante à distorção da forma de onda de tensão do barramento principal. A pesquisa se desenvolve por meio da introdução das principais tecnologias de geração eólica e conversores aplicados. Na sequência, são mostradas as harmônicas geradas por uma turbina e salientada a correlação com a necessidade de utilização de conversores de frequência. Por intermédio de simulações, constata-se que uma turbina isolada produz baixo conteúdo harmônico, porém, a instalação de várias delas pode gerar altos índices de distorção harmônica. Tais efeitos são maximizados quando o sistema possui baixa potência de curto-circuito.

Nos trabalhos citados acima, tem-se contribuições na direção de se investigar a emissão e propagação das distorções no contexto da geração eólica. Contudo, é importante realizar a quantificação dessas distorções. Na literatura, observa-se a adoção de metodologias alternativas à DFT para estimar as componentes harmônicas. Algumas representam uma adaptação de técnicas baseadas na própria DFT, como o trabalho de Carvalho (2008), que expõe uma abordagem baseada no erro de fase da DFT para sinais com desvio de frequência. Ele faz uso de filtros digitais para eliminação das oscilações dos resultados da DFT e estimação do desvio da frequência do sinal. Com as equações de resposta em frequência do filtro são realizadas as correções de amplitude e fase.

No trabalho de Zhu (2007) é exibido um método numérico para o cálculo de harmônicas e inter-harmônicas, em sistemas trifásicos, usando a Transformada de Fourier com Janela Adaptativa. O método proposto ajusta adaptativamente a largura da janela com base no cálculo de correlação, reduzindo significativamente os erros atrelados ao espalhamento espectral no domínio da frequência, causado pelo truncamento do sinal no domínio do tempo. $\mathrm{O}$ algoritmo iterativo não requer qualquer conhecimento sobre a frequência do sistema e das componentes inter-harmônicas. O único parâmetro de entrada é a sequência do sinal, obtido por amostragem do sinal analógico no intervalo de amostragem equidistante. Vários estudos de casos, utilizando dados de simulação, dados experimentais 
e dados reais, mostram que o algoritmo adaptativo fornece uma solução numérica diante do problema de espalhamento espectral.

A pesquisa de Souza et al (2014) propõe uma metodologia alternativa baseada em arquiteturas de Redes Neurais Artificiais para estimar a presença de componentes harmônicos em formas de ondas usualmente encontradas em um Sistema Elétrico de Potência. Os conteúdos espectrais das formas de ondas geradas e resultantes da conexão de cargas não lineares frequentemente instaladas no sistema, bem como as geradas em consideração aos limiares de distorção harmônica pré-definidos pelos Procedimentos de Distribuição de Energia Elétrica no Sistema Elétrico Nacional (PRODIST), são diagnosticados. Resultados evidenciam que a vantagem da utilização do modelo neural está no fato do mesmo ser capaz de representar adequadamente o espectro de frequência do sinal, ainda que não representado por um ciclo completo. A desvantagem consiste na restrição ao tipo de banco de dados utilizado, influenciando diretamente na qualidade da resposta.

Costa (2005) propõe uma metodologia de análise de harmônicos e inter-harmônicos de sinais de corrente e de tensão adquiridos em sistemas elétricos. Para tanto, foi desenvolvido um estimador de frequências, denominado método de Prony Modificado, que foi combinado a um estimador linear, implementado por meio do Filtro de Kalman. Na metodologia proposta, as amplitudes das senoides presentes nos sinais analisados são rastreadas pelo Filtro de Kalman, enquanto os regressores do filtro são construídos a partir das frequências fornecidas pelo método de Prony Modificado. O autor propõe também algumas sugestões no sentido de melhorar o desempenho do método de Prony na presença de ruídos de medição. As técnicas propostas foram aplicadas em sinais elétricos reais e simulados. Nessa pesquisa, o autor concluiu que o procedimento apresenta como principal vantagem a robustez para a análise espectral de sinais com alta resolução em condições de variação temporal.

A característica aleatória da velocidade do vento sugere uma representação estatística das distorções harmônicas geradas por diferentes topologias de usinas eólicas, como é tratado por Tentzerakis (2007). A metodologia empregada pelo autor para a representação das harmônicas assemelha-se à metodologia aplicada por Machado (2008), que, para caracterizar as injeções de harmônicos de uma usina eólica à velocidade variável, emprega 
técnicas de estimação recursivas para garantir o rastreamento das harmônicas ao longo do tempo. Em função da velocidade do vento ser uma variável estocástica, descrita por uma função de densidade de probabilidade de Weibull, as distorções harmônicas também podem ser representadas por funções de distribuição de probabilidades conhecidas. Com isso, é possível correlacionar as distorções harmônicas com a velocidade do vento.

Um aspecto adicional ainda pode ser observado na revisão em curso: o período de monitoramento das distorções. Não foram encontrados estudos que discutam a escolha do período de medição para a análise das distorções. Porém, reportando a outras áreas de investigação, pode ser citado o trabalho de Feitosa (2009) o qual questiona se o período de medição empregado, de acordo com a IEC, de 7 dias é suficiente para efetuar qualquer julgamento sobre a qualidade da energia. Por meio de um conjunto de procedimentos estatísticos, para o caso específico da avaliação da estacionariedade do índice de desequilíbrio de tensão, o autor recomenda um período de 13 semanas consecutivas.

Nos trabalhos supracitados, podem ser constatados alguns estudos sobre a emissão e propagação de distorções, além de soluções para a quantificação e medição dessas distorções em sinais dos sistemas de potência. Vale salientar que a escolha do procedimento de quantificação de distorções mais adequado está diretamente relacionada com as características dos sinais e também à sua aplicação. Logo, a ponderação de todos os aspectos mencionados sugere que a metodologia de medição da IEC pode ser adaptada para o contexto da geração eólica, a partir da avaliação do tamanho da janela e do período de medição.

\section{4 - OBJETIVOS E METAS}

Considerando-se os aspectos ora mencionados, surgiu a ideia de desenvolvimento desta dissertação que objetiva propor uma metodologia de análise que possibilite a adequação do procedimento de medição de distorções da IEC para instalações eólicas. Os objetivos específicos estabelecidos para este trabalho são: i) identificar a influência da utilização de diferentes tamanhos de janelas de tempo retangulares para processamento de sinais via DFT e ii) avaliar a adequabilidade do período de medição de 7 dias da IEC na caracterização das distorções. Para tanto, é empregada uma metodologia de processamento de sinais derivada da combinação do Método de Prony com o Filtro de Kalman. 
As metas definidas para atingir os objetivos supracitados são:

- Adquirir sinais de tensão e corrente de um aerogerador pertencente a uma central de geração eólica durante 30 dias;

- Analisar e comparar os resultados do processamento dos sinais, empregando a DFT com janelas de tempo de diferentes tamanhos, tomando o Método híbrido de Prony-Kalman como referência;

- Calcular as variáveis representativas das distorções: sub-grupos IEC de harmônicas e inter-harmônicas, THD e TID;

- Avaliar, por meio de análise estatística, os intervalos de estacionariedade dos indicadores de distorção, visando à identificação de um período mínimo de medição necessário para a caracterização das distorções harmônicas e interharmônicas.

\section{5 - ESTRUTURA DO TRABALHO}

Com o intuito de atender aos objetivos ora apresentados, além do presente capítulo introdutório, este trabalho apresenta-se estruturado com os seguintes capítulos:

Capítulo 2: exibe conceitos sobre distorções de forma de onda, sistemas eólicos e métodos para análise das distorções;

Capítulo 3: apresentação da metodologia de aquisição e análise dos sinais obtidos em uma instalação eólica;

Capítulo 4: os resultados são exibidos. A investigação consiste na avaliação da influência das janelas de tempo e dos períodos de medição no sistema de geração em pauta;

Capítulo 5: síntese das conclusões gerais bem como apresentação de propostas para pesquisas futuras. 


\section{2 - FUNDAMENTAÇÃO TEÓRICA}

\section{1 - CONSIDERAÇÕES INICIAIS}

O presente capítulo define os principais conceitos relativos às distorções harmônicas e inter-harmônicas, bem como os procedimentos de medição encontrados nas normas vigentes. Em seguida, apresenta-se o comportamento das unidades eólicas quanto à geração das distorções de forma de onda. Discorre-se sobre o processamento dos sinais com a DFT, e suas limitações para a presente aplicação. Baseando-se na revisão da literatura, alternativamente à DFT, é apontada uma metodologia híbrida para processamento de sinais que decorre da combinação do método de Prony com o Filtro de Kalman. Por último, são exibidos alguns conceitos relacionados ao estudo de processos aleatórios.

\section{2 - DISTORÇÕES DE FORMA DE ONDA}

\subsection{1 - Harmônicas e inter-harmônicas}

As distorções de forma de onda incluem os desvios de tensão ou corrente em relação ao sinal senoidal ideal tido como referência, com base na frequência fundamental (Dugan et al, 2003). Tais distorções podem ser caracterizadas em termos de harmônicas e interharmônicas.

As harmônicas são definidas como componentes com frequências múltiplas inteiras da fundamental, que podem se manifestar na tensão ou corrente do sistema. Já as interhamônicas apresentam componentes de frequência múltiplas não-inteiras da frequência fundamental (IEEE 519, 2014).

O surgimento das harmônicas no Sistema Elétrico de Potência se deve, principalmente, à presença de cargas com características não-lineares conectadas à rede. As interharmônicas, por sua vez, são encontradas em redes de diferentes classes de tensão, sendo as suas principais fontes geradoras os conversores de frequência estáticos, ciclo conversores, motores de indução e equipamentos a arco (Dugan et al, 2003). 
Segundo Dugan et al (2003), as correntes harmônicas injetadas no sistema de potência podem interagir com vários equipamentos, a exemplo de capacitores e transformadores, ocasionando perdas, aquecimentos e sobrecargas. Os principais efeitos das tensões e correntes harmônicas no sistema de potência são a redução da eficiência e da vida útil de equipamentos; envelhecimento do isolamento de componentes; perdas jáulicas adicionais em condutores e o funcionamento inadequado de equipamentos eletrônicos e dispositivos de proteção (Arrillaga et al, 2003).

\subsection{2 - Normas IEC para Medição de Distorções}

As normas da IEC (do inglês, International Electrotechnical Comission) para monitoração de QEE estão disponíveis na série 61000 de normas individuais que especificam requisitos para distúrbios relacionados à QEE. Os padrões IEC 61000-4-30 e IEC 61000-4-7 são aplicáveis à medição de harmônicas e inter-harmônicas.

O escopo da IEC 61000-4-7 compreende a instrumentação e a medição de componentes espectrais que são sobrepostas à fundamental dos sistemas de potência de $50 \mathrm{~Hz}$ ou $60 \mathrm{~Hz}$ (IEC, 2002). Nessa norma são considerados alguns métodos, denominados como grupos e subgrupos de harmônicas e inter-harmônicas, que tem como função agrupar a energia das componentes espalhadas ao longo do espectro de frequência e estabelecer sua respectiva amplitude. A Figura 2.1 exibe grupos e subgrupos formados empregando-se o padrão IEC 61000-4-7.

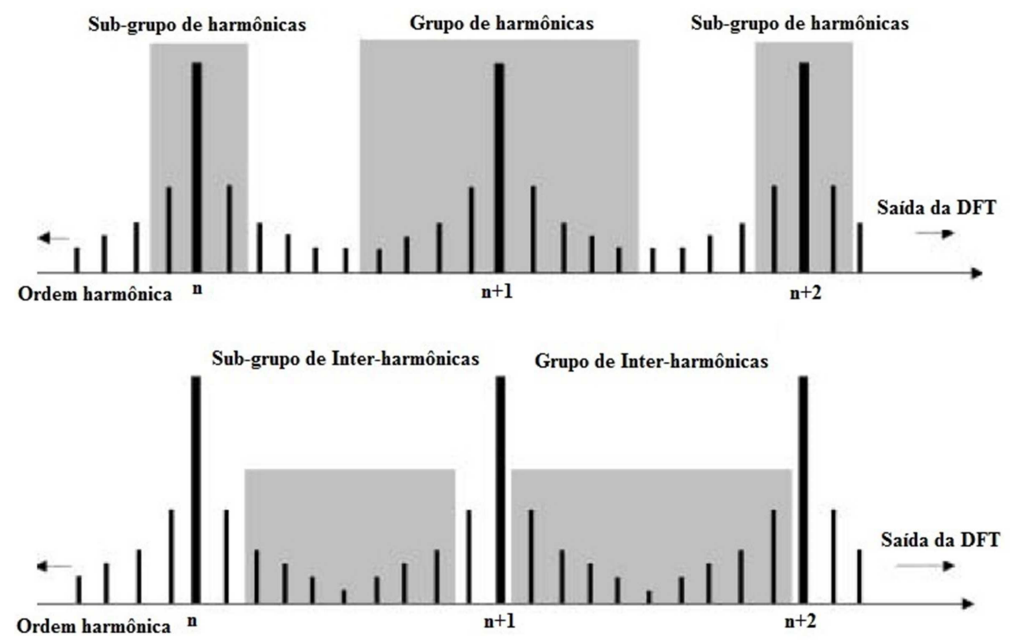

Figura 2.1. Grupos e subgrupos do padrão IEC 61000-4-7. Fonte: Hanzelka\&Bierí, 2004. 
Na Figura 2.1, é possível observar o conceito que define as amplitudes RMS dos diversos grupos e subgrupos. O subgrupo da n-ésima harmônica, por exemplo, tem seu valor RMS dado pela agregação das duas barras espectrais imediatamente adjacentes à barra harmônica. Um subgrupo $n$ de inter-harmônicas engloba todas as barras entre duas harmônicas consecutivas de ordem $n$ e ordem $n+1$, com exceção daquelas que são adjacentes a estas.

As magnitudes dos subgrupos $n$ de harmônicas e inter-harmônicas são calculadas, respectivamente, conforme (2.1) e (2.2).

$$
\begin{aligned}
& G_{s g, n}^{2}=\sum_{i=-1}^{1}\left(C_{k+i}\right)^{2} \\
& G_{i s g, n}^{2}=\sum_{i=2}^{10}\left(C_{k+i}\right)^{2}
\end{aligned}
$$

em que $G s g$, $n$ é o $n$-ésimo subgrupo de harmônicas; $C_{k}$ é a barra espectral correspondente à $n$-ésima harmônica e Gisg,n é o $n$-ésimo subgrupo de inter-harmônicas. Vale ressaltar que em (2.2), com a resolução de $5 \mathrm{~Hz}$, o somatório é realizado de 2 a 10 porque existe um conjunto de 11 barras entre duas harmônicas consecutivas, mas a primeira e a última barras são excluídas do subgrupo.

O principal indicador de distorção referenciado nas normas técnicas nacionais e internacionais é o THD (do inglês, Total Harmonic Distortion). Em (2.3) apresenta-se a definição da IEC 61000-4-7 para esse indicador.

$$
T H D=\frac{\sqrt{\sum_{h=2}^{H}\left(G_{s g, h}\right)^{2}}}{G_{s g, 1}}
$$

em que $G_{s g, h}$ é o valor RMS do subgrupo da harmônica de ordem $h$. O somatório é efetuado até a harmônica de maior ordem $H$, e $G_{s g, l}$ é o valor RMS do subgrupo da fundamental.

Para as inter-harmônicas, pode-se empregar um indicador semelhante ao THD, denominado neste trabalho como Distorção Inter-harmônica Total, TID (do inglês, Total Interharmonic Distortion), definido em (2.4). 


$$
T I D=\frac{\sqrt{\sum_{n=2}^{I H}\left(G_{i s g, n}\right)^{2}}}{G_{s g, 1}}
$$

em que $G_{i s g, n}$ é o valor RMS do n-ésimo subgrupo de inter-harmônicas. O somatório é efetuado até o subgrupo $I H$ de inter-harmônicas, e $G_{s g, l}$ é o valor RMS do subgrupo da fundamental. Indicadores individuais também podem ser estabelecidos para harmônicas ou subgrupos de inter-harmônicas específicos.

Na IEC 61000-4-30 é descrito como os resultados da IEC 61000-4-7 podem ser agregados no tempo. Esse padrão especifica os equipamentos de medição em três classes de desempenho: A, S e B. Para a classe A, tratada no escopo deste trabalho, o intervalo de medição de magnitudes dos diversos parâmetros de QEE deverá ser de 12 ciclos para sistemas de alimentação em $60 \mathrm{~Hz}$, isto é, $200 \mathrm{~ms}$ (IEC, 2008). Tal aspecto resulta em um espectro com resolução de $5 \mathrm{~Hz}$. Esses parâmetros são então agregados em intervalos de tempo regulares.

Ao processar os sinais via DFT a cada $200 \mathrm{~ms}$ é necessário observar, dentre outras considerações técnicas, que o mesmo deve ser adquirido com um procedimento de sincronização PLL (do inglês, Phase Locked Loop), e a taxa de amostragem mínima recomendada deve ser de 128 amostras por ciclo de $60 \mathrm{~Hz}$.

A IEC 61000-4-30 define como 7 dias o período mínimo para a medição das distorções. Para a quantificação dos índices é determinado o valor estatístico percentil de 95\% (P95\%) dos períodos diário e semanal do conjunto de valores obtidos.

Os procedimentos de quantificação supracitados pela metodologia do padrão IEC fazem parte do escopo de análise desta dissertação.

\section{3 - SISTEMAS EÓLICOS}

\subsection{1 - Funcionamento dos Aerogeradores}

Sistemas eólicos são capazes de converter a energia cinética dos ventos em energia elétrica. $\mathrm{O}$ funcionamento desses divide-se, basicamente, em duas partes: o rotor, que retira 
energia cinética do vento e a converte em conjugado mecânico e o gerador elétrico, que o converte em eletricidade (Matias, 2007).

Em geral, tal sistema é formado por turbina eólica, multiplicador mecânico, gerador elétrico e dispositivos de controle (Pavinato, 2005). A Figura 2.2 exibe os componentes básicos de um sistema de geração de energia eólica.

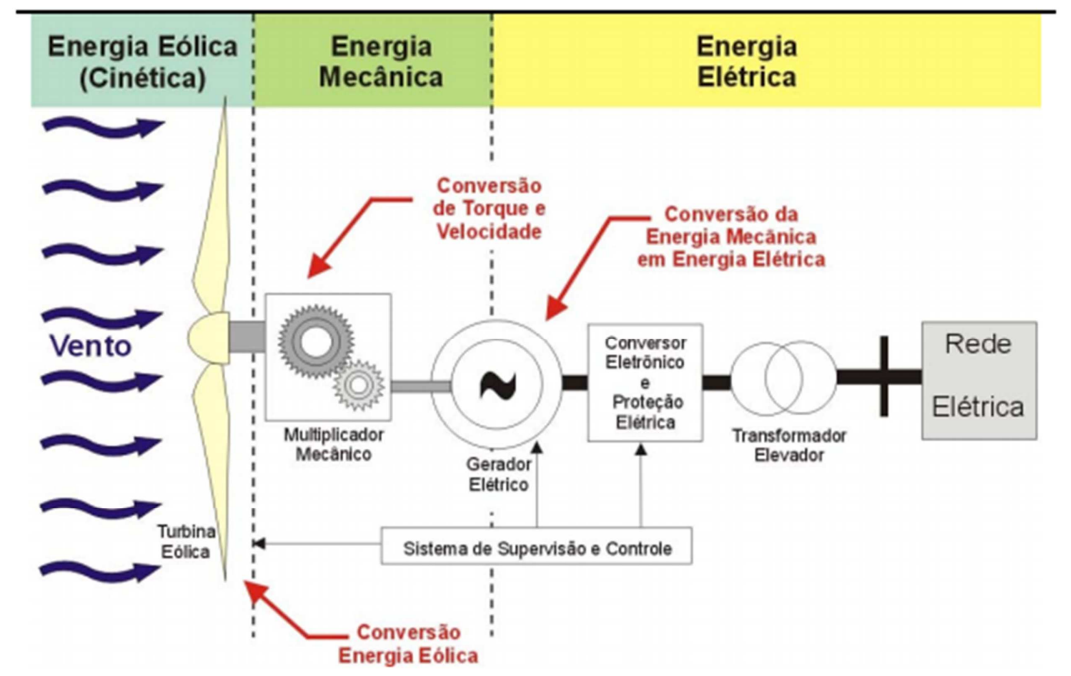

Figura 2.2. Esquema geral de um sistema eólico. Fonte: Pavinato, 2005.

A turbina eólica, que é responsável pela conversão da energia cinética do vento em conjugado mecânico, é composta pelo cubo do rotor e pás. A caixa multiplicadora é responsável pela conversão de torque e velocidades. A energia elétrica é obtida por meio da conversão da energia mecânica no gerador elétrico que pode ser de indução ou síncrono. O gerador pode ser ligado diretamente à rede elétrica por intermédio de um transformador ou conectado ao transformador por meio de conversores estáticos de frequência (Pavinato, 2005).

\subsection{2 - Principais topologias para os sistemas eólicos}

Existem três conceitos atuais de sistemas de conversão eólicos, sendo as outras versões existentes variações desses. A primeira topologia consiste em sistemas de velocidade fixa dotados de gerador de indução diretamente conectado na rede elétrica. Essa configuração está associada, normalmente, a um gerador de indução em gaiola de esquilo. Nesse caso, o rotor da turbina está conectado ao gerador elétrico por meio de uma caixa de transmissão de velocidade. No conceito descrito, a potência extraída do vento é limitada, de forma tal 
que a sua eficiência diminui à medida que a velocidade do vento aumenta (Heier, 1998; Larsson, 2000 \& Slootweg et al, 2003).

O segundo arranjo consiste em sistemas de conversão eólicos que operam com velocidade variável e são compostos por gerador de indução. A principal técnica utilizada pelos fabricantes de aerogeradores desse tipo de topologia são os sistemas dotados de Gerador de Indução de Dupla Alimentação - DFIG (do inglês, Doubly-Fed Induction Generator), conectado na rede elétrica por meio de um conversor de frequência. Em sistemas dessa natureza, o enrolamento do rotor é alimentado usando um conversor VSI (do inglês, Voltage Sourced Imposed). Como no caso do conceito anterior, o rotor da turbina eólica está conectado ao gerador por meio da uma caixa de transmissão. Entretanto, nessa topologia, é permitida a variação da velocidade numa faixa estreita (Silva, 2005 \& Carvalho, 2006).

Por fim, tem-se os sistemas de velocidade variável dotados de gerador síncrono conectado na rede elétrica por meio de conversor de frequência. Esse conceito consiste em uma turbina eólica de velocidade variável, equipada com um gerador síncrono de acionamento direto. O gerador pode ter um rotor enrolado ou utilizar imãs permanentes (Heier, 1998 \& Carvalho, 2006).

\subsection{3 - Sistemas eólicos e QEE}

Os principais fatores que impactam a QEE nas fontes eólicas são: o comportamento dinâmico do vento e a utilização dos conversores de frequência. A dinâmica da velocidade do vento gera variações de potência e flutuações de tensão. Já os conversores de frequência, devido a sua característica operacional, contribuem para a emissão de distorções nas formas de onda (Machado, 2008).

Os conversores são compostos por uma ponte retificadora e um inversor de frequência. A ponte retificadora transforma a tensão alternada da saída do gerador em uma tensão contínua em um barramento CC. Já o inversor de frequência converte a tensão contínua do barramento CC em uma tensão alternada, com frequência igual a da rede (Carvalho, 2006). 
O funcionamento dos inversores está baseado no chaveamento de dispositivos semicondutores. Em sistemas eólicos, o dispositivo semicondutor mais utilizado para integrar os conversores é o IGBT (do inglês, Insulated Gate Bipolar Transistor), por ser um dispositivo controlável, e apresentar uma potência de saída elevada a uma faixa de frequência de chaveamento bastante ampla, se comparada com outros semicondutores. Em geral, uma estratégia PWM (do inglês, Pulse Width Modulation) também é utilizada na determinação da sequência de chaveamento dos elementos semicondutores (Erickson, et al, 2004 \& Skvarerina, 2002).

Os conversores estáticos aplicados na configuração do DFIG são constituídos de dois conjuntos trifásicos de chaves a comutação forçada, interconectados por um barramento de corrente contínua. Uma característica peculiar desse tipo de configuração é a alteração da frequência das harmônicas. As distorções emitidas pelo conversor interagem de forma bastante particular com a máquina: a frequência das correntes injetadas no rotor é transformada no estator. Essa transformação é devida ao escorregamento e ao sentido de rotação dos campos girantes gerados pelas correntes harmônicas. Tais efeitos combinados culminam com o aparecimento de harmônicas de frequências não-inteiras no estator, que, posteriormente, se propagarão pelo sistema (Machado, 2008).

\subsection{4 - Normas e Valores de Referência para Sistemas Eólicos}

Os Procedimentos de Rede são documentos elaborados pelo Operador Nacional do Sistema Elétrico - ONS, os quais estabelecem os procedimentos e os requisitos técnicos para o planejamento, a implantação, o uso e a operação do Sistema Interligado Nacional e as responsabilidades dos agentes de operação. O Módulo 2 dos Procedimentos de Rede trata dos Requisitos mínimos para instalações de transmissão e gerenciamento de indicadores de desempenho da rede básica. Os Padrões de Desempenho descritos são relevantes à avaliação da QEE em sistemas eólicos (ONS, 2011).

Dentre os Requisitos Técnicos Mínimos para Conexão de Centrais Eólicas na Rede Básica, define-se a Distorção de Tensão Harmônica Total (DTHT) como a raiz quadrada do somatório quadrático das relações de tensões harmônicas de ordens 2 a 50 pela fundamental (ONS, 2011). 
Os limites globais inferiores correspondentes aos indicadores de tensões harmônicas individuais de ordens 2 a 50, bem como o indicador DTHTS95\% estão apresentados na Tabela 2.1. O indicador DTHTS95\% é determinado observando o valor que foi superado em apenas 5\% dos registros obtidos no período de 1 dia (24 horas), considerando os valores dos indicadores integralizados em intervalos de 10 minutos, ao longo de 7 dias consecutivos. $\mathrm{O}$ indicador corresponde ao maior entre os 7 valores obtidos, em base diária (ONS, 2011).

Tabela 2.1 - Limites globais inferiores de tensão em porcentagem da tensão fundamental. Fonte: ONS, 2011.

\begin{tabular}{|c|c|c|c|c|c|c|c|}
\hline \multicolumn{4}{|c|}{$\mathrm{V}<69 \mathrm{kV}$} & \multicolumn{4}{|c|}{$\mathrm{V} \geq 69 \mathrm{kV}$} \\
\hline \multicolumn{2}{|c|}{ ÍMPARES } & \multicolumn{2}{|c|}{ PARES } & \multicolumn{2}{|c|}{ ÍMPARES } & \multicolumn{2}{|c|}{ PARES } \\
\hline ORDEM & VALOR & ORDEM & VALOR & ORDEM & VALOR & ORDEM & VALOR \\
\hline \multirow[t]{2}{*}{$3,5,7$} & $5 \%$ & & & $3,5,7$ & $2 \%$ & & \\
\hline & & $2,4,6$ & $2 \%$ & & & $2,4,6$ & $1 \%$ \\
\hline \multirow[t]{2}{*}{$9,11,13$} & $3 \%$ & & & $9,11,13$ & $1,5 \%$ & & \\
\hline & & $\geq 8$ & $1 \%$ & & & $\geq 8$ & $0,5 \%$ \\
\hline 15 a 25 & $2 \%$ & & & 15 a 25 & $1 \%$ & & \\
\hline$\geq 27$ & $1 \%$ & & & $\geq 27$ & $0,5 \%$ & & \\
\hline \multicolumn{4}{|c|}{ DTHTS95\% $=6 \%$} & \multicolumn{4}{|c|}{ DTHTS95\% $=3 \%$} \\
\hline
\end{tabular}

Os limites individuais de tensões harmônicas de ordens 2 a 50, bem como o limite para a Distorção de Tensão Harmônica Total (DTHTS95\%), são apresentados na Tabela 2.2.

Tabela 2.2 - Limites individuais em porcentagem da tensão fundamental.

Fonte: ONS, 2011.

\begin{tabular}{|c|c|c|c|c|c|c|c|}
\hline \multicolumn{3}{|c|}{$13,8 \mathrm{kV} \leq \mathbf{V}<69 \mathbf{k V}$} & \multicolumn{5}{c|}{ V $\geq 69 k V$} \\
\hline IIMPARES & \multicolumn{2}{|c|}{ PARES } & ÍMPARES & \multicolumn{2}{c|}{ PARES } \\
\hline ORDEM & VALOR & ORDEM & VALOR & ORDEM & VALOR & ORDEM & VALOR \\
\hline 3 a 25 & $1,5 \%$ & & & 3 a 25 & $0,6 \%$ & & \\
\hline & & todos & $0,6 \%$ & & & todos & $0,3 \%$ \\
\hline$\geq 27$ & $0,7 \%$ & & & $\geq 27$ & $0,4 \%$ & & \\
\hline \multicolumn{3}{|c|}{ DTHTS95\% = 3\% } & \multicolumn{5}{c|}{ DTHTS95\%=1,5\% } \\
\hline
\end{tabular}


Finalmente, é estabelecido nos Procedimentos de Rede que, no caso onde determinadas ordens de tensão harmônica e/ou a distorção harmônica total variem de forma intermitente e repetitiva, os limites especificados podem ser ultrapassados em até o dobro, desde que a duração cumulativa acima dos limites contínuos estabelecidos não ultrapasse $5 \%$ do período de monitoração (ONS, 2011).

Os procedimentos de rede estabelecem as exigências para a QEE, mas ainda não tratam de forma específica os quesitos relacionados à geração eólica, estabelecendo padrões, limites e métodos de medição e controle das grandezas envolvidas para esta aplicação.

A ABNT NBR IEC 61400-21 fornece recomendações para medição e avaliação das características da QEE de turbinas eólicas conectadas à rede. A norma estabelece que a distorção harmônica total de tensão, incluindo todas as harmônicas, deve ser inferior a 5\%. Para as análises, são recomendadas janelas de 12 ciclos, adotando como método de cálculo principal a DFT (ABNT, 2010). A norma apesar de tratar especificamente sobre instalações eólicas, onde são esperadas distorções com grau de variação temporal, não traz alternativas à DFT que, nessas condições, pode apresentar resultados imprecisos. A seguir, será realizada uma breve revisão teórica sobre o assunto, a fim de esclarecer as consequências da utilização desse método.

\section{4 - APLICAÇÃO DA DFT NA ANÁLISE DE SINAIS}

O conteúdo espectral de sinais estacionários e discretos pode ser estimado via aplicação da DFT. Considere um sinal analógico $y(t)$, submetido a um processo de amostragem, por meio da DFT, com intervalo $T s$. O resultado desse processo é a sequência discreta $y[n]$, que representa as amostras de $y(t)$ nos instantes de tempo $\mathrm{t}=n T_{S}$, com $n$ inteiro. $\mathrm{O}$ espectro de $y[n]$ corresponde a uma replicação periódica do espectro de $y(t)$ multiplicado por $1 / T s$ (Oppenheim et al, 1998). A análise espectral de $y[n]$ pode ser realizada via Transformada de Fourier de Tempo Discreto (ou DTFT, do inglês Discrete-Time Fourier Transform), apresentada em (2.5).

$$
Y(\Omega)=\sum_{n=-\infty}^{\infty} y[n] e^{-j \Omega n}
$$


em que $Y(\Omega)$ é a DTFT de $y[n]$ e $\Omega$ é a frequência digital, expressa em $\mathrm{rad}$.

Um sinal $y[n]$ no tempo discreto pode ser representado por um somatório infinito de senoides de freqüência $\Omega$. Devido à questão prática de armazenamento e processamento limitados das máquinas digitais, faz-se necessária a delimitação de uma janela de dados do sinal. Nesse sentido, a DFT pode ser percebida como uma amostragem de $N$ pontos da DTFT (Oppenheim et al, 1998). A DFT de uma sequência discreta $y[n]$ de tamanho $N$ é definida em (2.6).

$$
Y(k)=\frac{1}{N} \sum_{n=0}^{N-1} y[n] e^{-j k \frac{2 \pi}{N} n}
$$

em que $Y(k)$ é a DFT de $y[n]$.

Pode-se estabelecer uma relação entre a DFT e a DTFT considerando a frequência digital do expoente da DTFT como $\Omega_{k}=k 2 \pi / N \mathrm{rad}$. Além disso, a DFT do sinal analisado é determinada por meio da convolução no domínio da frequência entre o espectro com duração infinita e a função de janelamento $w[n]$ de $N$ pontos amostrais. Logo, uma formulação mais genérica de (2.6) é apresentada em (2.7).

$$
Y(k)=\frac{1}{N} \sum_{n=0}^{N-1} w[n] y[n] e^{-j k \frac{2 \pi}{N} n}
$$

Dentre algumas funções de janelamento são encontradas a janela retangular, a janela de Hanning, Hamming e Bartlett (triangular). Essas janelas podem ser apresentadas no domínio do tempo como apresentado na Tabela 2.3 (Ribeiro et al, 2014).

Ao longo deste trabalho, será considerada apenas a janela padrão de tempo retangular, a qual é empregada pela IEC. Em (2.8) está indicada a sua formulação matemática. 
Tabela 2.3 - Janelas no domínio do tempo. Fonte: Ribeiro et al, 2014.

\begin{tabular}{|c|c|}
\hline Janelas & Função no Tempo Discreto \\
\hline Retangular & $w[n]=1$ \\
\hline Barlet (triangular) & $w_{B}[n]=1-|2 n /(N-1)-1|$ \\
\hline Hanning & $w_{H n}[n]=0.5-0.5 \cos (2 \pi n / N)$ \\
\hline Hamming & $w_{H m}[n]=0.54-0.46 \cos (2 \pi n / N)$ \\
\hline
\end{tabular}

$$
w[n]=\left\{\begin{array}{lr}
1, & 0 \leq n \leq N \\
0, & \text { c.c. }
\end{array}\right.
$$

Vale enfatizar que a função $w[n]$ definida em (2.8) é uma janela retangular que não deforma o sinal no tempo. A transformada de Fourier da janela $w[n]$ é descrita por (2.9).

$$
W(\Omega)=e^{j \Omega / 2} \frac{\sin (\Omega N / 2)}{\sin (\Omega / 2)}
$$

em que $W(\Omega)$ é a DTFT de $w[n]$.

A multiplicação entre $y[n]$ e $w[n]$ gera uma co-senoide discreta, $v[n]$, com tamanho $N$. Conforme (2.10), tal multiplicação no domínio da frequência corresponde a uma convolução entre $Y(\Omega)$ e $W(\Omega)$ (Oppenheim et al, 1998).

$$
V(\Omega)=\frac{1}{2 \pi} \int_{-\pi}^{\pi} Y(\theta) W(\Omega-\theta) d \theta
$$

em que $V(\Omega)$ é a DTFT de $v[n]$ e $\theta$ é a fase da co-senoide.

A solução para (2.10), descrita em (2.11), é obtida aplicando-se a propriedade do deslocamento de frequência (Oppenheim et al, 1998).

$$
V(\Omega)=\frac{A}{2} e^{j \theta} W\left(\Omega-\Omega_{0}\right)+\frac{A}{2} e^{j \theta} W\left(\Omega+\Omega_{0}\right)
$$


Como a DFT de $y[n]$ é uma amostragem do espectro fornecido por $V(\Omega)$, então a amostragem do espectro pode ser representada por (2.12) e a DFT de $v[n]$ por (2.13) (Oppenheim et al, 1998).

$$
\begin{gathered}
V[k]=\left.V(\Omega)\right|_{\Omega=2 \pi k / N} \\
V[k]=\frac{A}{2} e^{j \theta} W\left(\frac{2 \pi k}{N}-\Omega_{0}\right)+\frac{A}{2} e^{j \theta} W\left(\frac{2 \pi k}{N}+\Omega_{0}\right)
\end{gathered}
$$

Considerando as equações anteriores, nota-se que a aproximação de $y(t)$ só é feita corretamente quando $V[k]$ apresenta resultados diferentes de zero para dois valores de $k$, correspondentes as frequências $\pm \Omega_{0}$. Para que essa condição seja satisfeita, é necessária que a superposição das funções $\mathrm{W}\left(\Omega-\Omega_{0}\right)$ e $\mathrm{W}\left(\Omega+\Omega_{0}\right)$ não altere as localizações originais dos cruzamentos de zero de cada uma delas, ou seja a frequência $\Omega_{0}$ deve ser múltipla de $2 \pi / N$. Essa última condição só é verificada para os casos em que a co-senoide discreta for janelada em um número inteiro de ciclos do sinal (Brigham, 1974).

Em um sinal periódico no domínio do tempo, o comprimento da janela dos dados em análise deve ser um múltiplo inteiro do período fundamental para que a amostragem coincida com as frequências presentes no mesmo. Se outro comprimento for utilizado, as amostragens da DFT não coincidirão com os harmônicos e o sinal não será representado adequadamente no domínio da frequência (Oppenheim et al, 1998). Nesse caso, ocorrerá o fenômeno conhecido como espalhamento espectral, que decorre do erro de resolução atrelado ao janelamento inadequado do sinal (Testa et al, 2007). A resolução de frequência espectral da DFT é definida em (2.14).

$$
\text { resolução }=\frac{f_{0}}{N_{c}}
$$

em que $f_{0}$ é a frequência fundamental e $N_{c}$ é o número de ciclos da componente fundamental na janela analisada. Quanto maior esse parâmetro, melhor a resolução na frequência e, portanto, maior o número de componentes que podem ser extraídas.

Deve-se ressaltar que um ciclo inteiro do sinal representa uma janela correspondente a um 
múltiplo inteiro do mínimo múltiplo comum de todos os períodos do sinal (Hanzelka \& Bierí, 2004). Essa janela de tempo é conhecida como período fundamental de Fourier.

Da exposição precedente, conclui-se que duas condições são necessárias para a correta aplicação da DFT em sinais senoidais. A primeira delas é a condição de Nyquist. A outra é o janelamento do sinal em um número inteiro de ciclos. Contudo, deve-se mencionar que, para garantir essas condições é preciso que se conheçam a priori todas as frequências das senoides que compõem o sinal a ser analisado.

Além das restrições impostas sobre o intervalo da janela de dados e sobre a frequência de amostragem do sinal, é importante ressaltar que a DFT foi concebida para ser aplicada em sinais em regime permanente, pois sinais variantes no tempo possuem um espectro infinito e não podem ser corretamente descritos apenas por suas harmônicas (IEC, 2002). Com isso, a variação do sinal dentro da janela de tempo culminará também no espalhamento espectral.

Nesse contexto, a escolha de janelas de tempo grandes, apesar de resultarem em uma maior resolução espectral, está sujeita aos efeitos indesejáveis das variações temporais das componentes espectrais. Por outro lado, janelas de tempo pequenas, apesar de viabilizarem o acompanhamento mais eficaz das variações das distorções, diminuem a resolução.

As limitações advindas na aplicação da DFT sugerem a busca e o desenvolvimento de novas técnicas que permitam uma análise espectral com alta resolução dos sinais de tensão e corrente da rede elétrica. Na próxima seção, é apresentada uma metodologia paramétrica que além de não necessitar de um janelamento correspondente a um número inteiro de períodos, pode ser adaptada em sinais variantes no tempo.

\section{5 - MÉTODOS PARAMÉTRICOS PARA A MEDIÇÃO DE DISTORÇÕES}

A análise espectral pode ser realizada por meio de métodos paramétricos e nãoparamétricos. Dentre os métodos de análise espectral não-paramétricos, cita-se a DFT, apresentada na seção anterior. Os métodos paramétricos empregam um modelo específico baseados em parâmetros que podem ser estimados a partir de um conjunto de amostras do próprio sinal (Sachin \& Singh, 2011). 
Como exemplo de técnicas paramétricas, tem-se o estimador de frequências denominado método de Prony Modificado, que pode ser combinado a um estimador bayesiano linear, implementado por meio do Filtro de Kalman. Costa (2005) apresenta uma metodologia em que as amplitudes das senoides presentes nos sinais analisados são estimadas pelo Filtro de Kalman e os regressores do Filtro são construídos por meio das frequências fornecidas pelo método de Prony Modificado. Neste trabalho, é feita uma avaliação comparativa entre essa metodologia com outra baseada nos padrões IEC.

\subsection{1 - Método de Prony Modificado}

O método de Prony é uma técnica de estimação paramétrica capaz de ajustar $p$ senoides exponencialmente amortecidas a um conjunto de $N$ amostras de um sinal de dados (Marple, 1987).

No entanto, em geral, o número de amostras é muito maior do que a ordem $p$ do modelo. Por isso, outra versão do método se baseia no ajuste dos $2 p$ parâmetros do modelo a um conjunto $N \gg 2 p$ de amostras do sinal de dados $y[n]$, o que conduz a um problema sobredeterminado (Marple, 1987). O modelo do sinal também pode ser facilmente adaptado para estimação dos parâmetros de senoides não amortecidas, conforme (2.15).

$$
\hat{y}[n]=\sum_{k=1}^{p}\left(h_{k} z_{k}^{n-1}\right)+\sum_{k=1}^{p}\left(h_{k}^{*}\left(z_{k}^{n-1}\right)^{*}\right) n=1,2, \ldots N
$$

em que $T_{S}$ é a taxa de amostragem; os parâmetros $h_{k}=A_{k} \exp \left(j \theta_{k}\right)$ e $z_{k}=\exp \left(j \omega_{k} T_{S}\right)$.

Caso o sinal analisado seja composto apenas de senoides, a ordem do modelo deve ser par, pois um sinal senoidal é representado pela soma de duas exponenciais complexas conjugadas. Então, a ordem do sistema é usualmente indicada por $2 p$ (Marple, $1987 \&$ Hildebrand, 1956).

A determinação dos parâmetros $z_{k}$ pode ser realizada por (2.16). Nesta equação, os coeficientes do polinômio são determinados por meio da resolução de um sistema linear 
que emprega as amostras de $y[n]$. Os parâmetros $h_{k}$ são então obtidos a partir da resolução de outro sistema linear resultante de $\hat{y}[n]=y[n], n=1,2, \ldots N$.

$$
\Phi(z)=\prod_{k=1}^{p} a_{0}\left(z-z_{k}\right)=\sum_{m=0}^{p} a_{m} z^{p-m}
$$

Como o sistema descrito em (2.16) é sobredeterminado, um algoritmo de mínimos quadrados deve ser utilizado para estimar uma solução que forneça os valores dos coeficientes do polinômio. Com os valores dos coeficientes, constrói-se o polinômio cujas raízes são os pólos ou modos do modelo. Para se calcular as amplitudes e fases associadas a cada componente senoidal é necessária a utilização de outro algoritmo de mínimos quadrados. Esse aspecto do método é importante porque ele implica que qualquer ruído aditivo presente no sinal de dados é ajustado pelas exponenciais complexas do modelo (Marple, 1987).

Costa (2005) propõe uma adaptação do método de Prony Clássico, chamando o novo algoritmo de Prony Modificado (PM). Para o desenvolvimento desse método, considera-se que os parâmetros de frequência retornados pelo método de Prony Clássico são, na verdade, pólos de sucessivos filtros digitais de coeficientes $b_{k}$ aplicados ao sinal, tal como indicado em (2.17).

$$
\begin{aligned}
& y_{1}[n]=y[n], \rightarrow n=1,2, \ldots, N, \\
& y_{2}[n]=y_{1}[n-1]+b_{1} y_{1}[n]+y_{1}[n+1], \rightarrow n=2, \ldots,(N-1), \\
& y_{3}[n]=y_{2}[n-1]+b_{2} y_{2}[n]+y_{2}[n+1], \rightarrow n=3, \ldots,(N-2), \\
& \vdots \\
& y_{p+1}[n]=y_{p}[n-1]+b_{p} y_{p}[n]+y_{p}[n+1], \rightarrow n=p+1, \ldots,(N-p+1),
\end{aligned}
$$

Os coeficientes $b_{k}$ são obtidos por meio da Equação (2.18).

$$
b_{k}=-2 \cos \left(\omega_{k} T_{s}\right)
$$

em que $\omega_{k}$ é a frequência e $T_{s}$ é a taxa de amostragem.

Se as frequências contidas no sinal forem corretamente estimadas, então os coeficientes $b_{k}$ 
também o serão, e o processo de filtragem apresentado em (2.17) resultará em um vetor residual $y_{p+1}[n]$, cuja norma é nula. Caso as premissas estabelecidas para o processo de filtragem não sejam atendidas, o vetor de resíduos não será nulo, mas será mínimo (Costa, 2005).

Após o procedimento de filtragem, determina-se o vetor $b$ de parâmetros $b_{k}$ por meio de um processo de otimização de Newton, aplicando um algoritmo de três passos, a saber (Costa, 2005):

1. Escolha um vetor inicial $\mathbf{b}^{\mathbf{0}}$, calcule $\mathbf{y}_{\mathbf{p}+\mathbf{1}}$ e a matriz jacobiana $\mathbf{J}$;

2. Corrija o vetor $\mathbf{b}^{\mathbf{0}}$ utilizando (2.19): $\quad \mathbf{b}^{\mathbf{1}}=\mathbf{b}^{\mathbf{0}}-\mu \mathbf{J}^{-1} \mathbf{y}_{\mathrm{p}+1}$

3. Repita (1)-(2) até a norma de $\mathbf{y}_{\mathrm{p}+1}$ ficar abaixo de uma determinada tolerância.

Para auxiliar a convergência do processo de otimização, a constante $\mu$ foi inserida na equação (2.19), podendo ser arbitrada ou escolhida a partir de outro método de otimização auxiliar. Uma vez obtido o vetor $\mathbf{b}$ que contém os parâmetros $b_{k}$, as frequências contidas no sinal são diretamente calculadas por (2.20).

$$
b_{k}=\cos \left(\omega_{k} \Delta T\right)
$$

O ponto crítico do método de Prony é a sensibilidade aos ruídos presentes no sinal de dados. Isso ocorre devido à polarização do estimador de mínimos quadrados. Para evitar a utilização desse método e atenuar o efeito degenerativo dos ruídos no sinal de dados, Costa (2005) propõe uma abordagem que possibilita incorporar um procedimento de filtragem FIR (do inglês, Finite Impulse Response). O procedimento para se determinar esse filtro digital $w$ é iterativo e consiste em aplicar sucessivamente o método PM e resolver o problema de Mínimos Quadrados apresentado em (2.21).

$$
\begin{gathered}
a * w=\delta[n]+e[n] \\
v[n]=\sum_{n=1}^{p+q} e^{2}[n]
\end{gathered}
$$


em que o vetor de Prony $a$ tem um tamanho $p+1$. Ele é determinado conforme (2.22), em que (*) representa o operador de convolução. $\mathrm{O}$ filtro digital $w$ é assumido ter um tamanho $q$, e $e[n]$ representa o erro com relação ao vetor impulso unitário $\delta[n]$, esperado como resultado da convolução em (2.21).

$$
a=\left\lfloor\begin{array}{lll}
1 & b_{p} & 1
\end{array}\right] *\left\lfloor\begin{array}{lll}
1 & b_{p-1} & 1
\end{array}\right] * \ldots *\left[\begin{array}{lll}
1 & b_{2} & 1
\end{array}\right] *\left[\begin{array}{lll}
1 & b_{1} & 1
\end{array}\right]
$$

É importante ressaltar que, com o processo de filtragem iterativa FIR, o método PM se torna mais robusto à presença de ruídos. Entretanto, o problema que permanece é o da seleção do número $p$ de senoides do modelo, informação que raramente se conhece de antemão. O método PM com a filtragem iterativa pode ser inserido em um algoritmo onde a ordem $p$ do modelo é alterada e algum critério de parada é avaliado, como, por exemplo, a norma do vetor de sinal residual $(\|\mathbf{y p}+\mathbf{1}[\mathrm{n}]\|)$ se tornar inferior a um limiar préestabelecido (Costa, 2005).

\subsection{2 - Filtro de Kalman}

O Filtro de Kalman (FK) pertence à classe dos estimadores bayesianos lineares. A estimação bayesiana pressupõe que se tenham disponíveis modelos estatísticos tanto para o sinal $y[n]$, que é considerado um processo estocástico, quanto para os parâmetros a serem estimados (Gelb, 1974). Para aplicação desse método de estimação, considera-se que cada componente $C_{i}[n]$ senoidal do sinal seja escrita conforme (2.23) (Costa, 2005).

$$
\begin{aligned}
& C_{i}[n]=A_{i} \cos \left(\omega_{i} T_{s} n+\theta_{i}\right) \\
& =A_{i} \cos \left(\theta_{i}\right) \cos \left(\omega_{i} T_{s} n\right)-A_{i} \operatorname{sen}\left(\theta_{i}\right) \operatorname{sen}\left(\omega_{i} T_{s} n\right)
\end{aligned}
$$

em que $A_{i}$ é a amplitude da $i$-ésima componente; $\omega_{i}$ é a frequência estimada pelo método de Prony; $T_{s}$ é a taxa de amostragem e $\theta_{i}$ é a fase admitida da componente.

Para este caso, é utilizado o modelo no espaço de estados apresentado em (2.24). A estimação dos estados é realizada em duas etapas: predição e correção. O vetor de estados $\mathbf{x}_{\mathbf{n}}$ representa as amplitudes das harmônicas e inter-harmônicas, para as quais se admite a existência de variação temporal e $y[n]$ é o sinal de dados, entendido como uma medição que se relaciona aos estados do sistema por meio de $\mathbf{h}_{\mathbf{n}}$. 


$$
\begin{aligned}
& x_{n+1}=\Phi_{n} x_{n}+\omega_{n} \\
& y[n]=h_{n} x_{n}+\eta[n]
\end{aligned}
$$

em que $x_{n}$ é um vetor $(2 p \times l)$ que representa as amplitudes das componentes senoidais no tempo conforme $(2.25) ; \phi_{n}$ é uma matriz identidade $(p \times p) ; w_{n}$ é um vetor $(p \times 1)$ que representa o ruído de processo não correlacionado no tempo, com matriz de covariância $Q$; $y[n]$ é o sinal de dados; $h_{n}$ é o vetor $(2 p \times l)$ de regressores do modelo, cujos elementos são dados em (2.26) e $\eta[n]$ representa o ruído branco de medição com variância $r$.

$$
\begin{aligned}
& x_{i}[n]=A_{i}[n] \cos \left(\theta_{i}\right) \rightarrow i=1,3,5, \cdots, 2 p-1 \\
& x_{i}[n]=A_{i}[n] \sin \left(\theta_{i}\right) \rightarrow i=2,4,6, \cdots, 2 p \\
& h_{i}[n]=\cos \left(\omega_{i} \Delta T n\right) \rightarrow i=1,3,5, \cdots, 2 p-1 \\
& h_{i}[n]=-\sin \left(\omega_{i} \Delta T n\right) \rightarrow i=2,4,6, \cdots, 2 p
\end{aligned}
$$

A covariância do ruído de medição $\eta[n]$ e do vetor $\psi_{\mathrm{n}}$, são definidas, respectivamente, por (2.27) e (2.28).

$$
\begin{aligned}
& E[\eta[k] \eta[i]]=\left\{\begin{array}{c}
r[k], \quad k=i \\
0, k \neq i
\end{array}\right. \\
& E\left[\boldsymbol{\psi}_{k} \boldsymbol{\Psi}_{i}^{T}\right]=\left\{\begin{array}{cc}
\mathbf{Q}_{k}, & k=i \\
0, & k \neq i
\end{array}\right.
\end{aligned}
$$

em que E[.] é o operador esperança matemática (Papoulis, 2001); r [k] é um escalar e Q é uma matriz $(p \times p)$.

A seleção da matriz $\mathbf{Q}$ é baseada no conhecimento sobre o grau de variação de cada estado do processo. Se um dos estados varia mais do que outros, então o elemento da diagonal principal de $\mathbf{Q}$ correspondente a esse estado deve ser fixado em um valor maior do que os outros elementos da diagonal. Para a seleção do escalar $r$, geralmente, estima-se qual é a variância do ruído de fundo no local de aquisição do processo analisado (Costa, 2005).

Os componentes do vetor de estados $\mathbf{x}_{\mathbf{n}}$ e os regressores do modelo de estimação paramétrica $\mathbf{h}_{\mathbf{n}}$ são calculados por meio das relações em (2.29) e (2.30). As frequências $\omega_{i}$ devem ser informadas a partir dos resultados da aplicação do método de PM. 


$$
\begin{aligned}
& x_{i}[n]=A_{i}[n] \cos \left(\theta_{i}\right) \rightarrow i=1,3,5, \cdots, 2 p-1 \\
& x_{i}[n]=A_{i}[n] \sin \left(\theta_{i}\right) \rightarrow i=2,4,6, \cdots, 2 p \\
& h_{i}[n]=\cos \left(\omega_{i} T_{S} n\right) \rightarrow i=1,3,5, \cdots, 2 p-1 \\
& h_{i}[n]=-\sin \left(\omega_{i} T_{S} n\right) \rightarrow i=2,4,6, \cdots, 2 p
\end{aligned}
$$

Ao processo de estimação a priori do vetor de estados $\mathbf{x}_{\mathbf{n}}$ estão atrelados dois erros: o próprio erro do vetor de estados estimados $\hat{x}_{n}^{0}$ e o erro da estimativa do sinal de dados $\hat{y}^{0}[n]$, realizada por meio de (2.24). O primeiro deles pode ser modelado estatisticamente por uma matriz de covariância $\mathbf{P}_{\mathrm{n}}$, definida por (2.31). Na etapa de predição, esta matriz é simbolizada por $\mathbf{P}_{n}^{0}$.

$$
\mathbf{P}_{n}=E\left[\left(\mathbf{x}_{n}-\hat{\mathbf{x}}_{n}^{0}\right)\left(\mathbf{x}_{n}-\hat{\mathbf{x}}_{n}^{0}\right)^{T}\right]
$$

A matriz de covariância $\mathbf{P}_{\mathbf{n}}$ estabelece uma relação direta com um fator que representa a diferença entre o valor medido e o previsto, chamado de ganho de Kalman $\left(\mathbf{K}_{\mathrm{n}}\right)$. Quanto mais elevados forem os elementos de $\mathbf{P}_{\mathbf{n}}$, menor será a confiabilidade da estimação e maior será o peso da inovação. Se os valores dos elementos de $\mathbf{P}_{\mathbf{n}}$ forem pequenos, haverá diminuição do peso da atualização do vetor de estados (Machado, 2008). Esse ganho é dado por (2.32).

$$
\mathbf{K}_{n}=\mathbf{P}_{n}^{0} \mathbf{h}_{n}^{T}\left(\mathbf{h}_{n} \mathbf{P}_{n}^{0} \mathbf{h}_{n}^{T}+r[n]\right)
$$

Com base no modelo apresentado, constata-se que o filtro de Kalman tem a vantagem de explicitar a variação temporal de seus parâmetros, além de garantir um custo de processamento ponderado para modelos com ordens moderadas. Entretanto, devido a não linearidade do problema, a estimação das frequências pelo método PM é consideravelmente mais onerosa em termos computacionais do que a estimação das amplitudes pelo Filtro de Kalman. Por isso, a solução híbrida que decorre da aplicação conjunta dos dois métodos é feita apenas em uma análise offline dos dados (Costa, 2005). 


\section{6 - PROCESSOS ALEATÓRIOS}

A natureza aleatória dos fenômenos associados à presença de harmônicos nos sistemas elétricos indica que trabalhos relacionados a esse assunto devem ser realizados no contexto estatístico/probabilístico (Oliveira et al, 1997 \& Ferreira Filho et al, 2004). O tratamento estatístico dos dados permite caracterizar o seu comportamento enquanto processos aleatórios, avaliar condições de estacionariedade e estabelecer um período típico que melhor caracteriza as distorções harmônicas de uma dada instalação.

Assim, neste trabalho, utiliza-se do ferramental estatístico para a realização de um estudo sobre os indicadores de distorção THD e TID. Serão apresentadas, de forma sucinta, as bases matemáticas que fundamentam a realização dessa investigação.

\subsubsection{Conceitos de Probabilidade e Estatística}

O estudo da probabilidade descreve e prevê fenômenos em termos das chances de uma dada ocorrência vir a ser observada dentre todas as suas repetições. Tal argumentação se baseia em que, embora cada observação individual de uma repetição seja irregular, o total de observações apresenta uma regularidade estatística após várias repetições. Deste conceito, denomina-se Espaço Amostral $(\Omega)$ o conjunto formado por todos os possíveis resultados advindos de um fenômeno, onde cada subconjunto dele corresponde a um evento (Feitosa, 2009).

O conceito de estatística advém da teoria das probabilidades. A estatística compreende o conjunto de métodos e processos quantitativos para o estudo e medição dos fenômenos aleatórios. Muitas vezes, o interesse de um estudo não é o fenômeno em si, mas sim os resultados aleatórios que ele apresenta. Quantidades regidas por incertezas correspondem a funções no espaço de probabilidades ditas variáveis aleatórias (V.A.s). Uma variável aleatória $X$ é uma função que associa um número real $X(\zeta)$ a cada resultado $\zeta$ no espaço amostral $\Omega$ de um experimento aleatório (Meyer, 2000). As variáveis aleatórias podem ser discretas ou contínuas. Quando discreta, admite valores discretos com probabilidades especificadas. Quando contínua, assume um número infinitamente grande de valores (Grimmett, 2001). 
Uma variável aleatória tem suas propriedades descritas pela função de distribuição de probabilidade, também conhecida como função de distribuição acumulada- CDF (do inglês, Cumulative Distribution Function), representada como $F_{X}(x)$ (Jazwinski, 1970). A função de distribuição de probabilidade de uma variável aleatória $X$ é a probabilidade de que $X$ seja menor ou igual a um valor específico de $x\left(P_{X}(x)\right)$. Para uma V.A. discreta define-se $F_{X}(x)$ como (Billinton \& Li, $1994 \&$ Papoulis, 2001)

$$
F_{X}(x)=\sum_{j} p_{X}\left(x_{j}\right), \quad-\infty<\mathrm{x}<\infty
$$

em que o somatório é estendido a todos os índices $j$ que satisfaçam à condição $x_{j} \leq x \mathrm{e}$ $p_{\mathrm{X}}(\mathrm{x})$ é a função de massa de probabilidade da V.A. discreta $X$.

A definição análoga para V.A.s contínuas é apresentada em (2.34).

$$
F_{X}(x)=\int_{-\infty}^{x} f_{X}(s) d s
$$

em que $f_{X}(x)$ é a função densidade de probabilidade da V.A. contínua $X$. Neste caso, ela se relaciona à $\mathrm{CDF}$ por meio de (2.35).

$$
f_{X}(x)=\frac{d F_{X}(x)}{d x}
$$

A função de densidade de probabilidade $f_{x}(x)$ ou a função de distribuição de probabilidade $F_{X}(x)$ representa o modelo probabilístico de um experimento aleatório (Papoulis, 2001).

As V.A.s podem ser caracterizadas em termos do valor esperado de $X, E[X]$, que define a média $(\mu)$ conforme indicado em (36) para uma V.A. discreta $X$.

$$
E[X]=\mu_{X}=\sum_{j} x_{j} p_{X}\left(x_{j}\right)
$$

em que o somatório é estendido para todos os valores $x_{j}$ assumidos pela V.A. $X$. 
Ao considerar os valores de duas V.A.s genéricas $X_{1}$ e $X_{2}$, pode-se atribuir uma probabilidade de ocorrência simultânea dos eventos $X_{1} \leq x_{1}$ e $X_{2} \leq x_{2}$, conforme indicado por (2.37).

$$
F_{X_{1}, X_{2}}\left(x_{1}, x_{2}\right)=P\left(X_{1} \leq x_{1}, X_{2} \leq x_{2}\right)
$$

A medida de relação linear entre duas variáveis aleatórias é chamada de covariância. Se $X_{1}$ e $X_{2}$ são duas V.A.s, a covariância entre elas é definida conforme (2.38).

$$
\operatorname{cov}\left(X_{1}, X_{2}\right)=E\left[\left(X_{1}-E\left(X_{1}\right)\right)\left(X_{2}-E\left(X_{2}\right)\right)\right]
$$

O coeficiente de correlação, explícito em (2.39), mostra se há uma relação linear entre as dispersões das V.A.s. Em caso afirmativo, tal coeficiente é uma medida do grau dessa relação. Caso seja nula, estas são ditas não-correlacionadas (Papoulis, 2001).

$$
\rho\left(X_{1}, X_{2}\right)=\frac{\operatorname{cov}\left(X_{1}, X_{2}\right)}{\sqrt{\sigma_{X_{1}}^{2} \cdot \sigma_{X_{2}}^{2}}}
$$

em que $\sigma^{2}$ representa a variância da V.A. $X$, definida conforme (2.40). A variância mede a quantidade de dispersão ou variabilidade de uma distribuição (Papoulis, 2001).

$$
E\left[(X-E[X])^{2}\right\rfloor=\sigma_{X}^{2}=\sum_{j}\left(x_{j}-E[X]\right)^{2} p_{X}\left(x_{j}\right)
$$

em que o somatório é estendido para todos os valores $x_{j}$ assumidos pela V.A. $X$.

Para uma amostra de observações de uma população, a variância amostral próxima a média, $s^{2}$, é calculada sobre as amostras $X_{\mathrm{n}}$ obtidas em $N$ observações do fenômeno, como em (2.41). 


$$
s^{2}=\frac{1}{(N-1)} \sum_{n=1}^{N}\left(X_{n}-\bar{X}\right)^{2}
$$

em que a média amostral, $\bar{X}$, é definida conforme (2.42).

$$
\bar{X}=\frac{1}{N} \sum_{n=1}^{N} X_{n}
$$

Quando uma medida descritiva é calculada a partir dos dados da amostra, como em (2.41) e (2.42), ela é chamada de estimativa pontual. Se a estimação consiste em estabelecer um intervalo $[a, b]$ para o qual se pode afirmar que o parâmetro de interesse $\theta$ satisfaz $P(a<\theta$ $<b)=\gamma$, tem-se uma estimativa por intervalos. O objetivo da estimação por intervalos é a minimização do comprimento $(b-a)$ do intervalo de forma que a restrição $P(a<\theta<b)=\gamma$ seja satisfeita (Papoulis, 2001). O intervalo com nível de 95\% de confiança da média $\mu$ de uma V.A. $X$ normal com variância $\sigma^{2}$ conhecida é determinado conforme (2.43).

$$
\left[\bar{X}-\frac{1,96 \cdot \sigma}{\sqrt{N}}, \bar{X}+\frac{1.96 \cdot \sigma}{\sqrt{N}}\right]
$$

Outro procedimento de inferência estatística é o teste de hipóteses. Tal procedimento é baseado na evidência amostral e na teoria da probabilidade, usado para determinar se a hipótese de teste - também chamada de hipótese nula $\mathrm{H}_{0}$ - pode ser aceita em detrimento de uma hipótese alternativa $\mathrm{H}_{1}$, para um dado nível de significância $\alpha$. (Meyer, 2000). Existem vários testes que permitem fazer uma análise de problemas com esta abordagem, dentre eles, o teste de Kolmogorov-Smirnov.

O teste de Kolmogorov-Smirnov observa a máxima diferença entre as funções de probabilidades acumuladas, empírica e teórica, de variáveis aleatórias. A construção da estatística do teste parte da premissa que $F(x)$ é completamente conhecida e seus parâmetros são especificados (Naghettini, 2007).

Seja $X$ uma V.A., de cuja população extraiu-se $N$ amostras $\left\{X_{1}, X_{2}, \ldots, X_{N}\right\}$, a hipótese nula a 
ser testada é $\mathrm{H}_{0}: F_{X}(x) \equiv F(x)$, isto é, a CDF real, $F_{X}(x)$, é idêntica a uma CDF normal $F(x)$ conhecida analiticamente. Para implementar o teste, deve-se, inicialmente, classificar os elementos da amostra $\left\{X_{1}, X_{2}, \ldots, X_{N}\right\}$ em ordem crescente, de modo a constituir a sequência $\left\{x_{1}, x_{2}, \ldots, x_{m}, \ldots, x_{N}\right\}$, na qual $1 \leq m \leq N$ denota a ordem de classificação. Para cada elemento $x_{m}$ a distribuição empírica $\hat{F}(x)$ é calculada pela proporção de valores amostrais que não excedem $x_{m}$, ou seja (Papoulis, $2001 \&$ Naghettini, 2007),

$$
\hat{F}(x)=m / N
$$

Em seguida, deve-se calcular a variável de teste estatística, $q$, por meio de (2.45).

$$
q=|\hat{F}(x)-F(x)|
$$

em que $\hat{F}(x)$ é a função de distribuição empírica de $X$.

Considerando-se que o número de amostras da V.A. $X$ é grande (i.e. $N \geq 30$ ), se $q$ está próximo de zero, então $H_{0}$ não pode ser rejeitada. Na prática, basta que $q$ seja menor do que um limiar determinado em termos do nível de significância do teste. (Papoulis, 2001). A Figura 2.3 ilustra o conceito do teste.

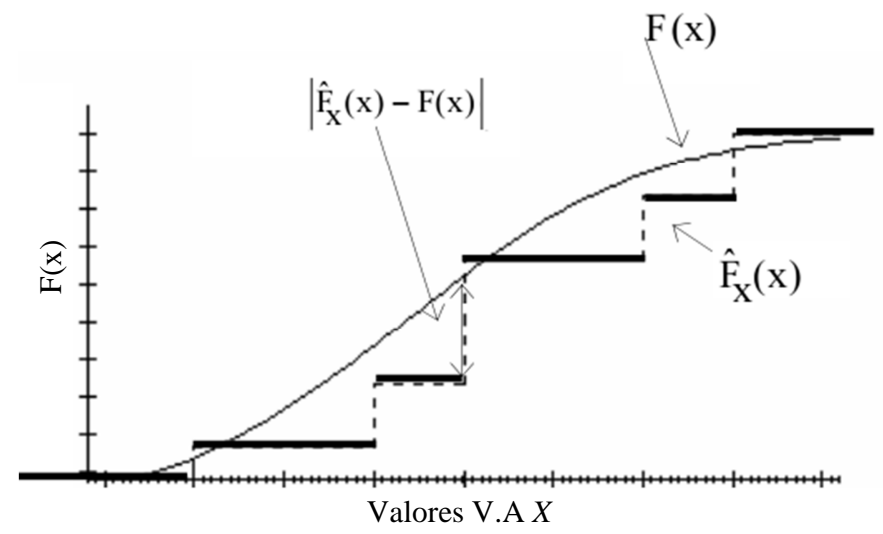

Figura 2.3. Ajustamento de funções de distribuição com o teste de Kolmogorov-Smirnov.

Para este trabalho, utiliza-se $\alpha=5 \%$ e a hipótese $\mathrm{H}_{0}$ não é rejeitada se, e somente se, (2.46) for satisfeita. 


$$
q<\sqrt{-\frac{1}{2 N} \ln \frac{\alpha}{2}}
$$

\subsubsection{Processos estocásticos}

Pode-se definir o processo estocástico $X(t, \zeta)$ como uma função de V.A.s definidas em um espaço amostral $\Omega$ que associa a cada resultado $\zeta$ uma função do tempo $X(t)$ (Jazwinsky, 1970). Um processo estocástico é dito discreto em relação aos estados se $X(t)$ é definido sobre um conjunto contável ou finito. Em relação ao tempo, o mesmo é dito discreto se $t$ ocorre em instantes discretos, indicando o tempo instantâneo da amostra $X(t)$. Caso contrário, o processo é contínuo (Albuquerque et al, 2008 \& Ross, 2010).

Considere um processo estocástico $X(t, \zeta)$. Para um tempo fixo $t_{1}, X\left(t_{1}\right)=X\left(t_{1} ; \zeta\right)$ é uma V.A. e a sua função de distribuição acumulada $F_{X}\left(x_{1} ; t_{1}\right)$ é definida por $F_{X}\left(x_{1} ; t_{1}\right)=P\left(X\left(t_{1}\right) \leq x_{1}\right)$. $F_{X}\left(x_{1} ; t_{1}\right)$ é conhecida como a distribuição de primeira ordem de $X(t, \zeta)$. De forma semelhante, para dois instantes fixos $t_{1}$ e $t_{2}$, define-se a distribuição de segunda ordem de $X(t, \zeta)$ por $F\left(x_{1}, x_{2} ; t_{1}, t_{2}\right)=P\left(X\left(t_{1}\right) \leq x_{1}, X\left(t_{2}\right) \leq x_{2}\right)$. De uma forma geral, a distribuição de $n$ ésima ordem de $X(t, \zeta)$ é dada por $F\left(x_{1}, \ldots, x_{n} ; t_{1}, \ldots, t_{n}\right)=P\left(X\left(t_{1}\right) \leq x_{1}, \ldots, X\left(t_{n}\right) \leq x_{n}\right)$.

Para uma caracterização completa do processo estocástico $X(t, \zeta)$, é preciso saber as distribuições de todas as ordens $(n \rightarrow \infty)$ (Papoulis, 2001). No entanto, esse é um procedimento matemático bastante complexo. Na prática, opta-se por modelar os processos por distribuições com ordem finita. Contudo, em geral, a obtenção de propriedades estatísticas que contemplam apenas as distribuições de primeira e segunda ordem do processo $X(t)$ é suficiente.

A média de probabilidade, ou valor esperado, é calculada para cada instante $t$ conhecendose a função densidade de probabilidade de primeira ordem $f(x ; t)$, conforme (2.47).

$$
\langle X(t)\rangle=E[X(t)]=\int_{-\infty}^{\infty} x f(x ; t) d x
$$

em que $\langle X(t)\rangle$ é definida como a média de probabilidade. 
A medida de dependência entre as V.A.s de $X(t)$ é dada pela função de autocorrelação, calculada entre os instantes $t_{1}$ e $t_{2}$, e pela função densidade de probabilidade conjunta entre as V.A.s $X\left(t_{1}\right)$ e $X\left(t_{2}\right)$, conforme (2.48).

$$
R\left(t_{1}, t_{2}\right)=E\left[X\left(t_{1}\right) X\left(t_{2}\right)\right]=\int_{-\infty}^{\infty} \int_{-\infty}^{\infty} x_{1} x_{2} f\left(x_{1}, x_{2} ; t_{1}, t_{2}\right) d x_{1} d x_{2}
$$

em que $R\left(t_{1}, t_{1}\right)$ representa a função de autocorrelação do processo $X(t)$.

Uma simplificação usualmente adotada no estudo de um processo estocástico admite a hipótese de que esse é estacionário. A propriedade de estacionariedade pressupõe que as características estatísticas do processo aleatório sejam independentes do tempo absoluto considerado. Ou seja, caso o processo seja dividido em outros com duração determinada, diferenças significativas nas propriedades estatísticas desses serão imperceptíveis (Haykin, 2001). Isso significa que a distribuição da V.A. $X(t ; \zeta)$ deve ser a mesma verificada para $X(t+\tau$; $)$ (Papoulis, 2001).

Dentro deste conceito, podem ser separados dois níveis de estacionariedade: sentido amplo e sentido estrito. O primeiro deles é o nível mais fraco e abrangente. Um processo estocástico $X(t)$ é estacionário em sentido amplo se exibir invariância temporal em relação a sua média de probabilidade $E[X(t)]$ e ter sua função de autocorrelação dependente apenas da diferença de tamanho entre $t_{2}$ e $t_{1}$, isto é, $R\left(t_{1}, t_{2}\right)=R\left(t_{2}-t_{1}\right)$. A estacionariedade em um sentido amplo implica também que a função de distribuição de primeira ordem do processo $X(t)$ seja invariante a translações no tempo. Assim, a variância do processo $X(t)$ também será constante, enquanto que a sua autocovariância será dependente apenas de $\left(t_{2}-t_{1}\right)$ (Papoulis, 2001).

Para um processo estacionário em sentido estrito, há um subgrupo de processos no qual todas as estatísticas que o descrevem são invariantes no tempo. Nesse caso, ele poderia ser completamente caracterizado com apenas uma realização, culminando assim em um tempo de observação mínimo. Logo, esse tipo de processo é bastante útil por permitir que essas características sejam adquiridas de amostras obtidas por um tempo finito de observação. Esses são chamados de processos ergódigos (Papoulis, 2001). 
Se o processo aleatório é ergódico, as médias estatísticas podem ser calculadas temporalmente, ou seja, os cálculos são realizados ao longo de uma única função amostra do processo, por meio da média temporal, calculada conforme (2.49).

$$
X_{T}=\lim _{T \rightarrow \infty} \frac{1}{2 T} \int_{-T}^{T} X(t) d t
$$

No caso do sentido estrito, além do citado para o sentido amplo, a função de densidade de probabilidade ou a função de distribuição de probabilidade que caracterizam o processo $X(t)$ devem ser invariantes para translações no tempo. Assim, suas estatísticas dependem apenas do intervalo de tempo considerado entre as observações (Papoulis, 2001).

\section{7 - CONSIDERAÇÕES FINAIS}

Este capítulo apresentou os fundamentos teóricos para a consolidação da abordagem proposta neste trabalho. Discorreu-se sobre o processamento dos sinais com a DFT, destacando as limitações atreladas à aplicação dessa metodologia. Mediante os aspectos mencionados, verificou-se a necessidade da proposição de uma metodologia que possibilite análise espectral com alta resolução em condições de variação temporal das magnitudes das componentes. Foram então destacados dois métodos alternativos que podem ser empregados na tarefa de estimação dos espectros: o método de Prony combinado com o Filtro de Kalman. Por fim, realizou-se uma exposição dos conceitos que subsidiam o estudo do comportamento dos indicadores de distorção enquanto processos aleatórios. No capítulo seguinte, será apresentada a metodologia de análise empregada nesta dissertação. 


\section{3 - METODOLOGIA}

\section{1 - CONSIDERAÇÕES INICIAIS}

Neste capítulo, é proposta a metodologia de análise dos sinais coletados. Inicialmente, é realizada uma breve descrição do sistema de aquisição de dados. Em seguida, é detalhada a metodologia de análise proposta, que visa identificar o tamanho de janela de tempo mais apropriado na estimação do espectro dos sinais utilizando a DFT, e o período mínimo de medição necessário para caracterizar as distorções de forma de onda.

\section{2 - MEDIÇÕES E FORMAÇÃO DO BANCO DE SINAIS}

Neste trabalho, a aquisição dos sinais é realizada com o analisador de QEE Classe A, ElspecTM BlackBox G4500. O equipamento atende aos requisitos exigidos pelos padrões IEC 61000-4-30 e IEC 61000-4-7 para medição de parâmetros de QEE.

Para medir os sinais de uma instalação eólica integrada ao Sistema Interligado Nacional (SIN), selecionou-se a taxa de amostragem de 128 amostras/ciclo. Para medição foram utilizados alicates transdutores que medem as tensões em uma faixa de $0-1 \mathrm{kV}$ com precisão de $\pm 0,1 \%$ da nominal, e as correntes em uma faixa de 0 -300A com precisão de $\pm 1 \mathrm{~A}$.

O analisador de QEE possui 32 GB de memória interna que, associado a um algoritmo de compressão de dados, viabiliza o armazenamento contínuo de 30 dias de medição (formas de onda) à taxa de amostragem selecionada.

\subsection{1 - Procedimento de medição e armazenamento}

Os dados coletados correspondem às aquisições de sinais trifásicos de tensão, corrente e potência ativa na saída de um aerogerador, em um sistema de geração eólica com máquinas DFIG. As suas características nominais são: potência de 1,67 MW, tensão de 0,69 kV e corrente de 0-1,2 kA. Devido à faixa de trabalho dos alicates de corrente do analisador de QEE utilizado (de 0-300A), a medição foi realizada em um dos quatro condutores de cada fase do aerogerador. 
Apesar de o instrumento permitir um armazenamento contínuo dos sinais, deve-se mencionar que uma grande quantidade de memória é requerida após a descompactação e transferência dos dados para formatos de arquivos tratáveis pelos programas desenvolvidos no Matlab®. Por essa razão, optou-se por gerar e armazenar, a cada 1 min, arquivos com 1 s de aquisição dos sinais de dados das correntes, tensões e potências, durante 24 horas por dia. Esse procedimento resultou em 1440 arquivos por dia, durante 30 dias.

\section{3 - METODOLOGIA DE ANÁLISE}

O desenvolvimento dos métodos e algoritmos que compõem a metodologia de análise deste trabalho foi realizado em ambiente Matlab®. A validação da metodologia PK como referência nas análises é realizada por meio de simulações com um sinal sintético que incorpora algumas das características esperadas nos sinais reais.

\subsection{1 - Simulações}

Nas simulações é realizada a comparação dos níveis de THD e TID obtidos a partir da estimação espectral pela metodologia PK e pela DFT considerando uma janela de 12 ciclos de $60 \mathrm{~Hz}$. O sinal sintético digital $y[n]$ utilizado é descrito por (3.1).

$$
\begin{aligned}
& y[n]=200 A[n] \sin \left(2 \pi 60 T_{S} n\right)+50 \sin \left(2 \pi 300 T_{S} n+60^{\circ}\right)+70 \sin \left(2 \pi 420 T_{S} n-45^{\circ}\right)-10 \sin \left(2 \pi 1140 T_{S} n\right) \\
& +40 \sin \left(2 \pi 732 T_{S} n+30^{\circ}\right)+40 \sin \left(2 \pi 48 T_{S} n+22,5^{\circ}\right)+25 \sin \left(2 \pi 1250 T_{S} n-45^{\circ}\right)+r[n]
\end{aligned}
$$

em que $T_{S}$ é a taxa de amostragem; $A[n]$ representa uma onda triangular que modula em $20 \%$ a amplitude da fundamental com período de $100 \mathrm{~ms} ; r$ [n] representa um ruído branco aditivo que resulta em uma relação sinal-ruído de $35 \mathrm{~dB}$ para o sinal.

Vale destacar que, por meio de (3.1), as amplitudes das componentes harmônicas e interharmônicas do sinal sintético são totalmente conhecidas em qualquer instante de tempo, o que permite predizer os valores dos indicadores THD e TID, bem como estabelecer as estatísticas de quantificação dos mesmos. 
Além disso, as frequências invisíveis na resolução de $5 \mathrm{~Hz}(732 \mathrm{~Hz}$ e $48 \mathrm{~Hz})$ e o termo de variação temporal representado pela modulação da fundamental evidenciam algumas limitações do processamento do sinal via DFT. Simula-se o monitoramento das distorções de $y[n]$ por $1 \mathrm{~min}$, o que corresponde a 120 ciclos de $500 \mathrm{~ms}$.

É oportuno ressaltar que, mesmo sendo pequeno, o ruído de medição gera uma situação em que as estimativas do espectro por ambos os métodos são afetadas.

\subsection{2 - Avaliação das Janelas de Tempo}

O processamento dos sinais para a avaliação do impacto do tamanho das janelas de tempo compara os resultados dos indicadores THD e TID obtidos via DFT de 1, 6, 10, 12, 15, 20, 30 e 60 ciclos com os da metodologia PK. Para facilitar a análise, as referências à DFT utilizando cada uma dessas janelas de tempo serão, respectivamente: $\mathrm{DFT}_{1}, \mathrm{DFT}_{6}, \mathrm{DFT}_{10}$, $\mathrm{DFT}_{12}, \mathrm{DFT}_{15}, \mathrm{DFT}_{20}, \mathrm{DFT}_{30}$ e $\mathrm{DFT}_{60}$. O procedimento adotado para a análise dos sinais é ilustrado no diagrama esquemático mostrado na Figura 3.1.

Para cada dia de medição, realiza-se a leitura de um dado arquivo que contém uma aquisição de $1 \mathrm{~s}$ do sinal. $\mathrm{O}$ espectro é então obtido por meio do processamento via metodologia PK e via DFT com a variação das janelas de tempo, definidas em termos do número de ciclos de $60 \mathrm{~Hz}$.

Em seguida, é realizado o processo de subagrupamento de acordo com a resolução espectral característica de cada método, a saber: $60 \mathrm{~Hz}$ para $\mathrm{DFT}_{1}, 10 \mathrm{~Hz}$ para a $\mathrm{DFT}_{6}, 6$ $\mathrm{Hz}$ para a $\mathrm{DFT}_{10}, 5 \mathrm{~Hz}$ para a $\mathrm{DFT}_{12}, 4 \mathrm{~Hz}$ para a $\mathrm{DFT}_{15}, 3 \mathrm{~Hz}$ para a $\mathrm{DFT}_{20}, 2 \mathrm{~Hz}$ para a $\mathrm{DFT}_{30}$ e $1 \mathrm{~Hz}$ para a $\mathrm{DFT}_{60}$. A metodologia PK, a princípio, apresenta resolução espectral ilimitada. Entretanto, neste trabalho, opta-se por utilizar a mínima frequência inteira possível, isto é, $1 \mathrm{~Hz}$. A forma como ocorre o processamento dos sinais pela metodologia PK será detalhada adiante. Na sequência, são calculados os indicadores THD e TID, segundo o padrão IEC. 


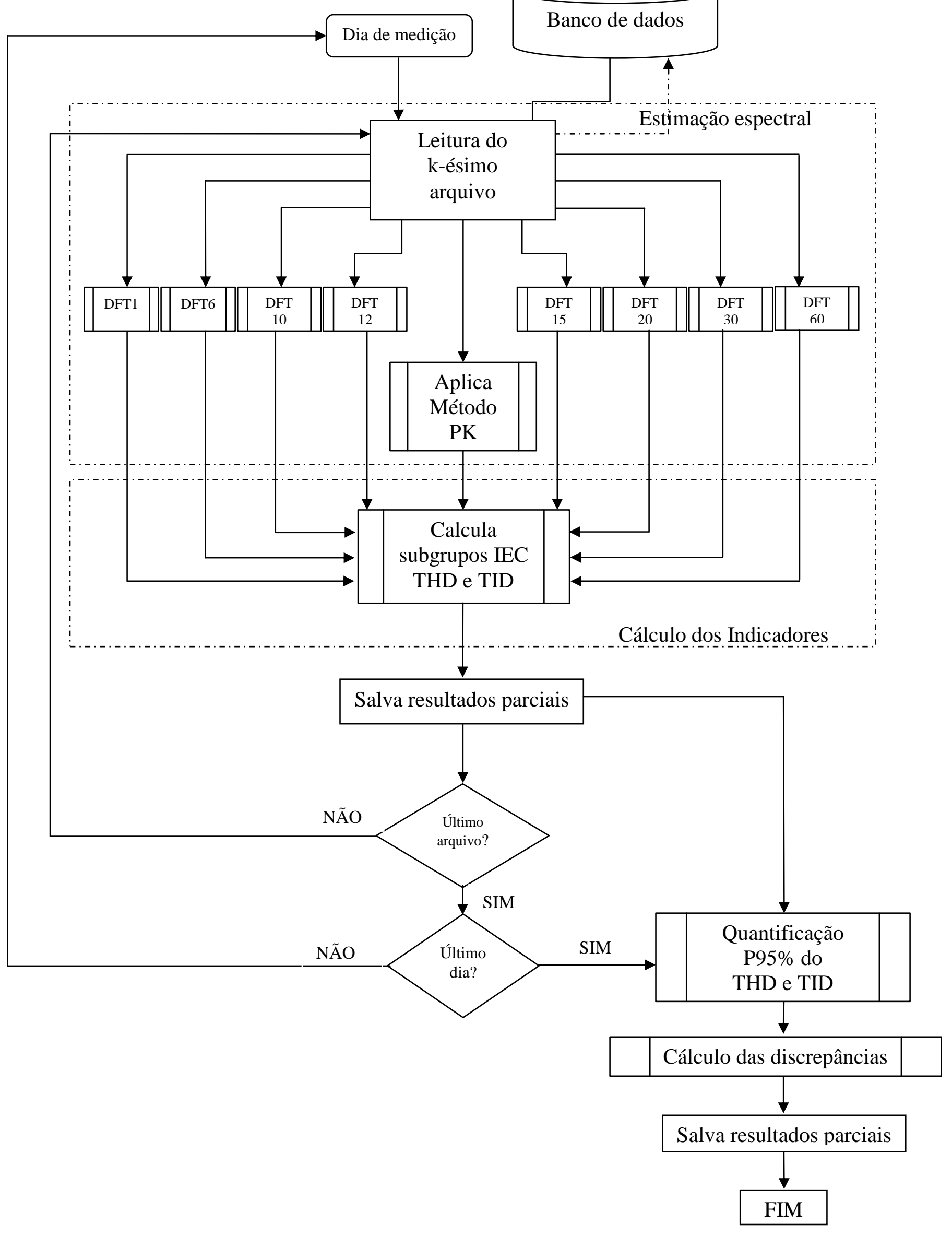

Figura 3.1. Diagrama de blocos para análise dos sinais coletados. 
Em virtude da mudança dos tamanhos das janelas de tempo utilizadas na análise, os números de espectros que podem ser estimados por arquivo são diferentes conforme o caso. Portanto, resultam de um único arquivo com $1 \mathrm{~s}$ de sinal de dados: 60 valores com a $\mathrm{DFT}_{1}(60$ janelas de 1 ciclo em $1 \mathrm{~s}) ; 10$ valores com a $\mathrm{DFT}_{6}(10$ janelas de 6 ciclos em $1 \mathrm{~s})$; 6 valores com a $\operatorname{DFT}_{10}(6$ janelas de 10 ciclos em $1 \mathrm{~s}) ; 5$ valores com a $\operatorname{DFT}_{12}(5$ janelas de 12 ciclos em $1 \mathrm{~s}$ ); 4 valores com a $\operatorname{DFT}_{15}$ (4 janelas de 15 ciclos em $1 \mathrm{~s}$ ); 3 valores com a $\mathrm{DFT}_{20}$ (3 janelas de 20 ciclos em $\left.1 \mathrm{~s}\right) ; 2$ valores com a $\mathrm{DFT}_{30}(2$ janelas de 30 ciclos em 1 s); e 1 valor com a $\operatorname{DFT}_{60}(1$ janela de 60 ciclos em 1 s). Na metodologia PK, a estimativa do espectro é realizada a cada nova amostra do arquivo. Logo, um único arquivo com $1 \mathrm{~s}$ de sinal de dados retorna um total de 7680 valores de THD e TID. Por isso, para a metodologia PK, admite-se como valor representativo de um arquivo a média dos valores de THD e TID obtidos.

O procedimento supracitado é aplicado para todos os arquivos de cada dia de medição. Em seguida, é realizada a quantificação do percentil 95\% (P95\%) dos indicadores THD e TID. Um percentil $P_{u}$ é o valor assumido por uma V.A. $X$ que apresenta a probabilidade acumulada de $100 . u \%$ de não ser excedido, conforme definido em (3.2).

$$
u=F_{X}\left(P_{u}\right)=P\left(X \leq P_{u}\right)
$$

Esses valores, gerados por cada método, para todo o período de medição de 30 dias, são referenciados por THD $_{95}$ e TID 95 . A discrepância é uma medida de desempenho que calcula as diferenças que cada método, baseado na DFT, apresenta com relação à metodologia de referência.

A metodologia PK aplicada nesta análise, adaptada do trabalho de Costa (2005), é indicada no fluxograma da Figura 3.2. Em decorrência da não linearidade do problema, a estimação das frequências pelo método PM é consideravelmente mais onerosa em termos computacionais do que a estimação das amplitudes pelo Filtro de Kalman. Por isso, o método PM é aplicado em um número restrito de arquivos (a cada 30 arquivos) e de amostras da janela atual do sinal de dados (as 512 primeiras amostras). Antes do método PM ser aplicado em cada janela, deve-se selecionar, entre as três tensões e as três correntes de fase, qual sinal será analisado. 


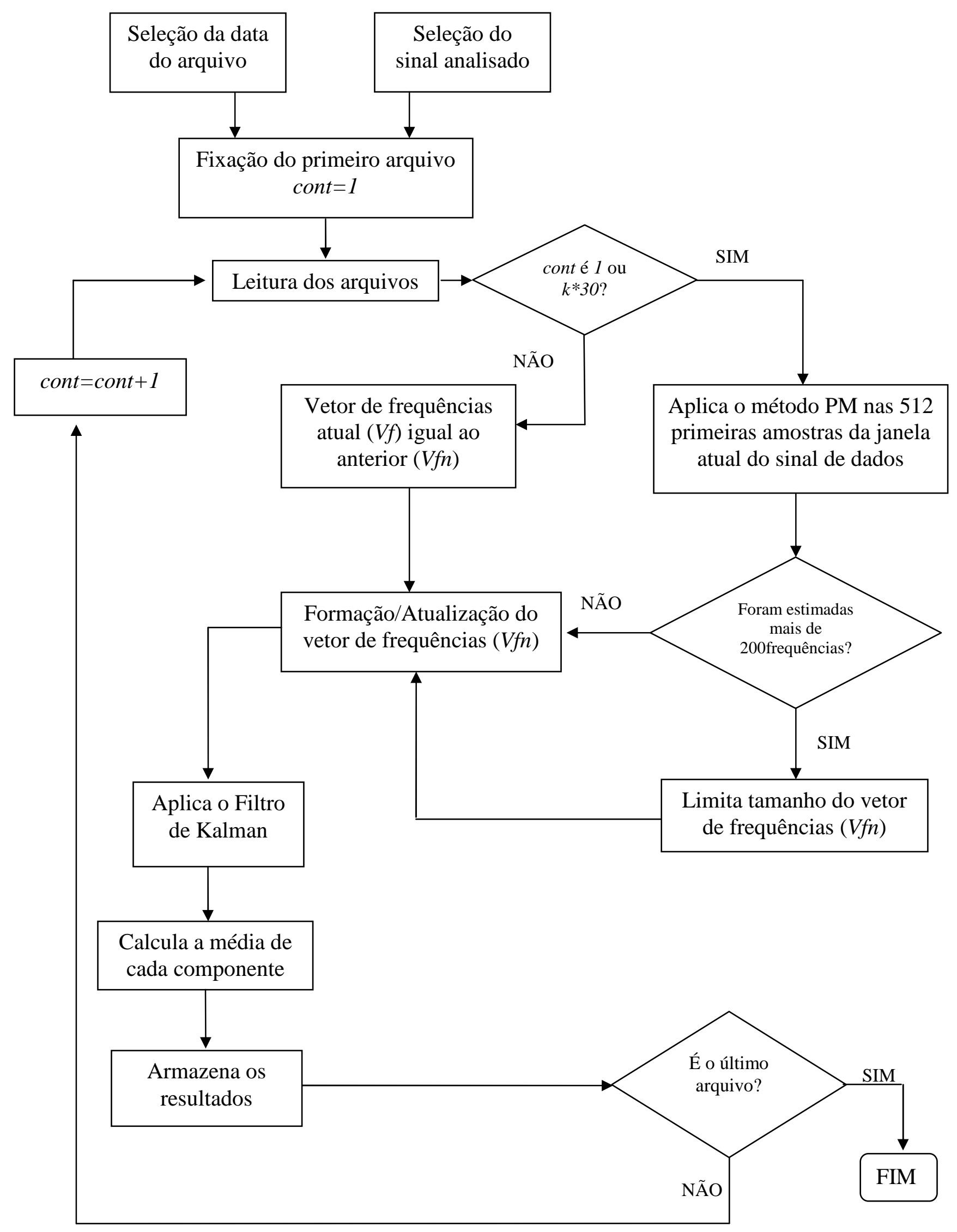

Figura 3.2. Fluxograma da metodologia PK. 
No rastreamento das magnitudes das componentes, o Filtro de Kalman é aplicado a todos os arquivos. A aplicação do Filtro de Kalman para cada janela do sinal resulta na evolução das amplitudes de cada componente senoidal presente em cada uma delas. Para tanto, ele recebe como entrada um vetor $\boldsymbol{V} \boldsymbol{f}$ com as últimas frequências obtidas. Esse vetor é formado a partir do vetor VfAnt, o qual é iniciado com um conjunto pré-fixado de frequências harmônicas. Caso as novas frequências estimadas pelo método de Prony não estejam em $\boldsymbol{V} \boldsymbol{f} \boldsymbol{A} \boldsymbol{n}$, então elas serão adicionadas, formando uma versão atualizada de $\boldsymbol{V} \boldsymbol{f}$. Em seguida, o vetor $\boldsymbol{V} \boldsymbol{f A n t}$ recebe o vetor $\boldsymbol{V} \boldsymbol{f}$ atualizado para que, na próxima aplicação de PM, o procedimento de atualização seja refeito. Devido às características do sinal de dados, foi necessário limitar o tamanho do vetor de frequências para 200. Logo, se $\boldsymbol{V} \boldsymbol{f}$ apresentar mais de 200 frequências, o valor mais antigo será substituído por um valor atualizado.

Os resultados obtidos com a aplicação dos procedimentos descritos acima subsidiam a análise sobre a influência do tamanho da janela de tempo no cálculo, via DFT, dos parâmetros THD e TID.

\subsection{3 - Avaliação do período de medição}

O processamento dos sinais visando à definição de um período mínimo de monitoramento para as distorções utiliza um conjunto de procedimentos de análise estatística para caracterizar o comportamento estocástico dos indicadores. Opta-se pela utilização dos resultados advindos da agregação de 60 ciclos com a metodologia de referência PK. A Figura 3.3 ilustra a interpretação do THD e TID como os processos aleatórios $T H D(t)$ e $T I D(t)$, observados a cada $1 \mathrm{~min}, 24$ horas por dia, durante 30 dias.

Os 1440 pontos amostrais de cada indicador tomados ao longo de cada dia de medição representam uma realização dos referidos processos aleatórios. O conjunto de valores de cada um desses processos em um instante de tempo fixo $t_{k}$, ao longo dos 30 dias, constitui o total de observações de cada uma das V.A.s. Cada um dos arquivos corresponde a um instante $t_{k}$ em que os respectivos processos são amostrados. Uma série temporal é representada por cada subconjunto de valores diários. 


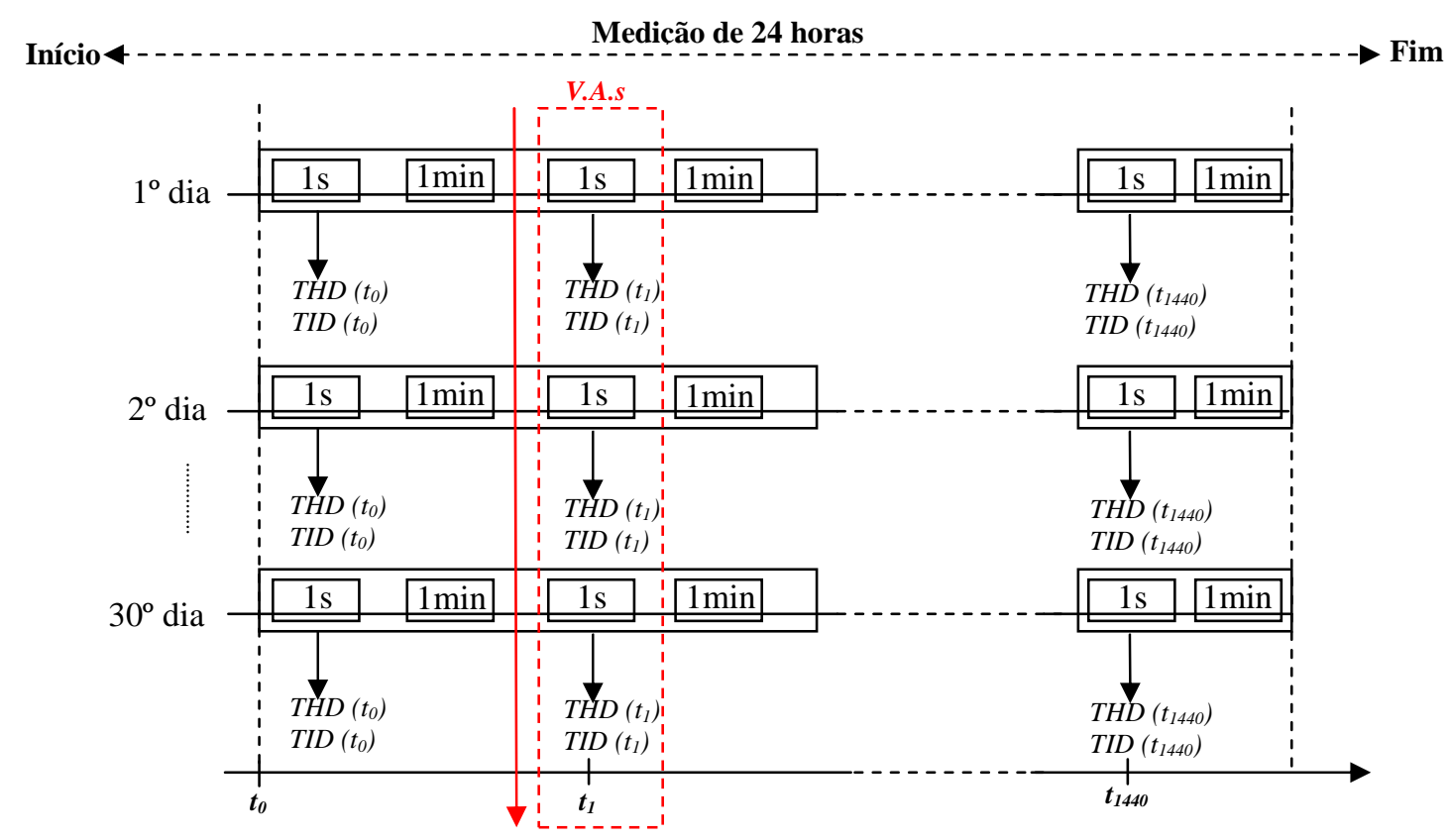

Figura 3.3. Abordagem para estudo dos processos aleatórios $T H D(t)$ e $T I D(t)$.

Após essas definições, visando uma verificação da distribuição característica dos dados e das condições de ergodicidade e estacionariedade, esta etapa da metodologia é dividida em três passos, executados sobre cada variável, conforme apresentado a seguir.

3.3.3.1 Verificação da adequabilidade dos dados a uma função de distribuição de probabilidade Gaussiana

O procedimento adotado para a verificação da hipótese de normalidade é o teste de Kolmogorov-Smirnov, já detalhado no capítulo 2. Esse procedimento é realizado a cada instante $t_{k}$. Para isso, são tomados os valores assumidos pela variável em estudo (THD ou TID) no instante $t_{k}$, ao longo dos 30 dias de medição. Nesse caso, podem ser testados 1440 conjuntos de 30 valores para cada variável. Além disso, são determinadas as seguintes estatísticas descritivas para o conjunto global (30 dias) de amostras dos respectivos processos aleatórios: P5\%, P25\%, mediana, P95\% e P99\%.

Além disso, registra-se o percentual de instantes de tempo diários em que o teste é positivo, ou seja, a hipótese de normalidade não é rejeitada ao nível de significância de $5 \%$. Esse resultado é importante para compreender o comportamento intrínseco das componentes aleatórias nas séries de dados. 
3.3.3.2 Cálculo da média de probabilidade e da média e variância temporal

Para realizar inferências sobre as condições de estacionariedade dos indicadores de distorção, são utilizadas a média de probabilidade e a média e variância temporais. A média de probabilidade é calculada conforme apresentado em (3.3).

$$
\left\langle X\left(t_{k}\right)\right\rangle=\sum_{d=1}^{30} X\left(t_{k}, d\right) p_{d}
$$

em que $\left\langle X\left(t_{k}\right)\right\rangle$ é a média de probabilidade do processo aleatório $X(t)$ no instante $t_{k}$; $X\left(t_{k}, d\right)$ é o valor da variável aleatória $X\left(t_{k}\right)$ na realização do dia $d$; e $p_{d}$ é a frequência relativa de ocorrência do valor da variável aleatória $X\left(t_{k}\right)$ nos 30 dias de medição no instante $t_{k}$. Nota-se que o cálculo em (3.3) remete à necessidade de que seja composto o histograma do conjunto de valores $X\left(t_{k}, d\right)$ para a determinação das frequências relativas $p_{d}$.

A média $(\hat{\mu})$ e a variância $(\hat{V})$ temporais de um processo aleatório são definidas como uma função do tempo, utilizando os valores das séries temporais diárias. Elas são calculadas, respectivamente, conforme (3.4) e (3.5).

$$
\hat{\mu}[n]=\hat{\mu}[n-1]+\frac{1}{n}(x[n]-\hat{\mu}[n-1])
$$

em que a média temporal estimada $\hat{\mu}[n]$ é resultante da atualização do valor da estimativa anterior $\hat{\mu}[n-1]$ pelo novo ponto amostral $x[n]$.

$$
\hat{V}[n]=\hat{V}[n-1]+\frac{1}{n} \cdot\left[\frac{n-1}{n} \cdot(x[n]-\mu[n-1])^{2}-\hat{V}[n-1]\right]
$$

em que a variância temporal estimada $\hat{V}[n]$ é resultante da atualização do valor da estimativa anterior $\hat{V}[n-1]$ pelo novo ponto amostral $x[n]$. 


\subsubsection{Verificação da estacionariedade}

A proposição de um período de monitoramento das distorções da instalação eólica é realizada com base na verificação da estacionariedade por meio de uma métrica proposta por Feitosa (2009).

Considera-se a variável em estudo (THD ou TID) ao longo do tempo, isto é, para cada instante $t_{k}$, o que implica utilizar as 1440 amostras da série temporal correspondente a cada dia, sequencialmente. Se o conjunto de amostras tem uma distribuição gaussiana, então pode-se empregar a métrica $M$ e o teste apresentado em (3.6).

$$
M=\frac{(2 \cdot 1,96 \cdot \sqrt{\hat{V}})}{\hat{\mu}}, \quad M \leq 0,05 \Rightarrow \text { Média } \quad \text { Estável }
$$

A interpretação do teste com a métrica $M$ em (3.6) pode ser realizada como: se o comprimento do intervalo de confiança a $95 \%$ da estimativa da média temporal for inferior a 5\% da própria estimativa da média, então esta apresenta variação mínima e pode ser considerada estável. A amostra a partir da qual essa condição é verificada define a quantidade mínima de amostras necessárias e, portanto, o período de monitoramento.

\section{4 - CONSIDERAÇÕES FINAIS}

Neste capítulo, foi apresentada a metodologia de análise proposta para a consecução dos objetivos estabelecidos nesta dissertação. Ela está baseada na análise offline de sinais obtidos em uma instalação eólica. Os resultados advindos da aplicação dessa metodologia são exibidos a seguir. 


\section{4 - RESULTADOS E DISCUSSÕES}

\section{1 - CONSIDERAÇÕES INICIAIS}

Neste capítulo, realiza-se a apresentação e as respectivas discussões dos resultados advindos do emprego da metodologia de análise descrita no capítulo 3. Ao longo do capítulo, são exibidos resultados numéricos e gráficos. Inicialmente, com o objetivo de validar a metodologia PK como referência das análises, são apresentados os resultados de uma avaliação comparativa entre esta e a DFT, executada com um sinal sintético que incorpora algumas características esperadas nos sinais reais. Em seguida, são expostos os sinais reais da instalação a ser estudada, adquiridos em um sistema eólico. Na sequência, avalia-se o impacto do tamanho das janelas de tempo no processo de medição de distorções por meio da DFT. Por fim, visando à definição de um período de medição para as distorções, adotase um conjunto de procedimentos de análise estatística dos indicadores THD e TID, decorrentes da aplicação da metodologia PK.

\section{2 - MEDIÇÕES EM UMA INSTALAÇÃO EÓLICA}

A Figura 4.1 apresenta uma visualização das formas de onda de tensão trifásica obtidas na instalação eólica em avaliação no período de $1 \mathrm{~s}$ de medição, que equivale a 1 arquivo de sinal de dados.

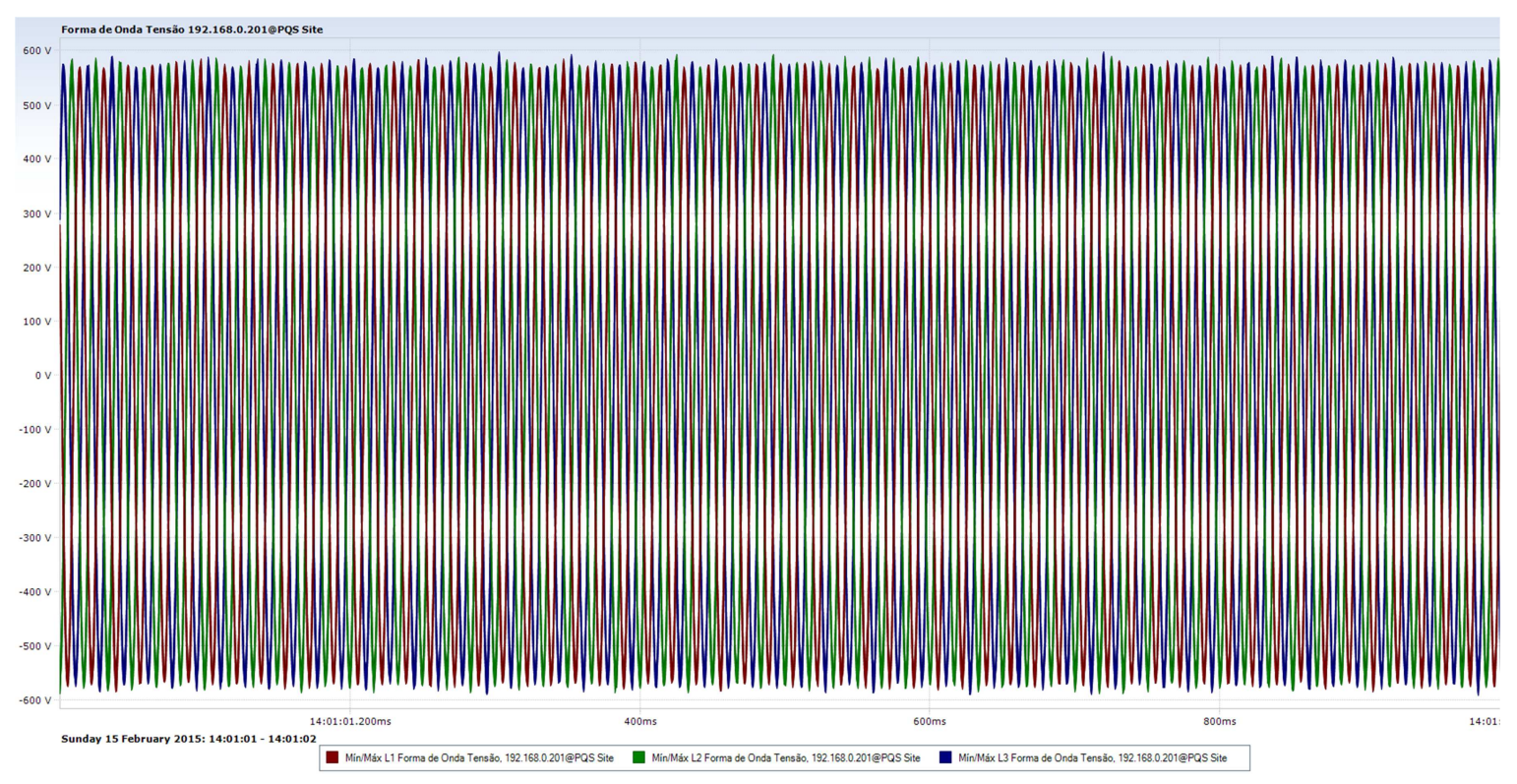

Figura 4.1. Formas de onda de tensão trifásica obtidas na instalação eólica.

Fonte: Instrumento de Medição. 
Da Figura 4.1 é possível notar que a forma de onda de tensão é simétrica, entretanto apresenta um envelope de modulação que evidencia a influência de componentes interharmônicas de baixa frequência ou sub-harmônicas. Tal comportamento é esperado, tendo em vista a variação contínua da velocidade do vento, que provoca oscilações em baixa frequência da potência mecânica nas turbinas eólicas (Pereira, 2004).

Considerando-se o grande volume de dados adquiridos nas medições, optou-se pela aplicação da metodologia de análise proposta no capítulo 3 para aquisições de 24 horas por dia do sinal de tensão apenas da fase $\mathrm{A}(V a)$ da instalação.

\section{3 - AVALIAÇÃO COMPARATIVA ENTRE OS MÉTODOS}

A Figura 4.2 apresenta uma visualização de $500 \mathrm{~ms}$ da forma de onda do sinal sintético utilizado na avaliação comparativa da metodologia PK com a DFT.

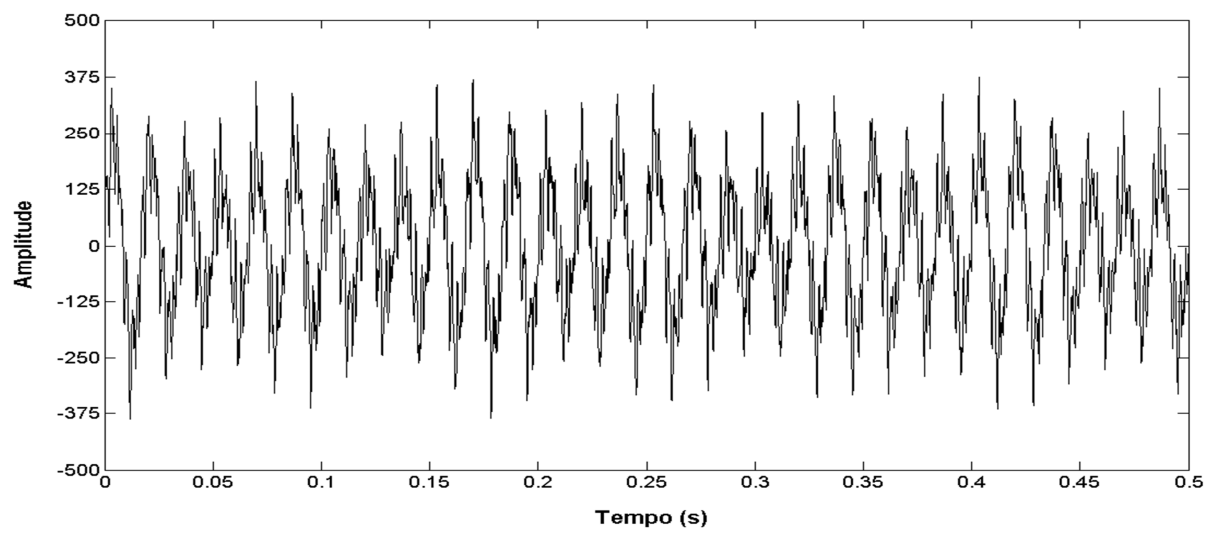

Figura 4.2. Visualização da forma de onda do sinal sintético. Fonte: Oliveira, 2015.

Nota-se da Figura 4.2, um elevado nível de modulação e distorção do sinal sintético. Para esta análise, é importante salientar duas características desse sinal: a ocorrência de interharmônicas dessincronizadas com a janela de tempo retangular de 12 ciclos e a variação temporal vinculada tanto à presença de ruídos quanto à modulação da amplitude da fundamental, que podem introduzir erros nos resultados.

A Figura 4.3 apresenta os diagramas tempo-frequência obtidos com o processamento (a) via DFT e (b) por meio da metodologia PK. A visualização foi ampliada para os $5 \mathrm{~s}$ iniciais do tempo simulado. A variação das cores representa, conforme a escala graduada da 
direita, a evolução das amplitudes de cada componente de frequência ao longo do tempo.
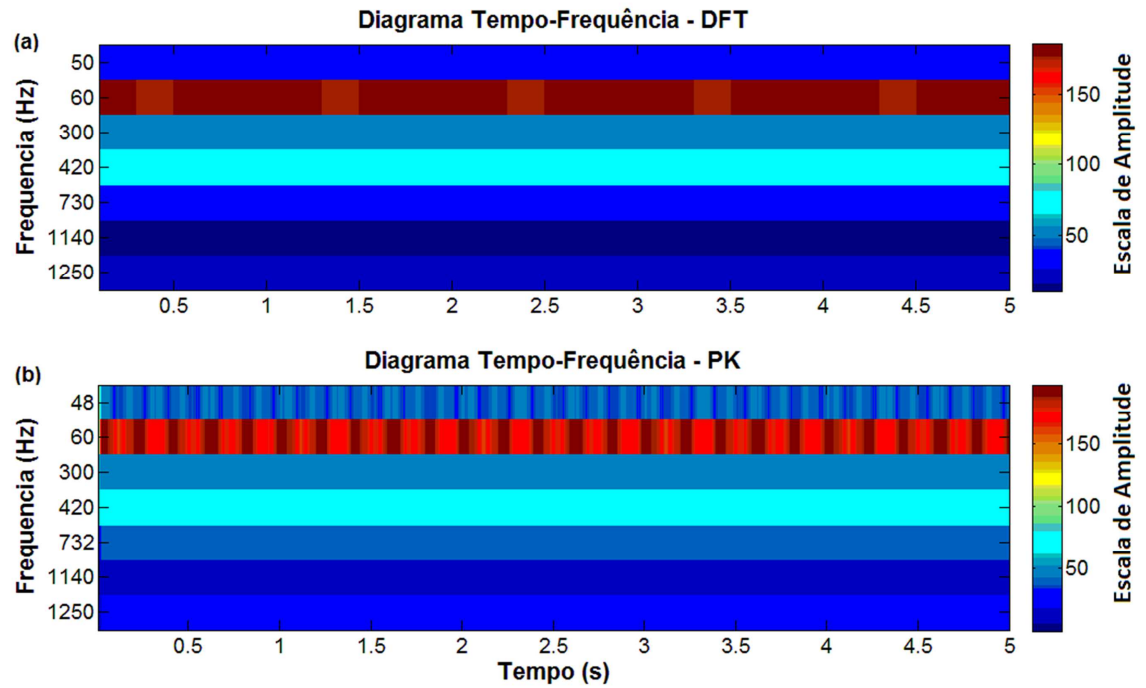

Figura 4.3. Diagramas tempo-frequência obtidos com o processamento (a) via DFT com janela de 12 ciclos e (b) por meio da metodologia PK. Fonte: Oliveira, 2015.

Da Figura 4.3, observa-se que cada método de cálculo estima várias barras espectrais, algumas com amplitudes mais significativas do que outras. Para essa análise são exibidas apenas as sete componentes com maior energia, pois o sinal sintético foi construído a partir da contribuição de sete senoides com frequências harmônicas e inter-harmônicas de $60 \mathrm{~Hz}$.

$\mathrm{Na}$ Tabela 4.1 estão indicadas as frequências e os valores P95\% de cada componente, estimados por cada método, e os valores teóricos esperados para esses parâmetros, no período de 1 minuto.

Tabela 4.1 - Estimação das amplitudes e das frequências para o sinal sintético.

\begin{tabular}{|c|c|c|c|c|c|}
\hline \multicolumn{3}{|c|}{ Frequências } & \multicolumn{3}{c|}{ Amplitudes P95\% } \\
\hline DFT & PK & Teórico & DFT & PK & Teórico \\
\hline 50,0 & 48,0 & 48,0 & 30,8 & 42,0 & 40,0 \\
\hline 60,0 & 60,0 & 60,0 & 185,2 & 195,9 & 198,1 \\
\hline 300,0 & 300,0 & 300,0 & 50,4 & 50,2 & 50,0 \\
\hline 420,0 & 420,0 & 420,0 & 70,2 & 70,1 & 70,0 \\
\hline 730,0 & 732,0 & 732,0 & 30,5 & 40,2 & 40,0 \\
\hline 1140,0 & 1140,0 & 1140,0 & 10,2 & 10,0 & 10,0 \\
\hline 1250,0 & 1250,0 & 1250,0 & 25,3 & 25,2 & 25,0 \\
\hline
\end{tabular}


Da Tabela 4.1, verifica-se que, para o mesmo sinal, as metodologias retornam diferentes valores. A DFT com a resolução de $5 \mathrm{~Hz}$ não identificou as frequências de $48 \mathrm{~Hz}$ e $732 \mathrm{~Hz}$, além de detectar com menor eficácia a variação de amplitude da fundamental. A metodologia PK apresentou valores mais próximos aos teóricos e um bom desempenho na identificação das frequências.

A Figura 4.4 apresenta a evolução no tempo dos indicadores THD e TID, retornados por cada método. No cálculo desses indicadores foram utilizados os métodos de cálculo dos subgrupos e as equações constantes no padrão IEC 61000-4-7.
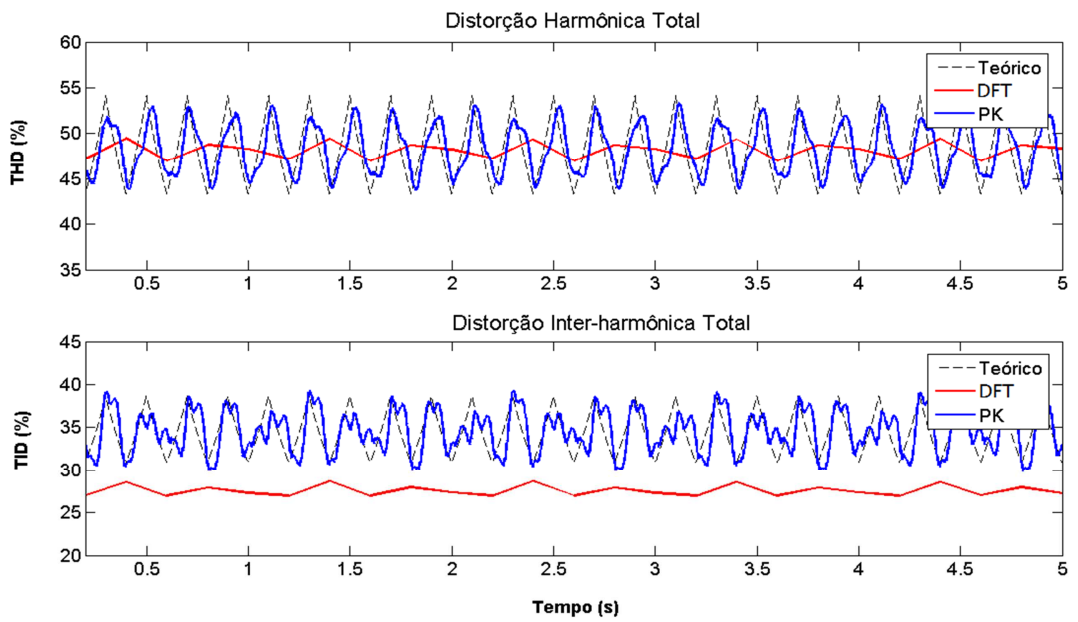

Figura 4.4. Evolução no tempo dos índices THD e TID para o sinal sintético. Fonte:

Oliveira, 2015.

Da Figura 4.4, tomando-se como referência os valores teóricos de THD e TID (linhas pretas tracejadas), percebe-se que ao longo do período simulado os comportamentos dos indicadores no tempo obtidos via DFT situam-se mais distantes do esperado.

A partir do estudo realizado nesta subseção e dos resultados apresentados por Costa (2005), Ferreira Filho et al (2015) e Oliveira (2015), constata-se que a metodologia PK representa uma opção para uma análise espectral com alta resolução em condições de variação temporal das magnitudes. Por esse motivo, tal metodologia será empregada como referência nas análises deste trabalho.

\section{4 - AVALIAÇÃO DAS JANELAS DE TEMPO}

Para os sinais de tensão da instalação eólica em estudo, calculam-se os índices THD e TID por meio da estimação espectral realizada tanto com a metodologia PK, quanto com a DFT 
com janelas de tempo de 1 ciclo, 6 ciclos, 10 ciclos, 12 ciclos, 15 ciclos, 20 ciclos, 30 ciclos e 60 ciclos de $60 \mathrm{~Hz}$, referenciadas, respectivamente, por $\mathrm{DFT}_{1}, \mathrm{DFT}_{6}, \mathrm{DFT}_{10}$, $\mathrm{DFT}_{12}, \mathrm{DFT}_{15}, \mathrm{DFT}_{20}, \mathrm{DFT}_{30}$ e DFT 60 .

A Figura 4.5 ilustra o comportamento do indicador THD medido por meio da aplicação da DFT com janelas de tempo de tamanhos diferentes ao longo de um dia de medição. Também estão ilustrados em vermelho os valores de referência obtidos por meio da metodologia PK.

Da Figura 4.5, destacam-se as diferenças entre os valores máximos de THD de cada gráfico: $23,19 \%$ para a $\mathrm{DFT}_{1}, 6,62 \%$ para a $\mathrm{DFT}_{6}, 4,12 \%$ para a $\mathrm{DFT}_{10}, 3,51 \%$ para a $\mathrm{DFT}_{12}, 2,93 \%$ para a $\mathrm{DFT}_{15}, 2,35 \%$ para a $\mathrm{DFT}_{20}, 1,86 \%$ para a $\mathrm{DFT}_{30}$ e $1,47 \%$ para a DFT $_{60}$. Nota-se, por meio desses resultados, a diminuição dos níveis de THD à medida que se aumenta a janela de tempo. Para a metodologia PK, o nível máximo de THD é 3,73\%.
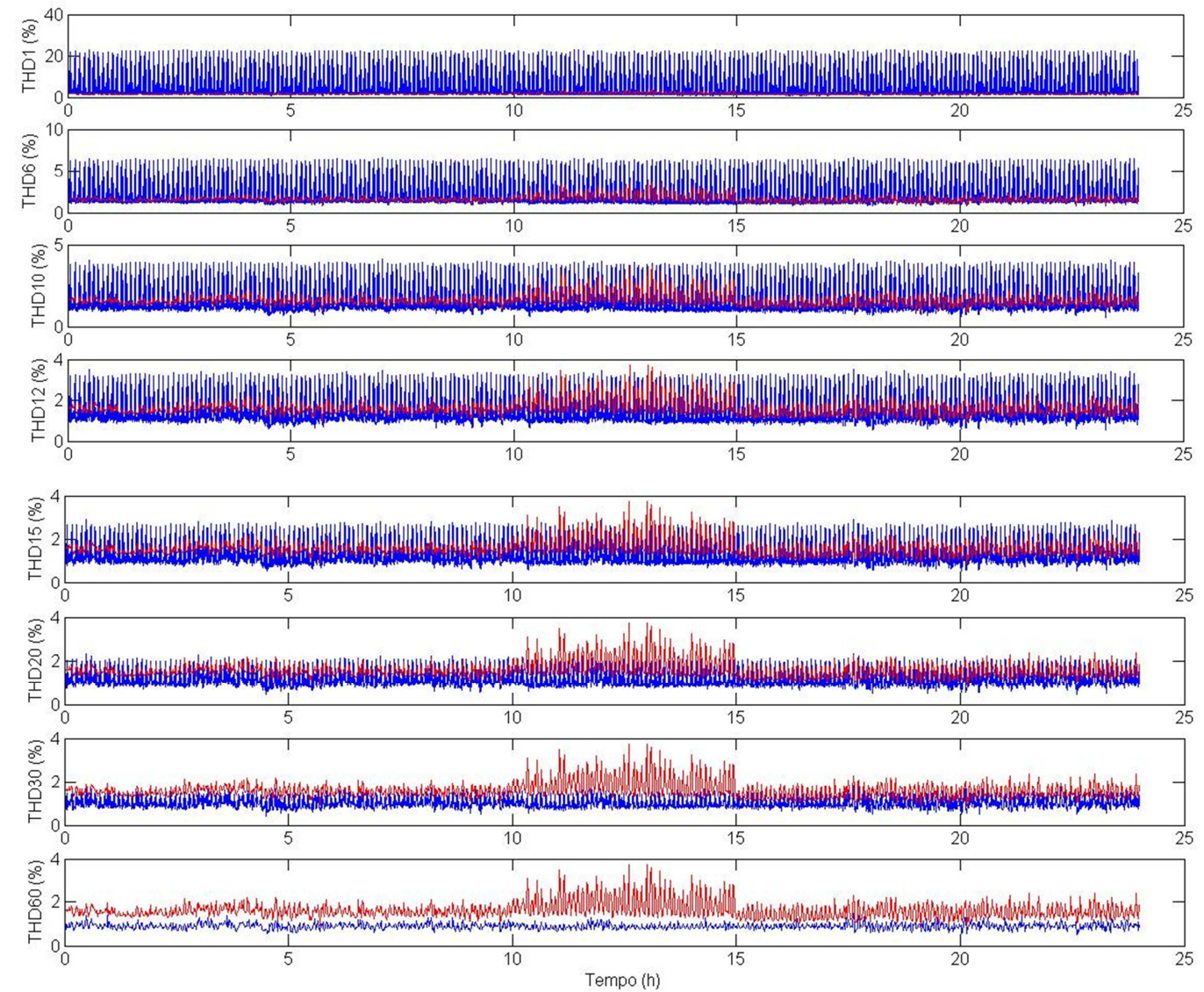

Figura 4.5. Valores de THD obtidos por meio da DFT para diferentes janelas de tempo ao longo de um dia de medição (em azul) comparados com a metodologia PK (em vermelho). 
A Figura 4.6 exibe o comportamento do TID medido por meio da aplicação da DFT com as janelas de tempo de tamanhos diferentes ao longo do mesmo período considerado na Figura 4.5. Também estão ilustrados em vermelho os valores de referência obtidos por meio da metodologia PK.

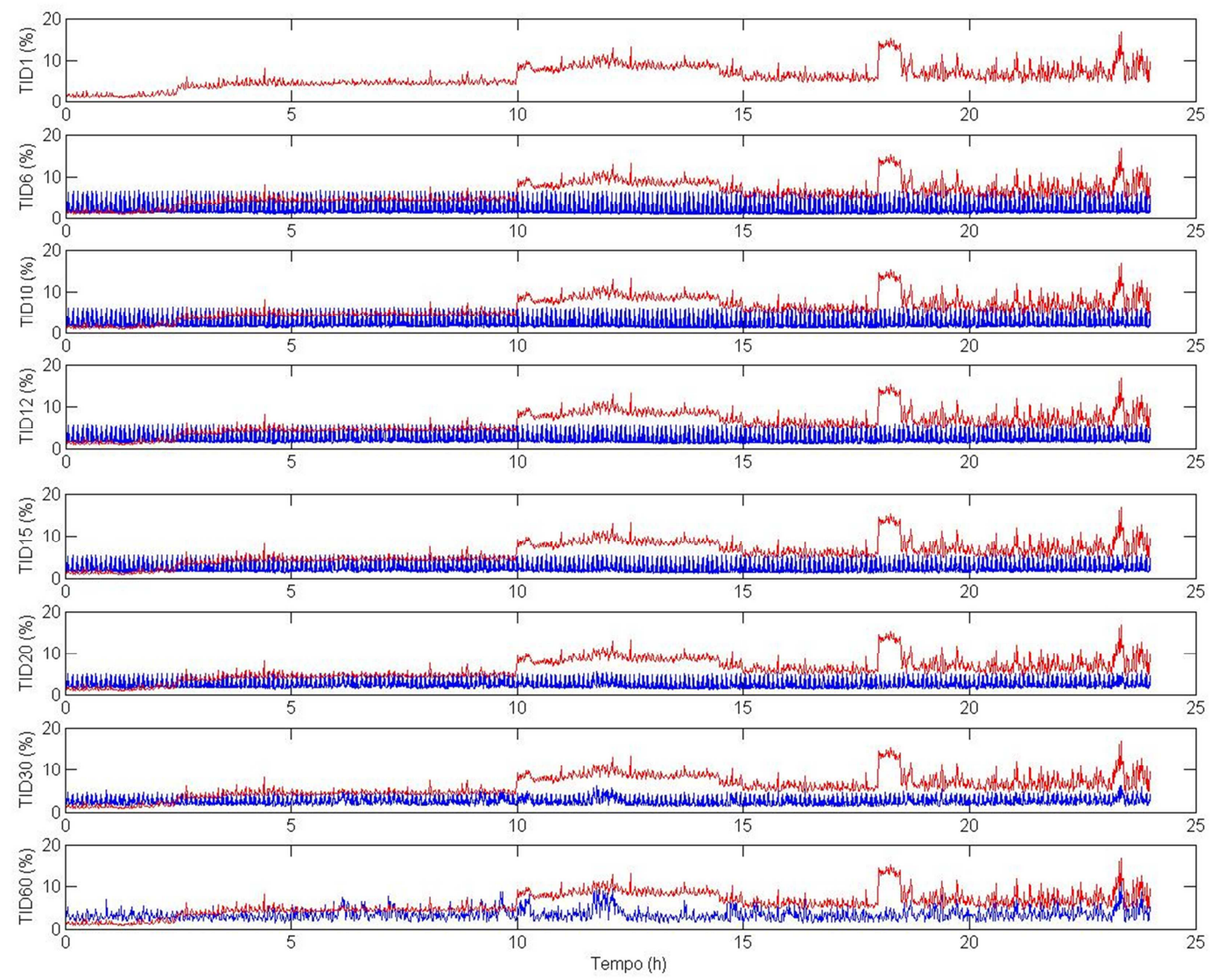

Figura 4.6. Valores de TID obtidos por meio da DFT para diferentes janelas de tempo ao longo de um dia de medição (em azul) comparados com a metodologia PK (em vermelho).

Da Figura 4.6, notam-se também as diferenças entre os valores máximos de TID de cada gráfico: $6,85 \%$ para a $\mathrm{DFT}_{6}, 6,33 \%$ para a $\mathrm{DFT}_{10}, 6,01 \%$ para a $\mathrm{DFT}_{12}, 5,79 \%$ para a $\mathrm{DFT}_{15}, 5,67 \%$ para a $\mathrm{DFT}_{20}, 6,26 \%$ para a $\mathrm{DFT}_{30}, 11,97 \%$ para a $\mathrm{DFT}_{60}$ e $16,75 \%$ para PK. No caso do TID, os níveis de distorção decrescem até a DFT $_{15}$ e então crescem à medida que se aumenta o tamanho da janela. É importante reiterar que a $\mathrm{DFT}_{1}$ não possui a resolução adequada que permita calcular as inter-harmônicas, por isso TID=0\%.

A Figura 4.7 ilustra o comportamento dos indicadores THD e TID gerados por cada método de cálculo em um período de 1 minuto de monitoramento do sinal. Também estão ilustrados os valores de referência obtidos por meio da metodologia PK. 


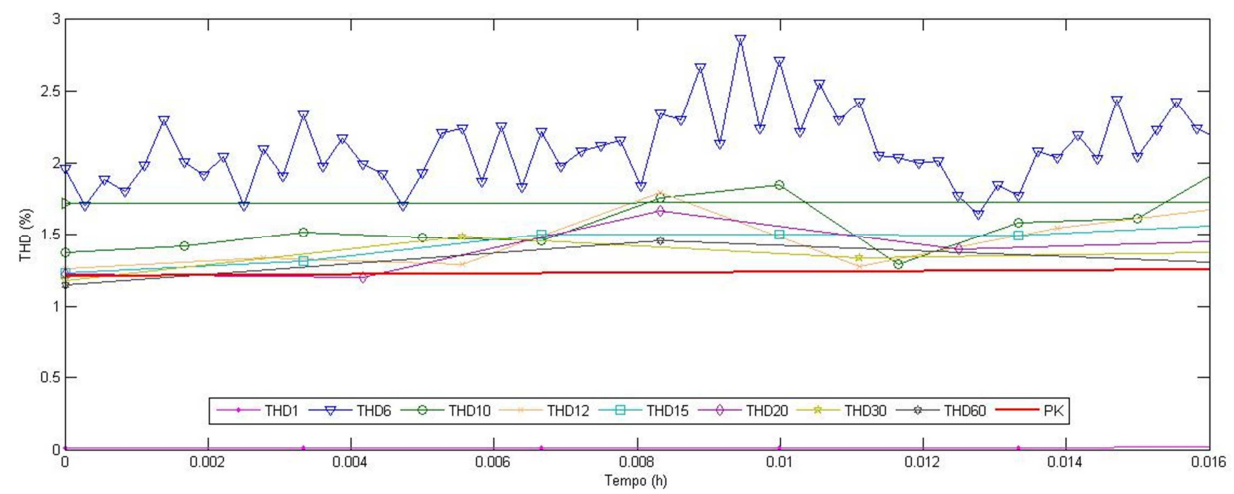

(a)

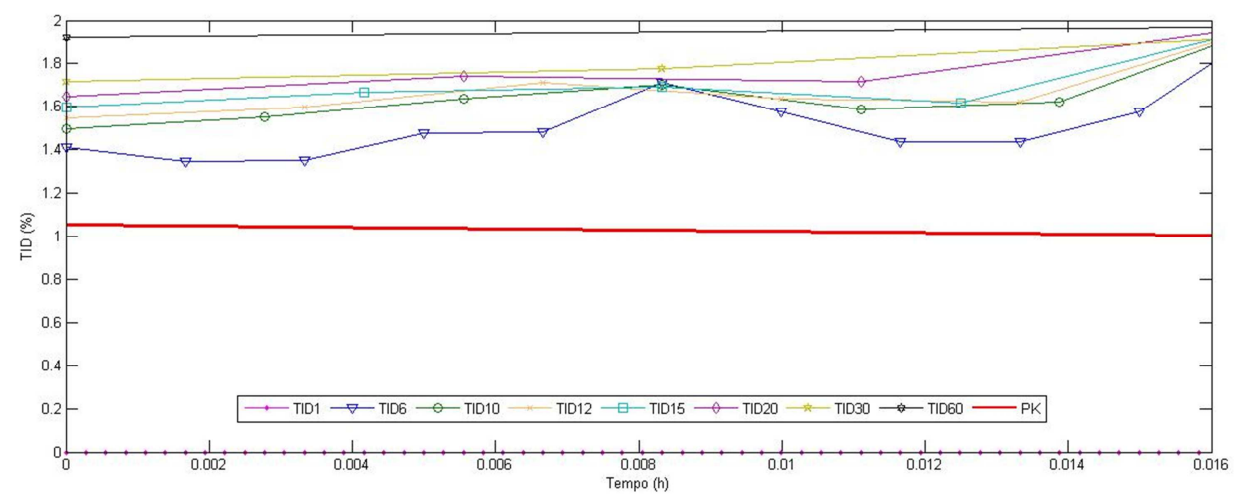

(b)

Figura 4.7. Valores de (a) THD e (b) TID em 1 minuto de monitoramento do sinal.

Da Figura 4.7, infere-se via comparação visual dos gráficos que, no caso do THD, a DFT 1 e a $\mathrm{DFT}_{15}$ resultaram em níveis médios mais próximos àqueles observados com a metodologia PK. No caso do TID, não é possível determinar graficamente quais os perfis identificados por meio da DFT que ficaram mais próximos ao perfil identificado por meio da metodologia de referência.

A Figura 4.8 traz os valores de $\mathrm{THD}_{95}$ decorrentes da quantificação dos valores gerados por meio de cada método de cálculo em um período de uma semana.

Da Figura 4.8, percebe-se que os valores de $\mathrm{THD}_{95}$ obtidos por meio da $\mathrm{DFT}_{1}$ e da $\mathrm{DFT}_{15}$ estão, em geral, mais próximos daqueles obtidos por meio da metodologia PK. Na análise da Figura 4.5, o valor máximo de THD foi obtido na DFT ${ }_{1}$ Entretanto, os níveis de $\mathrm{THD}_{95}$ obtidos ao longo de uma semana de medição para a $\mathrm{DFT}_{1}$ não seguiram essa tendência. Tal fato reflete o comportamento do THD, obtido via $\mathrm{DFT}_{1}$, que apresenta picos com baixa frequência estatística durante o período de monitoramento. 


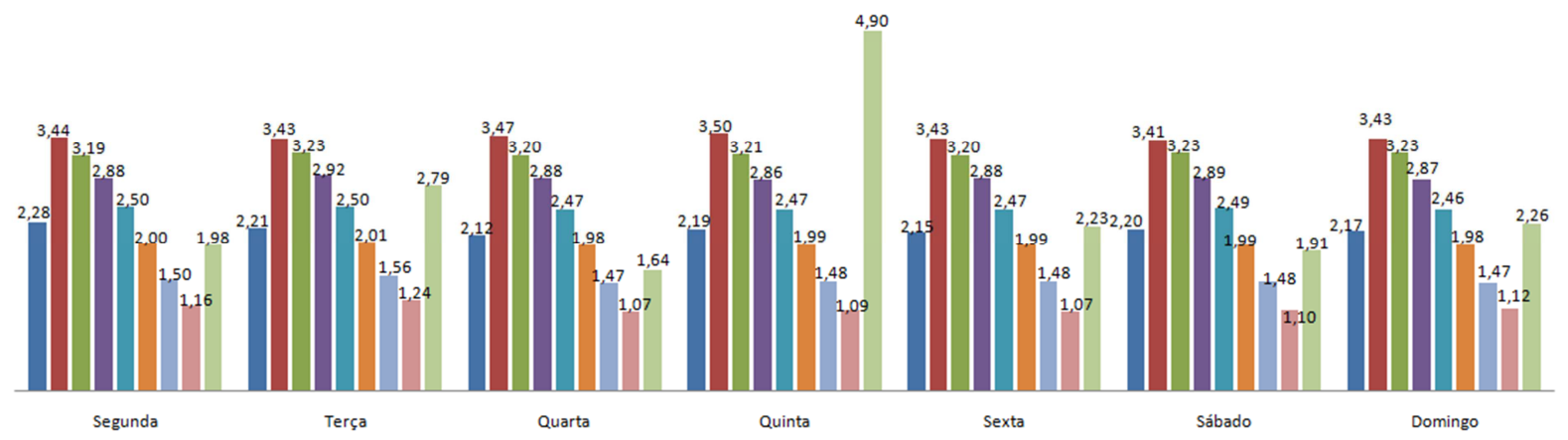

Figura 4.8. Valores de $\mathrm{THD}_{95}$ obtidos ao longo de uma semana de medição.

A Figura 4.9 traz os valores de TID $_{95}$ obtidos por meio da aplicação de cada método de cálculo em um período de uma semana.

TID

$\|$ DFT1 $\|$ DFT6 $=$ DFT10 $=$ DFT12 $=$ DFT15 $\|$ DFT20 $=$ DFT30 $\|$ DFT60 $=$ PK

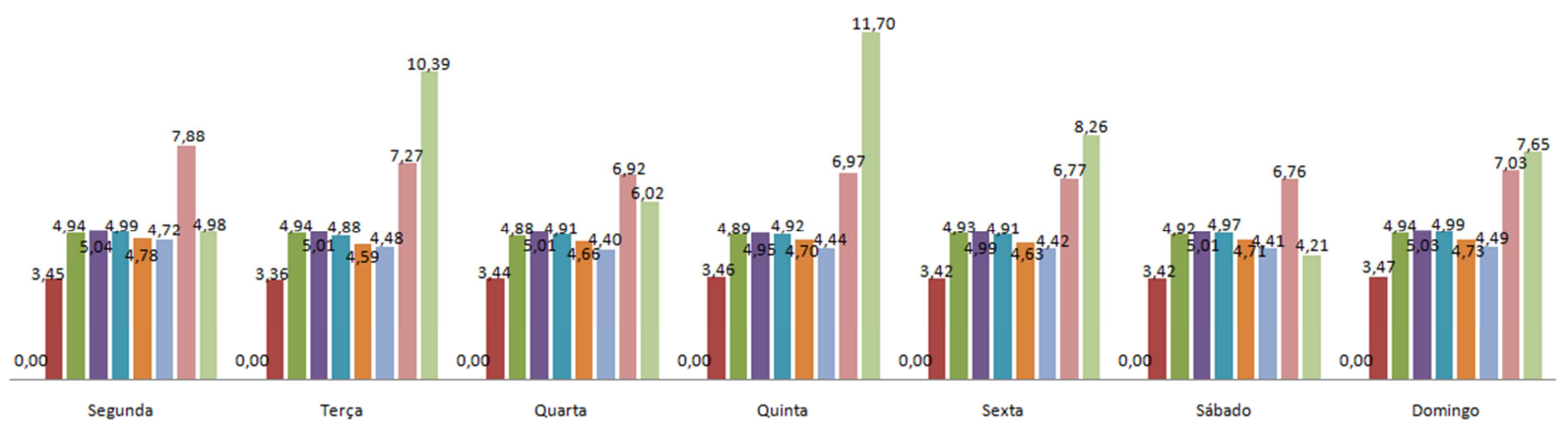

Figura 4.9. Valores de TID $_{95}$ obtidos ao longo de uma semana de medição.

Da Figura 4.9, percebe-se que os valores de TID $_{95}$ obtidos por meio da DFT $_{60}$ estão, em geral, mais próximos daqueles obtidos por meio da metodologia PK. Esse é um indicativo de que a alta resolução da $\mathrm{DFT}_{60}$ faz com que ela seja mais próxima de PK, que é uma metodologia também de alta resolução.

Para o THD e TID é observada a semelhança entre os resultados advindos pela aplicação da DFT em cada janela de tempo ao longo dos diferentes dias da semana. Tal fato reflete a pouca variação do sinal de tensão durante o período de medição. 


\subsection{1 - Análise das tendências}

Considerando-se que as discrepâncias observadas entre os métodos baseados na DFT e a metodologia PK sejam influenciadas pelo tamanho da janela de tempo, propõe-se uma análise das tendências observadas nas Figuras 4.8 e 4.9. Para tal, calculam-se as discrepâncias absolutas para cada parâmetro em cada dia, conforme (4.1).

$$
D_{J n, P K}^{d}=\left|\theta_{J n}^{d}-\theta_{P K}^{d}\right|
$$

em que $D_{J n, P K}^{d}$ é a discrepância absoluta procurada; $d$ indica o dia da semana sob avaliação; $\theta$ é o parâmetro de interesse, $\mathrm{TID}_{95}$ ou $\mathrm{THD}_{95}$; $J n$ indica uma janela de tempo de $n$ ciclos de $60 \mathrm{~Hz} ; \theta_{J n}^{d}$ é o parâmetro de interesse calculado por meio da DFT com janela $J n$ no dia $d ; \theta_{P K}^{d}$ é o parâmetro de interesse calculado por meio da metodologia PK no dia $d$.

Como os níveis de THD e TID mudam a cada dia de medição, as discrepâncias absolutas também apresentam valores diferentes ao longo da semana. Por isso, analisa-se separadamente as discrepâncias como função das janelas, utilizando-se os valores de discrepância absoluta calculados em cada dia. Em seguida, é realizada a normalização das discrepâncias por dia, conforme (4.2).

$$
\Delta_{J n, P K}^{d}=D_{J n, P K}^{d} / \max _{J n}\left(D_{J n, P K}^{d}\right)
$$

em que $\Delta_{J n, P K}^{d}$ é a discrepância $D_{J n, P K}^{d}$ normalizada pelo valor máximo das discrepâncias absolutas observadas no dia $d$.

O procedimento supracitado é aplicado para os índices THD $_{95}$ e TID $_{95}$ em cada conjunto de valores que representam os 7 dias de medição. A Figura 4.7 ilustra a aplicação do procedimento sobre o conjunto de valores de $\mathrm{THD}_{95}$ da segunda-feira.

Da Figura 4.10, observa-se que, para o conjunto de valores de $\mathrm{THD}_{95}$ obtido na segundafeira, a $\mathrm{DFT}_{6}$ apresenta a maior discrepância absoluta (1,46 pontos percentuais). Então, 
esse valor é utilizado como denominador de normalização das discrepâncias dos outros métodos para esse dia. Com essa abordagem, as discrepâncias obtidas para cada parâmetro em dias diferentes podem ser comparadas entre si e os pares ordenados do tipo $\left(J n, \Delta_{J n, P K}^{d}\right)$ são identificados.

THD

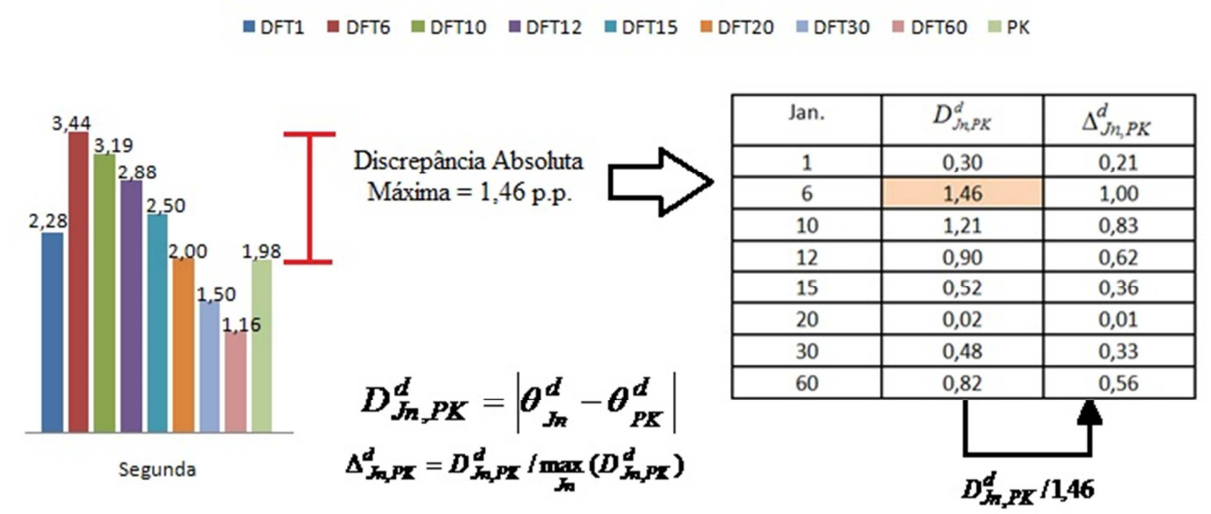

Figura 4.10. Exemplo do procedimento de cálculo das discrepâncias normalizadas.

Os resultados para os sete conjuntos de valores (sete dias) de que se dispõe para cada indicador estão apresentados nas Tabelas 4.2 e 4.3.

Esses pontos são utilizados na regressão de curvas de tendência, por meio do método dos mínimos quadrados, que expressam as discrepâncias absolutas normalizadas de cada indicador como uma função do tamanho das janelas de tempo. A Figura 4.11 apresenta as curvas obtidas e os pontos experimentais resultantes do procedimento exposto nesta subseção.

Tabela 4.2 - Discrepância normalizada para o índice THD.

\begin{tabular}{|c|c|c|c|c|c|c|c|}
\hline \multicolumn{7}{|c|}{ Discrepância normalizada - THD } \\
\hline Metodologia & Segunda & Terça & Quarta & Quinta & Sexta & Sábado & Domingo \\
\hline DFT $_{1}$ & 0.21 & 0.37 & 0.26 & 0.71 & 0.07 & 0.19 & 0.08 \\
\hline DFT $_{6}$ & 1.00 & 0.41 & 1.00 & 0.37 & 1.00 & 1.00 & 1.00 \\
\hline DFT $_{10}$ & 0.83 & 0.28 & 0.85 & 0.44 & 0.81 & 0.88 & 0.83 \\
\hline DFT $_{12}$ & 0.62 & 0.08 & 0.68 & 0.54 & 0.54 & 0.65 & 0.52 \\
\hline DFT $_{15}$ & 0.36 & 0.19 & 0.45 & 0.64 & 0.20 & 0.39 & 0.17 \\
\hline DFT $_{20}$ & 0.01 & 0.50 & 0.19 & 0.76 & 0.20 & 0.05 & 0.24 \\
\hline DFT $_{30}$ & 0.33 & 0.79 & 0.09 & 0.90 & 0.63 & 0.29 & 0.68 \\
\hline DFT $_{60}$ & 0.56 & 1.00 & 0.31 & 1.00 & 0.97 & 0.54 & 0.97 \\
\hline
\end{tabular}


Tabela 4.3 - Discrepância normalizada para o índice TID.

\begin{tabular}{|c|c|c|c|c|c|c|c|}
\hline \multicolumn{7}{|c|}{ Discrepância normalizada - TID } \\
\hline Metodologia & Segunda & Terça & Quarta & Quinta & Sexta & Sábado & Domingo \\
\hline DFT $_{1}$ & 1.00 & 1.00 & 1.00 & 1.00 & 1.00 & 1.00 & 1.00 \\
\hline DFT $_{6}$ & 0.31 & 0.68 & 0.43 & 0.70 & 0.59 & 0.19 & 0.55 \\
\hline DFT $_{10}$ & 0.01 & 0.52 & 0.19 & 0.58 & 0.40 & 0.17 & 0.35 \\
\hline DFT $_{12}$ & 0.01 & 0.52 & 0.17 & 0.58 & 0.40 & 0.19 & 0.34 \\
\hline DFT $_{15}$ & 0.00 & 0.53 & 0.18 & 0.58 & 0.41 & 0.18 & 0.35 \\
\hline DFT $_{20}$ & 0.04 & 0.56 & 0.23 & 0.60 & 0.44 & 0.12 & 0.38 \\
\hline DFT $_{30}$ & 0.05 & 0.57 & 0.27 & 0.62 & 0.46 & 0.05 & 0.41 \\
\hline DFT $_{60}$ & 0.58 & 0.30 & 0.15 & 0.40 & 0.18 & 0.61 & 0.08 \\
\hline
\end{tabular}

Da Figura 4.11 verifica-se a adequação de um modelo exponencial duplo para o comportamento das discrepâncias do TID 95 : uma componente de decaimento entre 1 e 12 ciclos, e outra componente de crescimento suave entre 15 e 60 ciclos. Para o THD 95 , devido ao comportamento variável desse índice, nenhum modelo analítico empregado culminou em um resultado preciso. Por isso, utilizou-se a técnica de aproximação Smoothing Spline, que consiste em se dividir o intervalo de interesse em vários subintervalos e interpolar, da forma mais suave possível nestes subintervalos, com polinômios de grau pequeno.

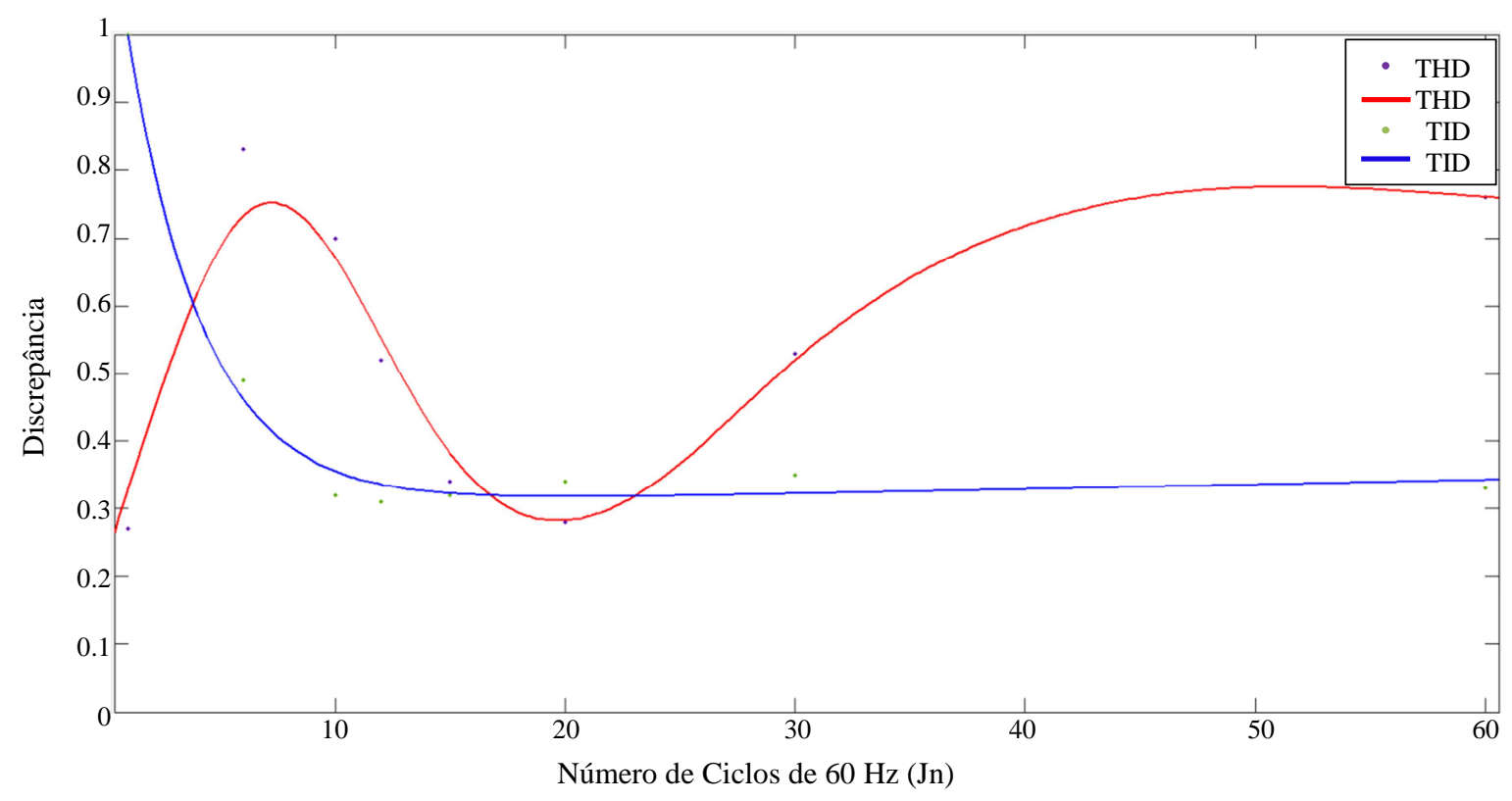

Figura 4.11. Curvas expressando as discrepâncias como função do número de janelas.

Nota-se da Figura 4.11 que a interseção entre as linhas de tendência ocorre em três pontos: para $J n=3,8,16,7$ e 23 ciclos. Entretanto, o par ordenado que possui o menor valor no 
eixo das ordenadas corresponde à janela de 16,7 ciclos, que está próxima da janela de 15 ciclos empregada nos testes. É oportuno ressaltar que, em 3 dos 7 dias analisados, a janela de 15 ciclos representou a segunda melhor opção de discrepância para o THD 95 , e para a discrepância do TID $_{95}$, foi a melhor em 1 dia e a segunda em 2 dos 7 dias analisados.

\section{5 - ANÁLISES ESTATÍSTICAS}

Nesta seção, apresenta-se a caracterização estatística dos dados de THD e TID advindos da aplicação da metodologia PK. Para tal, realiza-se uma investigação sobre o comportamento das distorções na instalação eólica e admite-se que os indicadores THD e TID representem processos estocásticos. Cada conjunto de medições tomado ao longo de um dia consiste de uma repetição (realização) desses processos.

Consideram-se os valores de THD e TID durante 30 dias, o que resulta em 30 séries temporais para cada índice. Após analisar o comportamento dos dados, optou-se por suavizá-los utilizando um filtro de média móvel, com o intuito não só de discernir mais facilmente entre tendências, mas também de facilitar as manipulações e análises.

A Figura 4.12 ilustra o comportamento do indicador THD ao longo das quatro semanas completas (segunda a domingo) contidas no período de medição.

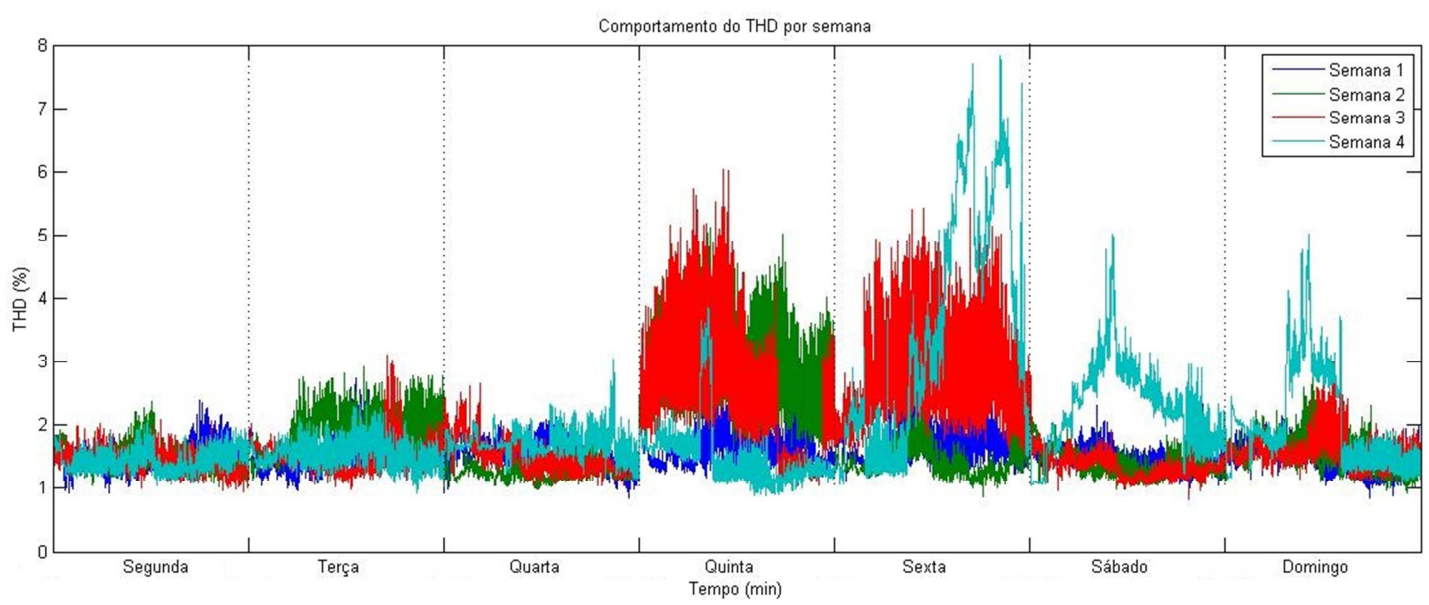

Figura 4.12. Comportamento do indicador THD ao longo das quatro semanas compreendidas no período de medição considerado.

Da Figura 4.12 é possível verificar o comportamento variante no tempo do indicador THD da instalação eólica. Infere-se que as diferenças entre os níveis de distorção são observados em todos os dias da semana (segunda a domingo). Nota-se um comportamento 
diferenciado nas semanas 2 e 3 na quinta-feira e nas semanas 2 e 4 na sexta-feira. Nesses dois dias, nas semanas 3 e 4, o índice de distorção ultrapassou o limiar de 5\% estabelecido pela norma. O maior THD foi de 7,83\% na sexta-feira da semana 4 . O período que a distorção permaneceu acima de 5\% foi de aproximadamente 508 min. O P95\%, valor médio e desvio padrão nesses dias, são, respectivamente, de 2,63\%, 1,05\% e 4,56\% na semana 3 da quinta-feira; de 2,93\%,0,86\% e 4,52\% na semana 3 da sexta-feira; e de $3,45 \%, 1,82 \%$ e $6,48 \%$ na semana 4 da sexta-feira.

A Figura 4.13 ilustra o comportamento do indicador TID. Nota-se da Figura 4.10 que, analogamente ao caso anterior, o indicador de distorção inter-harmônica apresenta um comportamento distinto em todos os dias da semana. Tal fato reforça a hipótese da não sazonalidade nas séries.

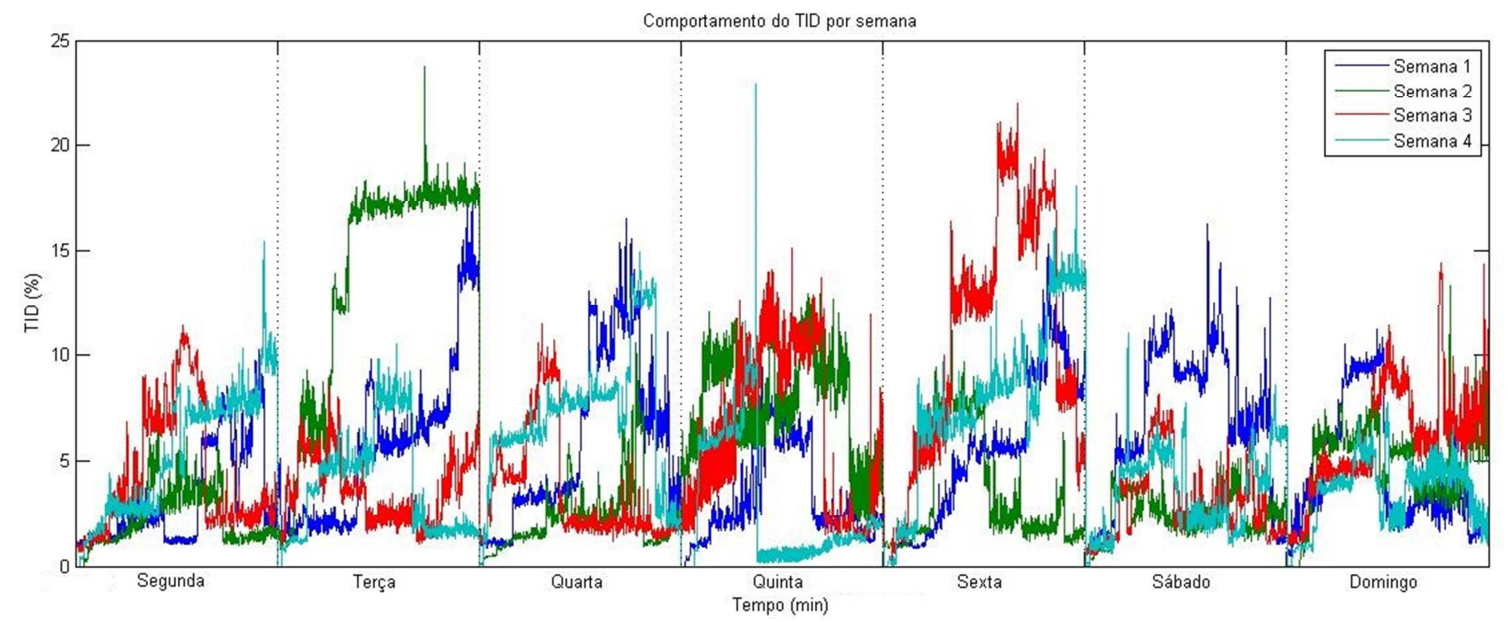

Figura 4.13. Comportamento do TID ao longo das quatro semanas compreendidas no período de medição considerado.

Da figura 4.13, nota-se que não há um padrão determinístico na alteração dos níveis de TID ao longo de um mesmo dia, o que inicialmente sugere um comportamento aleatório nos dados. As distorções do índice TID apresentaram valores maiores quando comparados ao THD. Em todos os dias, o índice de distorção ultrapassou o limiar de 5\%. O maior TID foi de $23,74 \%$ na terça-feira da semana 2 . Tal resultado evidencia a importância da análise do TID, já que a presença de inter-harmônica pode produzir oscilações de baixa frequência em sistemas mecânicos, falhas de sensores e equipamentos de proteção, saturação de transformadores de corrente e o fenômeno de cintilação luminosa (flicker) (Macedo Júnior, 2009). 
A Tabela 4.4 resume algumas das estatísticas descritivas extraídas do conjunto global das séries. Indica-se também nessa tabela (linha $\% t_{k}$ Normal) o percentual de instantes de tempo diários $t_{k}$ nos quais são positivos os testes de normalidade Kolmogorov-Smirnov realizados sobre cada uma das variáveis aleatórias representadas por $\operatorname{THD}\left(t_{k}, \mathrm{~d}\right)$ e $\operatorname{TID}\left(t_{k}, \mathrm{~d}\right)$.

Tabela 4.4 - Descrição do conjunto global das séries de THD e TID obtidas em 30 dias.

\begin{tabular}{|c|c|c|c|}
\hline \multicolumn{2}{|c|}{ THD (\%) } & \multicolumn{2}{c|}{ TID (\%) } \\
\hline P5\% & 1,17 & P5\% & 0,88 \\
\hline P25\% & 1,36 & P25\% & 1,95 \\
\hline P50\%(Mediana) & 1,87 & P50\%(Mediana) & 7,21 \\
\hline P95\% & 3,40 & P95\% & 13,20 \\
\hline P99\% & 5,02 & P99\% & 17,80 \\
\hline$\% t_{k}$ Normal & 50,80 & $\% t_{k}$ Normal & 88,48 \\
\hline
\end{tabular}

Da Tabela 4.4, nota-se que os valores P5\% e P99\% se distanciam das medianas, o que indica que as séries de THD e TID variam em uma faixa significativa ao longo dos 30 dias. Pela observação das Figuras 4.9 e 4.10, infere-se que isso ocorre em razão da variação dos níveis de distorção ao longo dos diferentes dias da semana. Da avaliação de normalidade dos dados pode ser constatado que em 50,80\% dos instantes de tempo de um dia os dados de THD podem ser considerados normalmente distribuídos. Para o TID, esse índice de normalidade foi de $88,48 \%$.

\subsection{1 - Avaliação da estacionariedade}

Para a avaliação da estacionariedade e da ergodicidade do processo aleatório $\operatorname{TH} D(t)$, a Figura 4.14 traz o comportamento dos seguintes parâmetros: (a) a média temporal calculada ao longo dos 30 dias; (b) a média de probabilidade para cada instante $t_{k}$; e (c) a média temporal calculada para cada dia.

Comparando-se a Figura 4.14 (a) com a Figura 4.14 (b), percebe-se que a média temporal e a média de probabilidade não convergem para os mesmos valores. Da Figura 4.14 (b), nota-se que a média de probabilidade do processo $T H D(t)$ não se estabiliza ao final de um dia. Esse resultado sugere a não-estacionariedade do processo $T H D(t)$ no período de 
realização diário. Percebe-se da Figura 4.14 (c) que a média temporal sequencial calculada a cada dia resulta em níveis diferentes diários ao longo do período de 30 dias.

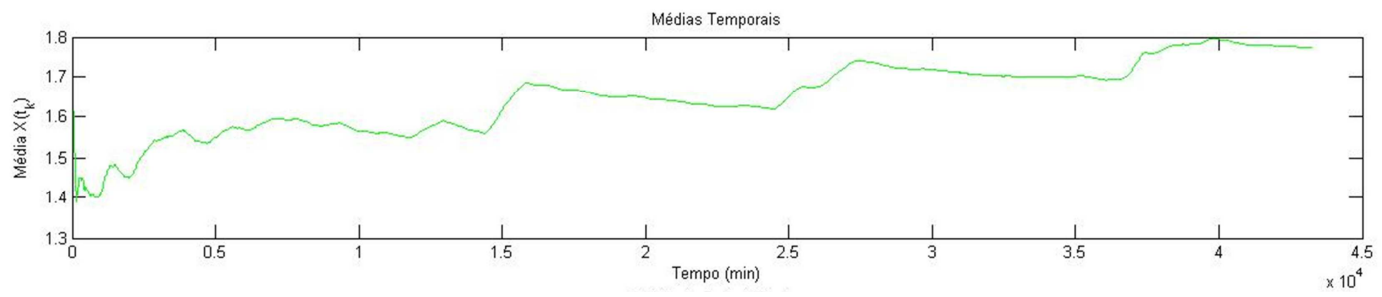

(a)

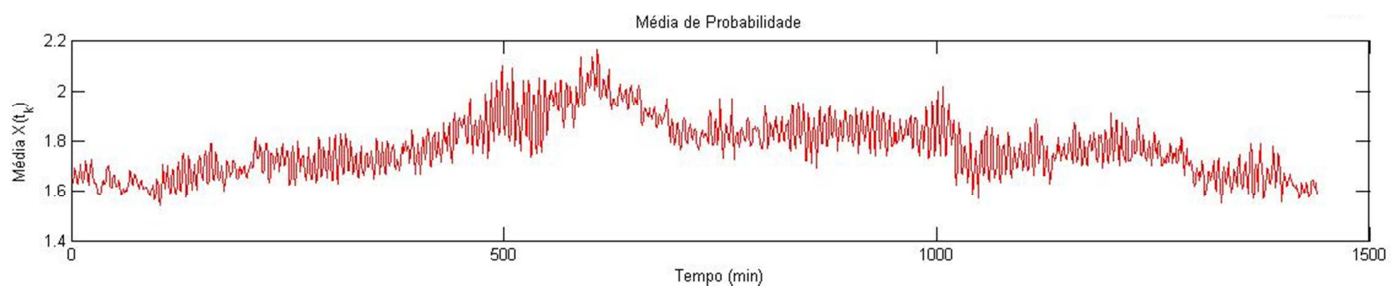

(b)

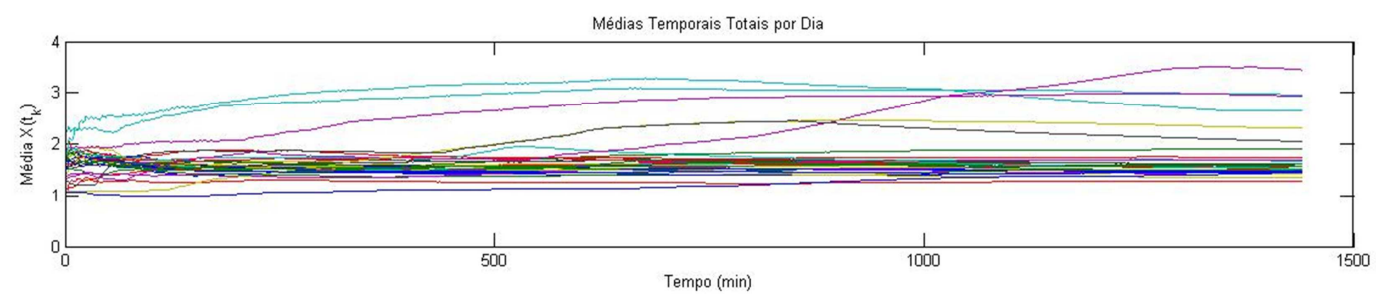

(c)

Figura 4.14. Parâmetros para o indicador THD (a) Média temporal ao longo dos 30 dias, (b) média de probabilidade e (c) média temporal total por dia.

A fim de investigar a hipótese de ergodicidade, subtraem-se as curvas das Figuras 4.14 (b) e (c), resultando no gráfico da diferença das médias temporais em cada dia com relação à média de probabilidade, ilustrado na Figura 4.15. Neste gráfico, também estão plotadas a média global dessas diferenças (reta preta) e o intervalo de confiança de $\pm 3 \sigma$ (retas vermelhas).

Da Figura 4.15, notam-se as diferenças entre a média temporal e a média de probabilidade para cada um dos 30 dias. Aplicando-se o teste de hipóteses de $t$-student, verifica-se que a média global do resíduo não é nula. Esse resultado comprova que a hipótese de ergodicidade não pode ser aplicada ao estudo do comportamento do indicador THD (LeonGarcia, 2008). 


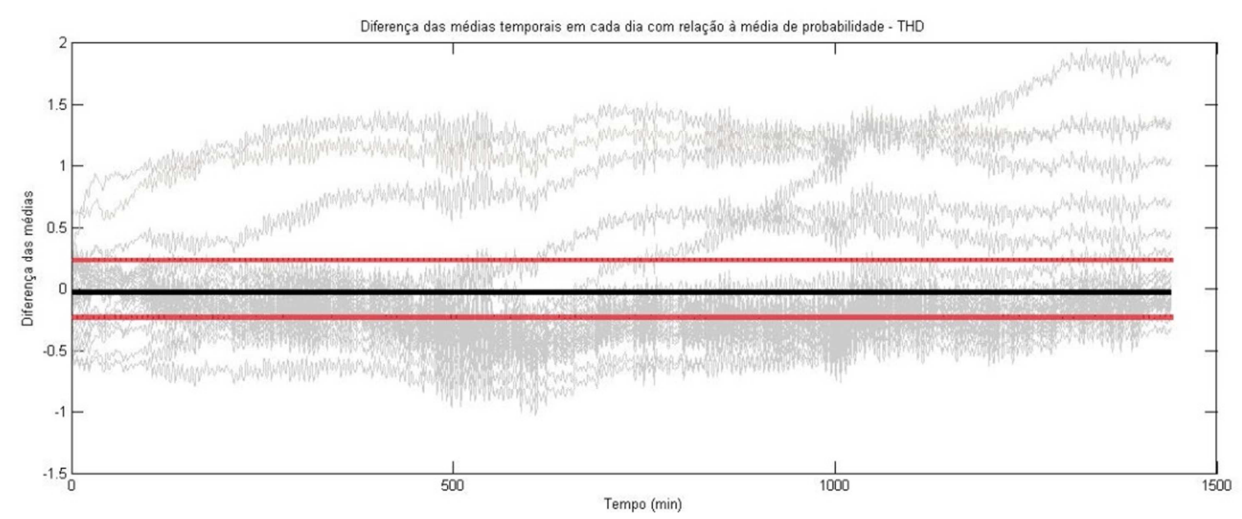

Figura 4.15. Diferença das médias temporais em cada dia com relação à média de probabilidade - THD.

A Figura 4.16 ilustra, para o processo aleatório $T I D(t)$, os resultados da mesma análise realizada para o THD.

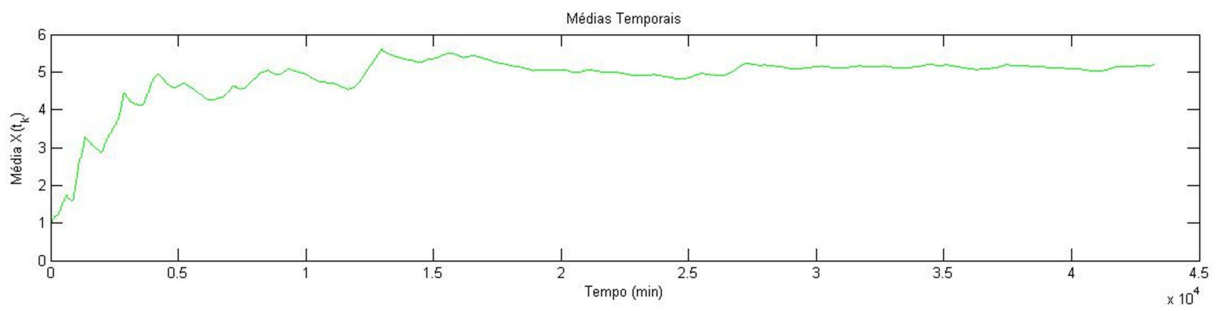

(a)

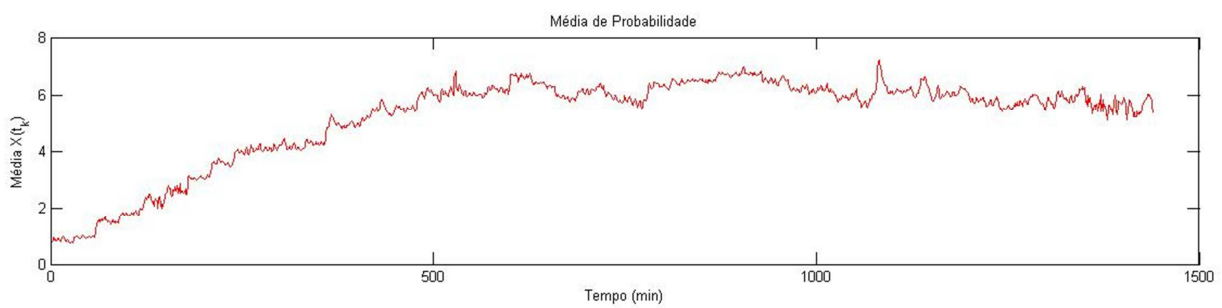

(b)

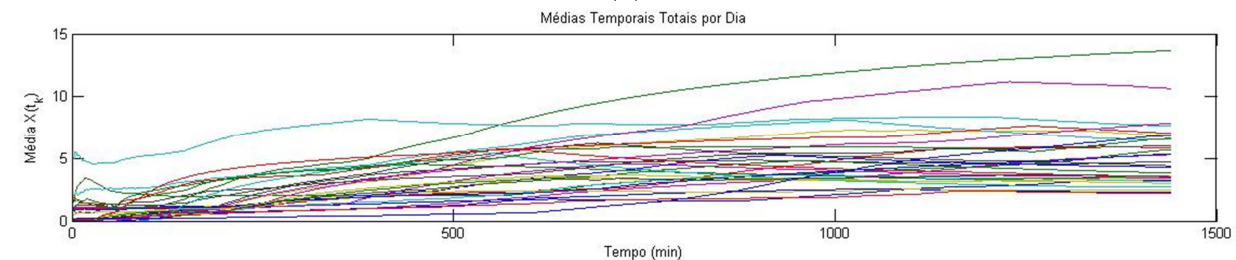

(c)

Figura 4.16. Parâmetros para o indicador TID (a) Média temporal ao longo dos 30 dias, (b) média de probabilidade e (c) média temporal total por dia.

Comparando-se a Figura 4.16 (a) com a Figura 4.16 (b), percebe-se que a média temporal e a média de probabilidade não convergem para os mesmos valores. Da Figura 4.16 (b), nota-se que a média de probabilidade do processo $T I D(t)$ não se estabiliza ao final de um dia. Este resultado sugere a não-estacionariedade do processo $T I D(t)$ no período de realização diário. Nota-se da Figura 4.16 (c) que a média temporal sequencial calculada a 
cada dia resulta em níveis diferentes diários ao longo do período de 30 dias.

A fim de investigar a hipótese de ergodicidade, subtraem-se as curvas das Figuras 4.16 (b) e (c), resultando no gráfico da diferença das médias temporais em cada dia com relação à média de probabilidade, ilustrado na Figura 4.17. Neste gráfico, também estão plotadas a média global dessas diferenças (reta preta) e o intervalo de confiança de $\pm 3 \sigma$ (retas vermelhas).

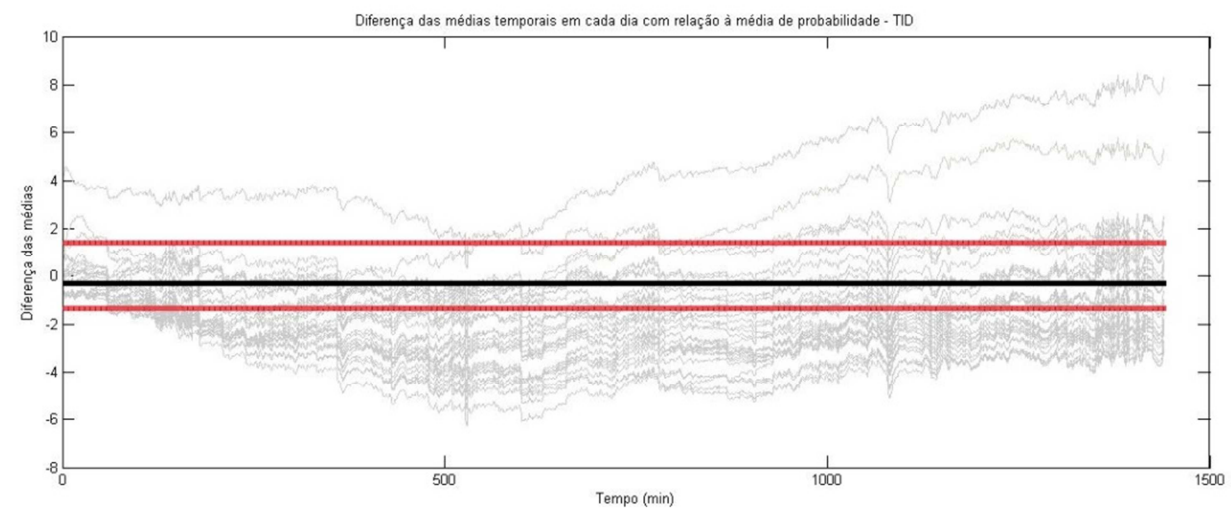

Figura 4.17. Diferença das médias temporais em cada dia com relação à média de probabilidade - TID.

Da Figura 4.17, notam-se as diferenças entre a média temporal e a média de probabilidade para cada um dos 30 dias. Aplicando-se o teste de hipóteses de $t$-student, verifica-se que a média global do resíduo não é nula. Esse resultado comprova que a hipótese de ergodicidade não pode ser aplicada ao estudo do comportamento do indicador TID (LeonGarcia, 2008).

\subsection{2 - Avaliação dos períodos de medição}

Nesta subseção avalia-se a influência dos períodos de observação das distorções no comportamento da métrica $\mathrm{M}$, apresentada no capítulo 3. A Figura 4.18 exibe a evolução do comportamento da métrica considerando-se a média temporal sequencial (a) do THD e (b) do TID. Em ambas as figuras, estão indicados os limiares de $\pm 5 \%$ definidos no critério de avaliação de estabilização da média.

Da Figura 4.18 (a) nota-se que o critério de teste é satisfeito quando o cálculo da média temporal sequencial do processo $T H D(t)$ prossegue por mais de 200 minutos, o que 
corresponde a menos de 1 dia de medição. Na Figura 4.18 (b), observa-se o atendimento do critério para o processo $T I D(t)$ quando o cálculo da média prossegue por cerca de 3.640 minutos, equivalente a 2,52 dias de monitoramento.

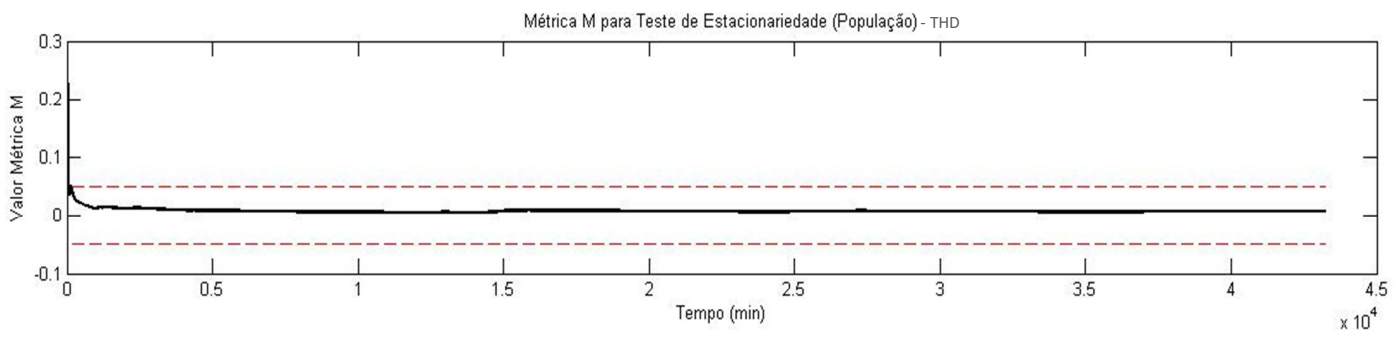

(a)

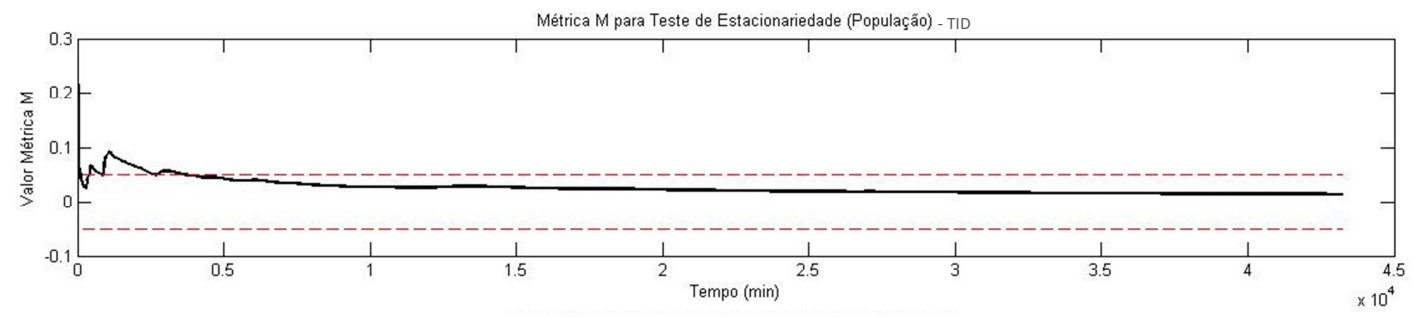

(b)

Figura 4.18. Testes de períodos de medição (a) para o THD e (b) para o TID.

Vale reiterar que o padrão IEC 61000-4-30 recomenda 7 dias seguidos de medição. Entretanto, as Figura 4.18 (a) e (b) mostram que um menor período de dias seguidos permite a estimativa das médias de ambos os indicadores a um limite inferior a $5 \%$ das mesmas. O período de observação indicado deve ser superior ao maior dos intervalos identificados, portanto, superior a 3 dias.

\section{6 - CONSIDERAÇÕES FINAIS}

Os resultados exibidos neste capítulo evidenciaram que a janela de tempo retangular de 15 ciclos de $60 \mathrm{~Hz}(250 \mathrm{~ms})$ representa a condição de equilíbrio em que se pode monitorar as distorções de tensão da instalação eólica atenuando os erros de medição do THD e do TID atrelados à aplicação da DFT com uma janela retangular fixa. Ressalta-se que essa medida de erro advém das diferenças observadas com relação às medições obtidas por meio da metodologia PK.

Em relação aos 12 ciclos propostos na IEC 61000-4-7, a adoção da janela de 15 ciclos resulta em melhor resolução espectral (de $5 \mathrm{~Hz}$ para $4 \mathrm{~Hz}$ ). Entretanto, por meio das 
tabelas 4.2 e 4.3 , verifica-se que os valores das discrepâncias normalizadas dessas duas janelas ficaram próximos. Além disso, como a utilização da janela de 12 ciclos já é consolidada, recomenda-se manter o procedimento padrão no cálculo das distorções dos sinais de tensão para uma instalação eólica.

Considerando-se a variação temporal dos sinais de dados, os índices THD e TID foram caracterizados como processos estocásticos. A análise das séries de dados decorreu da observação de cada um desses processos por um período de 30 dias. O resultado do teste de hipóteses de Kolmogorov-Smirnov evidenciou que as distribuições diferentes ao longo dos dias comprovam a característica aleatória dos dados. As curvas da média temporal não convergem para o valor da média de probabilidade. Esse resultado sugere a nãoestacionariedade e não-ergodicidade dos processos THD e TID no período de realização diário.

A avaliação dos períodos de medição evidenciou a necessidade de um intervalo de monitoramento mínimo de 3 dias, inferior ao recomendado pela IEC. Logo, a norma já contempla o período mínimo necessário para a geração eólica. Entretanto, é oportuno mencionar que a diminuição do período de monitoramento demandaria menos memória de massa de um medidor e menor quantidade de dados para análise.

Vale salientar que, para o período de medição considerado, o $\mathrm{THD}_{95}$ foi de $3,40 \%$, não ultrapassando o limiar de 5\% estabelecido pela norma. As distorções do índice TID apresentaram valores maiores quando comparados ao THD. O TID 95 foi de $13,40 \%$ e, em todos os dias, o índice de distorção ultrapassou o limiar de 5\%. Tal resultado evidencia a importância da análise do TID, tendo em vista os impactos associados à presença de interharmônicas nos sistema de energia elétrica. 


\section{5 - CONCLUSÕES E TRABALHOS FUTUROS}

\section{1 - CONCLUSÕES}

Este trabalho apresentou, no contexto de análise de distorções harmônicas e interharmônicas de sinais de tensão adquiridos em um sistema eólico, uma metodologia voltada para a adaptação de dois parâmetros encontrados nos padrões IEC 61000-4-7 e IEC 610004-30, a saber, o tamanho da janela de tempo para processamento dos sinais via DFT e o período mínimo de medição.

Nos capítulos 1 e 2, foram apresentados todos os aspectos teóricos envolvidos no trabalho, com a exposição dos conceitos sobre distorções de forma de onda e sistemas eólicos. Foi definida a problemática atrelada à seleção do tamanho de uma janela de tempo retangular para a análise espectral dos sinais por meio da DFT. Entretanto, uma complexidade que decorre desse processo é o conflito de escolha em que, ao tentar minimizar o efeito das inter-harmônicas alterando o tamanho da janela de tempo, pode-se intensificar o efeito das variações temporais na análise espectral. Outro ponto merecedor de destaque foi a definição do período mínimo de medição para o fenômeno, tendo como referência o comportamento das distorções.

No capítulo 3, foi detalhada a metodologia de análise proposta para a consecução dos objetivos estabelecidos neste trabalho. Essa metodologia foi dividida em duas partes, a saber, avaliação das janelas de tempo e análise estatística. A primeira parte consistiu da aplicação de métodos de estimação espectral que viabilizaram a avaliação comparativa das discrepâncias entre os valores dos indicadores THD e TID, advindos da metodologia PK e os valores obtidos para os mesmos indicadores com a DFT para diferentes tamanhos de janelas de tempo. Na segunda parte, visando à definição de um período de monitoramento para as distorções, adotou-se um conjunto de procedimentos de análise estatística para caracterizar o comportamento estocástico dos indicadores. Foi efetuada a caracterização estatística por meio da média de probabilidade e da média temporal das séries de dados dos indicadores THD e TID advindos da aplicação da metodologia PK. Realizaram-se testes com a métrica proposta no trabalho de Feitosa (2009) para verificação da estabilização da média temporal dos processos aleatórios representados por cada indicador, $T H D(t)$ e $T I D(t)$, com o intuito de propor o período mínimo de medição. 
A metodologia PK proposta no trabalho de Costa (2005) foi tomada como referência neste trabalho, tendo em vista sua robustez para uma análise espectral com alta resolução em condições de variação temporal das distorções harmônicas e inter-harmônicas. Entretanto, vale frisar que o tempo de processamento da metodologia PK é bastante superior ao da DFT, o que fundamentou a adoção de análise apenas para as investigações offline.

No capítulo 4, os resultados foram apresentados. A investigação foi dividida em avaliação da influência das janelas de tempo e análises estatísticas. A avaliação das discrepâncias obtidas durante 7 dias de medição evidenciou que uma janela de tempo retangular de 15 ciclos de $60 \mathrm{~Hz}$ representa uma condição de equilíbrio para o processamento dos sinais, minimizando as discrepâncias na medição do THD e do TID com a DFT para os sinais de tensão da instalação eólica analisada.

Em comparação aos 12 ciclos propostos na IEC, a adoção desse tamanho de janela resulta em maior resolução espectral (de $5 \mathrm{~Hz}$ para $4 \mathrm{~Hz}$ ). O maior custo de processamento nesse caso não é fator limitante, tendo em vista a boa eficiência computacional na implementação do método via algoritmos da transformada rápida de Fourier (FFT). Entretanto, deve-se ressaltar que os valores das discrepâncias normalizadas dessas duas janelas ficaram próximos. Além disso, como a utilização da janela de 12 ciclos já é consolidada, recomenda-se manter o procedimento padrão no cálculo das distorções dos sinais de tensão para uma instalação eólica.

Ainda no capítulo 4, no que tange às análises estatísticas, os indicadores THD e TID foram considerados como processos aleatórios. Com base nessa premissa, foi realizada a comparação da média de probabilidade e da média temporal das séries obtidas durante 30 dias por meio da metodologia PK. O resultado evidenciou o comportamento nãoestacionário e não-ergódico dos indicadores para o período de realização diário.

Por fim, foi identificado que o período de medição mínimo das distorções de tensão do sistema eólico estudado deve ser equivalente a 3 dias. Logo, o tempo proposto pela IEC de 7 dias de monitoramento é adequado. Não obstante, um período de tempo menor demandaria menos memória de massa. Tal conclusão foi realizada com base na avaliação do comportamento da métrica de estabilização da média temporal sequencial dos indicadores THD e TID. 


\section{2 - TRABALHOS FUTUROS}

Os resultados obtidos via aplicação da metodologia proposta neste trabalho para a usina eólica estudada são, a princípio, específicos para a instalação avaliada. Desta maneira, para que seja consolidado um procedimento de medição padrão, propõe-se que a análise do período de monitoramento e do tamanho da janela de tempo seja replicada em vários aerogeradores e em outros pontos do sistema eólico, para o maior número possível de instalações. Além disso, recomenda-se empregar essa investigação para sinais de corrente, com vistas ao estabelecimento de uma correlação com os resultados obtidos para a tensão.

Em sistemas eólicos, as inter-harmônicas apresentam grande dependência com a produção de energia ativa da turbina. Não obstante, o vento apresenta comportamento intermitente em sua velocidade e direção, o que causa variações no potencial energético desta fonte. Portanto, sugere-se um estudo que relacione a velocidade do vento, a potência gerada e as distorções na forma de onda. 


\section{REFERÊNCIAS BIBLIOGRÁFICAS}

AGÊNCIA NACIONAL DE ENERGIA ELÉTRICA - ANEEL (2014). Procedimentos de Distribuição de Energia Elétrica no Sistema Elétrico Nacional - PRODIST - Módulo 8: Qualidade da Energia Elétrica, Brasília.

Albuquerque, J.; Fortes, J.; Finamore, W. (2008). Probabilidade, Variáveis Aleatórias e Processos Estocásticos. Editora Interciência, Rio de Janeiro.

Arrilaga, J; Watson, N. R. (2003). Power System Harmonics.3rd edition.s.1. : John Wiley \& Sons.

ASSOCIAÇÃO BRASILEIRA DE NORMAS TÉCNICAS - ABNT (2010). ABNT NBR 61400-21: Medição e avaliação das características da qualidade da energia de aerogeradores conectados à rede. Rio de Janeiro.

Billinton, R. \& Li, W. (1994).Reliability Assessment of Electric Power Systems Using Monte Carlo Methods.Plenum Press.

Brigham, E. O. (1974). The Fast Fourier Transform. [S.1.]: Prentice Hall PTR.

Carvalho, B. C. (2006). Desenvolvimento de modelo computacional de sistemas eólicos utilizando geradores síncronos para estudos de desempenho no contexto da qualidade da energia elétrica, Tese de doutorado, Faculdade de engenharia elétrica, Universidade Federal de Uberlândia, Uberlândia.

Carvalho, J. R. de. (2008). Estimação de harmônicos/inter-harmônicos: uma abordagem multitaxa, Dissertação de Mestrado, Faculdade de Engenharia da Universidade Federal de Juiz de Fora, Juiz de Fora.

Costa, F. F. (2005). Estimação de Harmônicos e Inter-harmônicos em Sistemas de Elétricos, Tese de Doutorado, Centro de Ciências e Tecnologias, Universidade Federal de Campina Grande, Campina Grande.

Dugan, R. C. et al. (2003). Electrical power systems quality, 2a ed., McGraw-Hill, New York.

Empresa de Pesquisa Energética - EPE (2013). Plano Decenal de Expansão de Energia 2022. Brasília, 410p.

Erickson, R. et al. (2004). Novel Power Electronics Systems for Wind Energy Applications: Final Report. s.1. : National Renewable Energy Laboratory.

Feitosa, E. M. (2009). Estacionariedade e Periodicidade do Fator de Desequilíbrio de Tensão em Sistemas de Potência, Dissertação de Mestrado, Programa de PósGraduação em Engenharia Elétrica, Universidade de Brasília, Brasília. 
Ferreira Filho, A. L.; Oliveira, M. de; Mello, G. P. de; Freitas, P. de O. (2004). Uma ferramenta computacional para quantificação e qualificação das distorções harmônicas. In: IEEE/PES T\&D2004 Latin América, São Paulo.

Ferreira Filho, A. L.; Pena, J. S. G.; Oliveira, W. R.; Cormane, J. (2015). Avaliação de Metodologias para a Medição de Harmônicas e Inter-harmônicas em Instalações Fotovoltaicas. In: XI Conferência Brasileira sobre Qualidade da Energia Elétrica, 2015, Campina Grande - PB.

Grimmett, G.; Stirzaker, D. (2001).Probability and random processes, $3^{\circ}$ edição.Ed. Oxford University Press.

Global Wind Energy Council - GWEC (2014).Global Wind Report: Annual market update, Istanbul.

Hanzelka, Z. \&Bierí, A. (2004).Power Quality Application Guide - Section 3.1.1: Harmonics and Interharmonics. Leonardo Power Quality Initiative (Org. \& Ed.).AGH University of Science and Technology.

Haykin, S. (2001).Communication systems, $4^{\circ}$ edição, Ed. John Wiley\&Sons INC.

Heier, S. (1998).Grid Integration of Wind Energy Conversion Systems. [S.1.]: John Wiley and Sons, England.

Hildebrand, F. B. (1956). Introduction to Numerical Numerical Analysis, McGraw-Hill New York.

INSTITUTE OF ELECTRICAL AND ELECTRONICS ENGINEERS - INDUSTRY APPLICATIONS SOCIETY/POWER AND ENERGY SOCIETY [IEEE-IAS/PES] (Standard IEEE 519-2014).IEEE Recommended Practices and Requirements for harmonic Control in Electrical Power Systems. IEEE, 2014.

INTERNATIONAL ELECTROTECHNICAL COMISSION [IEC] (Guideline IEC 610004-7). Electromagnetic Compatibility - Part 4.7: Testing and Measurement Techniques - general guide on harmonics and interharmonics measurements and instrumentation for power supply systems and equipment connected thereto. 2nd Edition, IEC-CEI, 2002.

INTERNATIONAL ELECTROTECHNICAL COMISSION [IEC] (Guideline IEC 610004-30). Electromagnetic Compatibility - Part 4.30: Testing and Measurement Techniques - Power quality measurement methods. 2nd Edition, IEC-CEI, 2008.

Jazwinski, H. (1970). Stochastic processes and filtering theory, $1^{\text {st }}$ Ed., J. Academic Press INC. 
Larsson, A. (2000). The Power Quality of Wind Turbines, PhD's Thesis, Chalmers University of Technology, GÄoteborg, Sweden.

Leon-Garcia, A. (2008). Probability, statistics, and random processes for electrical engineering.3rd Ed. Pearson Prentice-Hall.

Macedo Júnior, J. B. (2009). Uma contribuição à análise das componentes interharmônicas e seus efeitos nos indicadores de flutuação de tensão, Tese de Doutorado, Universidade Federal do Espírito Santo, Espírito Santo.

Machado, O. F. (2008). Estimação e Análise Estatística de Distorções Harmônicas em Usinas Eólicas a Velocidade Variável, Dissertação de Mestrado, Departamento de Engenharia Elétrica, Universidade Federal de Minas Gerais, Belo Horizonte.

Marple Jr., S. L. (1987). Digital Spectral Analysis with Applications.Prentice-Hall EnglewoodCliffs.

Matias, F. de A. (2007). Comparação entre Modelos Equivalentes de Aerogeradores Síncronos Utilizando o Programa ATP, Dissertação de Mestrado, Programa de PósGraduação em Engenharia Elétrica e de Computação, Universidade Federal do Rio Grande do Norte, Natal.

Meyer, P. L. (2000). Probabilidade: Aplicações à Estatística. $2^{\mathrm{a}}$ Ed. - Reimpressão 2000.Addison-Wesley.

Naghettini, M. (2007). Hidrologia estatística. CPRM, Belo Horizonte.

Oliveira, A.; Ferreira Filho, A. L.; Vilaça, A. L. A. (1997). Uma Contribuição Para a Quantificação e Qualificação da Distorção Harmônica. In: IV Congresso Brasileiro de Eletrônica de Potência - COBEP'97, Belo Horizonte.

Oliveira, W. R. (2015). Uma Contribuição para a Medição de Distorções Harmônicas e Inter-harmônicas em Instalações de Geração Fotovoltaica, Dissertação de Mestrado, Programa de Pós-Graduação em Engenharia Elétrica, Departamento de Engenharia Elétrica, Universidade de Brasília, Brasília.

Operador Nacional do Sistema Elétrico - ONS (2011). Procedimentos de Rede, Módulo 2: Requisitos mínimos para instalações de transmissão e gerenciamento de indicadores de desempenho, Brasília.

Oppenheim, A.; Schafer, R. with Buck, L. R. (1998).Discrete-Time Signal Processing, $2^{\text {nd }}$ Ed., Prentice Hall, New Jersey.

Papoulis, A. (2001). Probability, Random Variables and Stochastic Processes. $4^{\text {th }}$ Ed. McGraw-Hill. 
Parreiras T. M.; Silva S. R. (2012). Distorções Harmônicas Geradas por um Parque de Turbinas Eólicas. In: IV Simpósio Brasileiro de Sistemas Elétricos, Goiânia.

Pavinato, E. F. (2005). Ferramenta para Auxílio na Análise da Viabilidade Técnica da Conexão de Parques Eólicos na Rede Pública, Dissertação de Mestrado, Universidade Federal do Rio de Janeiro, Rio de Janeiro.

Pereira, M. M. (2004). Um Estudo do Aerogerador de VelocidadeVariável e Sua Aplicação paraFornecimento de Potência ElétricaConstante, Dissertação de Mestrado, Universidade Federal de Juiz de Fora, Minas Gerais.

Press, W. H. et al. (1992).Numerical Recipes in Fortran - The Art of Scientifc Computation, Cambridge University Press, New Delhi.

Ribeiro, P. F. et al. (2014). Power Systems Signal Processing for Smart Grids. $1^{\mathrm{a}}$ edição. Ed. [S.1.]: Wiley.

Ringer, N. J. (2014). Desafios do setor de energia élica no Brasil: uma abordagem sistêmica, Dissertação de Mestrado, Faculdade de Economia, Administração e Contabilidade de Ribeirão Preto/USP, Ribeirão Preto.

Ross, S. (2010). Probabilidade: um curso moderno com aplicações. Bookman.

Sachin, K.J., Singh, S.N. (2011). Harmonics estimation in emerging power system: Key issues and challenges. In: Electronic Power Systems Research.

Schulz, D.; Tognon, E.; Hanitsch, R. (2003).Investigation of the harmonic transformation properties of double fed induction generators in wind energy converters. Proc. of PCIM Power electronicsConference.

Silva, S. R. (2005). Energia eólica. UFMG - Universidade Federal de Minas Gerais, v. 1.

Skvarerina, T. L. (2002). The Power Electronics Handbook, CRC Press, 2002;.s.1. : CRC Press.

Slootweg, J. G.; Polinder, H.; Kling, W. L. (2001).Initialization of wind turbine models in power system dynamics simulations. IEEE Porto Power Tech Conference, Portugal, v. 4.

Souza, M. G. M.; Oleskovicz, M.; Monaro, R. M. (2014). Um método alternativo para a estimação de componentes harmônicos por redes neurais artificiais. In: XX Congresso Brasileiro de Automática, Belo Horizonte.

Tentzerakis, S. T.; Papathanassiou, S. A. (2007). An Investigation of the Harmonic Emissions of Wind Turbines.IEEE Transactions on Energy Conversion, Vol. 22, NO.1, Vol. 22, $\mathrm{n}^{\circ} 1$. 
Testa, A. et al. (2007).Interharmonics: Theory and Modeling. In: IEEE Transactions on Power Delivery, vol. 22, no. 4, pp. 2335-2348.

Zhu, T. X. (2007). Exact Harmonics/Interharmonics Calculation Using Adaptive Window Width. In: IEEE Transactions on Power Delivery, vol. 22, no. 4.

Yang, K. (2015).On Harmonic Emission, Propagation and Aggregation in Wind Power Plants, PhD Thesis, Electric Power Engineering - Department of Engineering Sciences and Mathematics, Lulea University of Technology.Skelleftea, Sweden. 